\title{
Surface and subsurface fault and fracture systems with associated natural gas production in the Lower Mississippian and Upper Devonian, Price Formation, southern West Virginia
}

\author{
S. Reed Johnson \\ West Virginia University
}

Follow this and additional works at: https://researchrepository.wvu.edu/etd

\footnotetext{
Recommended Citation

Johnson, S. Reed, "Surface and subsurface fault and fracture systems with associated natural gas production in the Lower Mississippian and Upper Devonian, Price Formation, southern West Virginia" (2007). Graduate Theses, Dissertations, and Problem Reports. 2519.

https://researchrepository.wvu.edu/etd/2519

This Thesis is protected by copyright and/or related rights. It has been brought to you by the The Research Repository @ WVU with permission from the rights-holder(s). You are free to use this Thesis in any way that is permitted by the copyright and related rights legislation that applies to your use. For other uses you must obtain permission from the rights-holder(s) directly, unless additional rights are indicated by a Creative Commons license in the record and/ or on the work itself. This Thesis has been accepted for inclusion in WVU Graduate Theses, Dissertations, and Problem Reports collection by an authorized administrator of The Research Repository @ WVU. For more information, please contact researchrepository@mail.wvu.edu.
} 


\title{
Surface and Subsurface Fault and Fracture Systems with Associated Natural Gas Production in the Lower Mississippian and Upper Devonian, Price Formation, Southern West Virginia
}

\author{
S. Reed Johnson \\ Thesis submitted to the \\ Eberly College of Arts and Sciences \\ at West Virginia University \\ in partial fulfillment of the requirements \\ for the degree of \\ Master of Science \\ in \\ Geology \\ Committee Members: \\ Jaime Toro, Ph.D. \\ Richard Smosna, Ph.D. \\ Craig A. Edmonds, M.S. \\ Department of Geology and Geography \\ Morgantown, West Virginia \\ 2007
}

Keywords: Price Formation, Fractures, Faults, Natural Gas, 3DMove 


\section{Abstract \\ Surface and Subsurface Fault and Fracture Systems with Associated Natural Gas Production in the Lower Mississippian and Upper Devonian, Price Formation, Southern West Virginia}

\section{S. Reed Johnson}

Production from natural gas deposits is often enhanced by fault and fracture systems associated with reservoirs. This study presents analyses of fault and fracture systems within the Mississippian Price Formation in Southern West Virginia using subsurface well data and fracture data from surface analogs. The Price was analyzed at outcrops near the Allegheny Structural Front and in the Allegheny Plateau. Subsurface data analyses included mapping and modeling of the Price, fault delineation, cross section construction, and fractured zone identification. Production data was used to assess the potential for fractures and faults to enhance gas production. Fracture densities from outcrop were controlled by mechanical unit thickness, lithology, and deformation. Fault displacement ranged from 150-450 feet and major fault strike was 41-47 degrees. Production correlated well with faults from structure models but poorly with joint models. It was thus determined that joints are secondary to faults in gas production for the area. 


\section{Acknowledgements}

I would first like to thank Dominion E \& P for their generous donation of data and continued support throughout this thesis. Without their help this thesis would have been impossible. A similar thanks goes to the West Virginia Geologic and Economic Survey for making public well data available. I would also like to thank Landmark Graphics Corporation and Midland Valley Exploration for the extensive use of their software.

My committee, Jaime Toro, Richard Smosna, and Craig Edmonds, deserves many thanks for their direction and patience. Several other people have also greatly impacted not only my ability to finish this project, but my graduate school experience as a whole. These include but are not limited to my brother Daniel Johnson, whose experience in research far outreaches my own, and Adam Wisthoff for help with data collection in the field.

Finally, I would like to thank my parents, Tony and Carol Johnson. Their guidance and selflessness has shaped me into the person I am today. 


\section{Table of Contents}

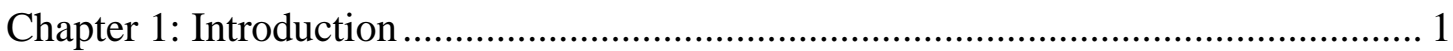

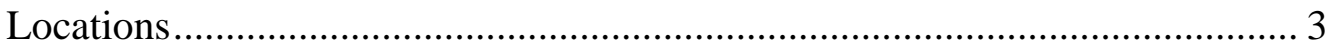

Fracturing in Sedimentary Rocks.......................................................... 7

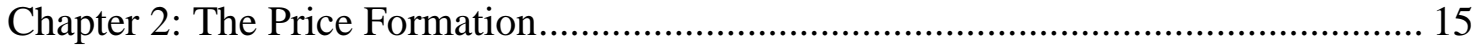

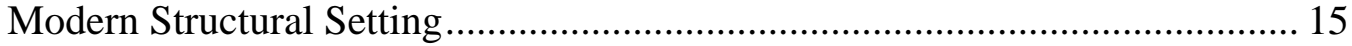

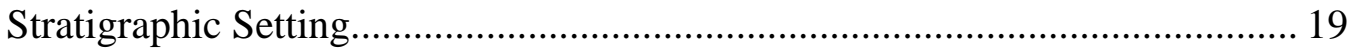

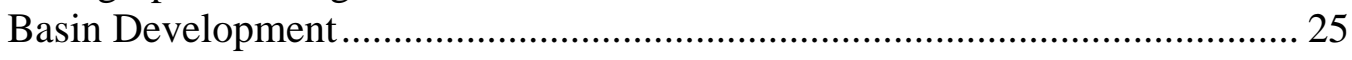

Chapter 3: Surface Methods and Results .............................................................. 27

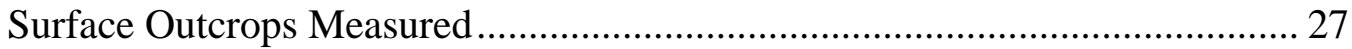

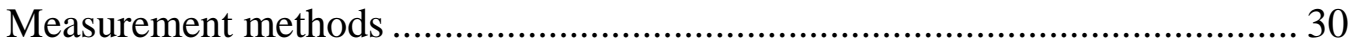

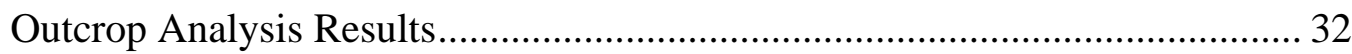

Chapter 4: Subsurface Analysis, Modeling and Results............................................ 39

Geophysical Log Correlation and Mapping.................................................. 39

Structural Model Creation........................................................................... 52

Fracture Model Creation and Analysis ............................................................ 57

Production Data Mapping and Analysis ...................................................... 69

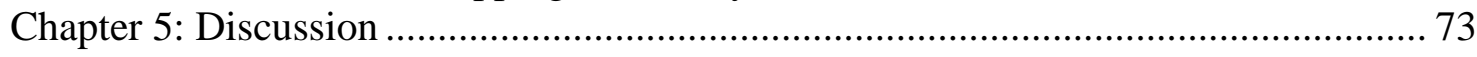

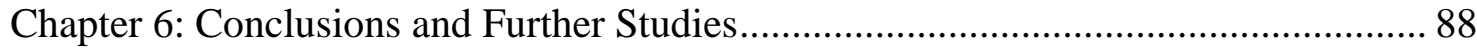

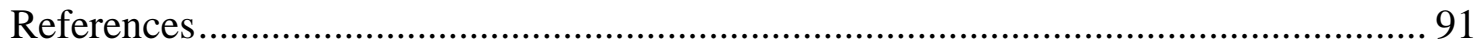

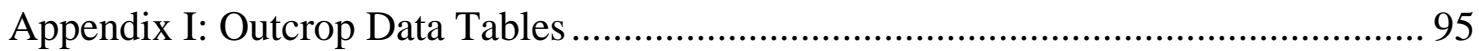

Appendix II: Production Data Per Well ................................................................ 96

Appendix III: Using 3DMove to create models..................................................... 98

Appendix IV: Previous Work on the Price Formation................................................ 102 


\section{List of Figures}

Figure 1: West Virginia map illustrating surface (Figure 2) and subsurface (1) study area locations, Edmonds (2004) study area (2), and Allegheny Structural Front bounding faults. 2

Figure 2: Major anticlines of the region with subsurface and surface study areas ....... 4

Figure 3: Regional geology and primary surface outcrop locations. ......................... 5

Figure 4: Well distribution in subsurface study area. ......................................... 6

Figure 5: Idealized joint orientation in relation to folding .................................... 9

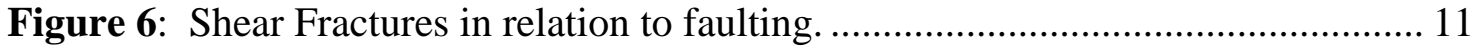

Figure 7: Mechanical stratigraphy in both "stratabound" and "non-stratabound" systems. Various types of jointing and associated mechanical stratigraphy and differential timing of jointing. 13

Figure 8: Cross Section illustrating typical foreland thrust structures for the region with

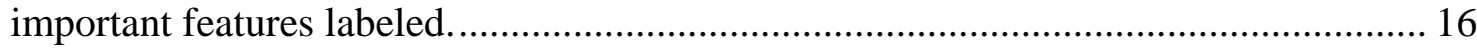

Figure 9: Simplified cross section of the surface study areas................................ 17

Figure 10: The Upper Price Formation as viewed in a geophysical log and associated markers used.

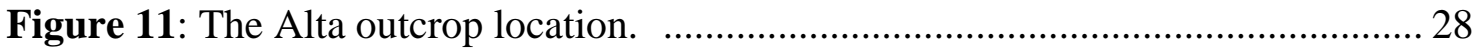

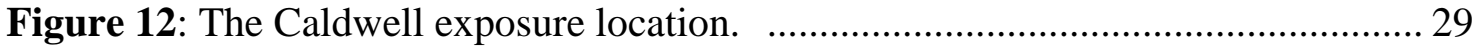

Figure 13: Photo of joint measurement at the Caldwell outcrop. ............................. 31

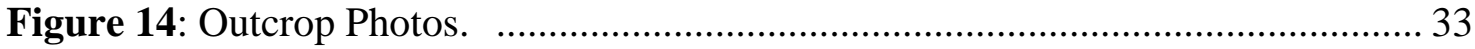

Figure 15: Photo of a shatter zone near a small normal fault in the Price near the St. Clair

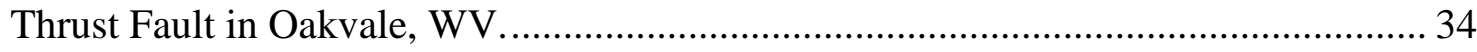

Figure 16: Joint density and mechanical unit thickness vs lithology, Caldwell .......... 36

Figure 17: Joint density vs. layer thickness graph for the Alta and Caldwell outcrops.37

Figure 18: Rose Diagrams of joints and fold axes for outcrops studied..................... 38

Figure 19: Repeated (faulted) intervals in gamma ray logs .................................. 40 
Figure 20: Map of thrust faults correlated and identified. 42

Figure 21A-G: Structure maps of all correlated markers with structures identified. ... 43

Figure 22: Isopach maps illustrating thickening by faults .................................... 51

Figure 23: 3D structure model illustrating major anticlines and synclines.................. 53

Figure 24: Cross section (XS-2) and associated modeling phases............................ 54

Figure 25: Strain based fracture model and gridding errors. .................................. 61

Figure 26: Joint Density comparison between R1 and R2 ................................... 62

Figure 27: Joints associated with anticlines and synclines. .................................. 63

Figure 28: R2 (4 step) fracture model for the Upper Price/Big Injun Equivalent ........ 65

Figure 29: Map view of 3DMove marker 2 with faults illustrated ............................ 66

Figure 30: Shear Fractures created using orientation data from Edmonds (2004). ...... 67

Figure 31: Shear fracture orientations in an FMI from Edmonds, (2004).................. 68

Figure 32: First 3-months and 12-months production map comparison ...................... 70

Figure 33: Graph of curvature and 3-month gas production from each well............... 71

Figure 34: Structure model with faults looking SW ......................................... 76

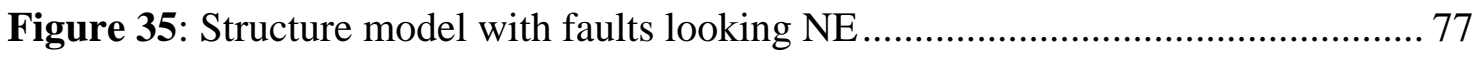

Figure 36: Structure model with faults looking NW .......................................... 78

Figure 37: Natural gas production (3 month) compared with the fault model. ............ 82

Figure 38: Natural gas production (3 month) compared with the strain based fracture

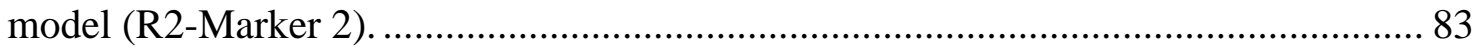

Figure 39: Natural gas production (3 month) and Marker 2 structure/R2(4step) fracture

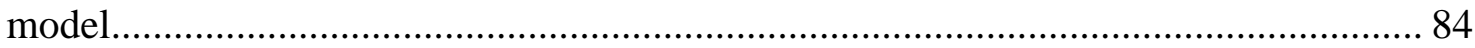

Figure 40: Natural gas production (3month) and Marker 2 curvature/R2(7step) fracture model. 85 


\section{$\underline{\text { List of Tables }}$}

Table 1: Lower Mississippian and Upper Devonian stratigraphic nomenclature ......... 20

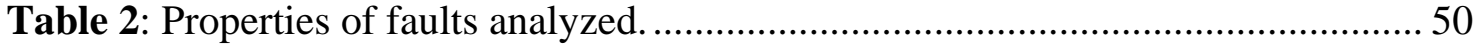

Table 3: Parameters for 3DMove fracture creation................................................ 59

Table 4: Highest and lowest production by well for each time interval analyzed........ 72 


\section{Chapter 1: Introduction}

Fracturing and faulting in sedimentary rocks are highly complex in nature and in some cases can enhance permeability or provide hydrocarbon flow pathways in oil and gas reservoirs. The concepts behind analysis and exploitation of fractured reservoirs have been slowly evolving for at least a half century (Stearns and Friedman, 1972; Nelson, 2001). Joints (extensional fractures), shear fractures, and faults have all been evaluated and exploited as conduits or permeability-enhancing features for petroleum exploration (Stearns and Friedman, 1972; Narr, 1991; Nelson, 2001; Edmonds, 2004). Fracture-related, porosity enhancing attributes include: width, spacing, roughness, and fill (Stearns and Friedman, 1972). Stearns and Friedman (1972) went on to state that fractures could be qualitatively predicted if lithology, layer thickness, principal stress magnitudes and orientations, strain, and other variables were known. However, the aforementioned variables, coupled with time, lithologic heterogeneity, and mechanical heterogeneity, can create fracture systems that are, at best, difficult to accurately model and quantitatively predict. This being said, many productive oil and gas fields exist worldwide whose primary production is from fractured reservoirs. As cited in Narr (1991), "Subsurface joints are responsible for the bulk of fracture-related oil production." A comprehensive list of documented fractured reservoirs for both the United States and international locations can be found in Nelson (2001).

In this study I have produced three-dimensional structural and fracture models for the Mississippian Price Formation of a subsurface study area in Raleigh and Mercer Counties, West Virginia (Figure 1). Joint information gathered at outcrop was used to make these subsurface fracture models. These models were produced for 


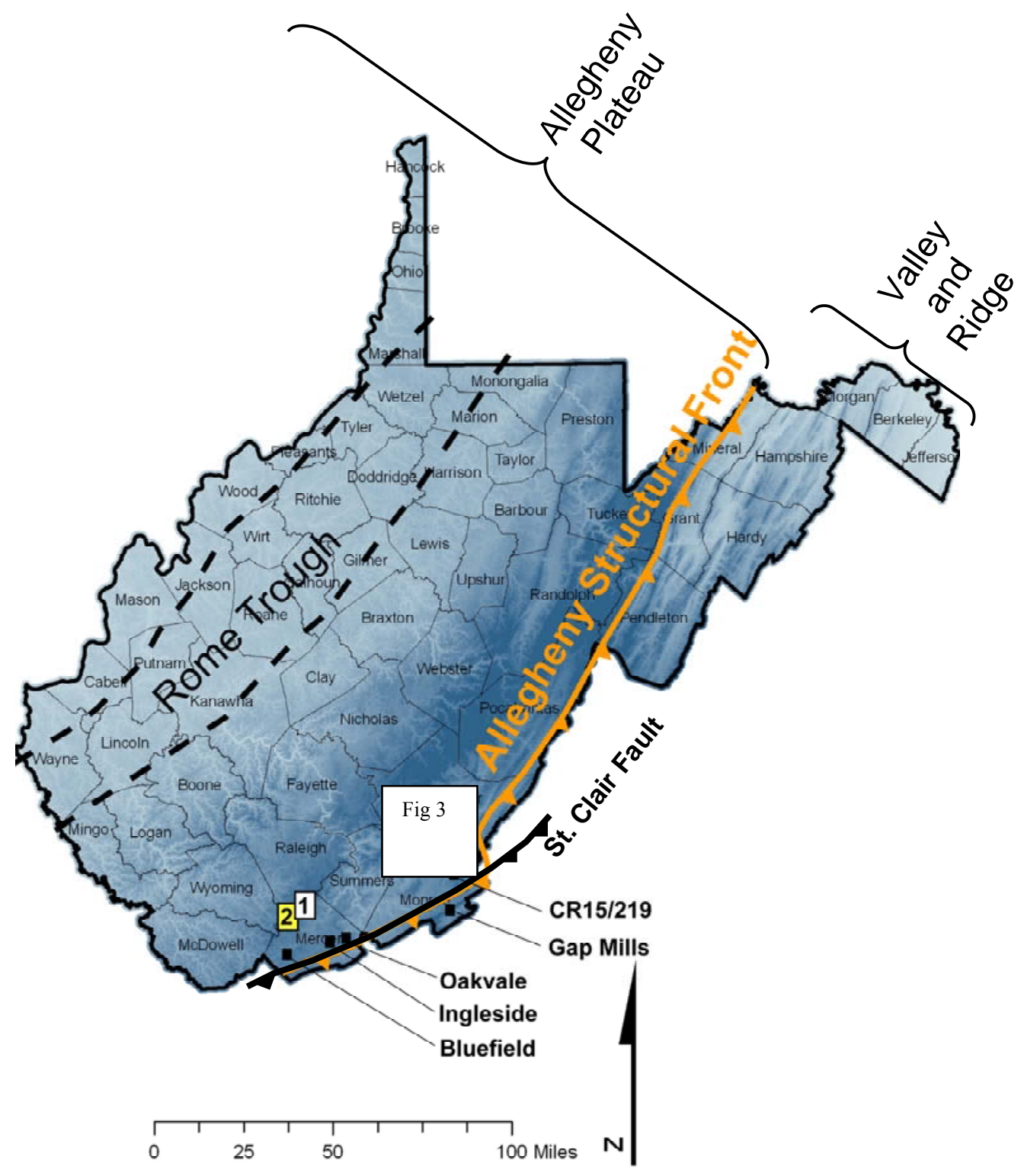

Figure 1: West Virginia map illustrating surface (Figure 3) and subsurface (1) study areas, Edmonds' (2004) study area (\#2 in yellow), and theAllegheny Structural Front bounding faults including the St. Clair Thrust. Darker blues = higher elevations. The maximum and minimum elevations are 4863 and $240 \mathrm{ft}$. above sea level respectively (www.netstate.com). Other Price outcrop locations examined as potential surface analogs are labeled. 
several reasons: 1) to more fully understand the subsurface structure, 2) to define the nature of potential fracture patterns within the Upper Price in this area, and 3) to compare both structural and fracture models against production data to assess the impact faults and fractures have on natural gas production in the region. Data used to construct these models included: Geophysical logs and well locations, outcrop fracture data, and monthly production data. Outcrop data including mechanical layer thickness, joint orientation, linear joint density (joint spacing), and bedding orientation data were used to better understand the fracturing nature of the Upper Price. Due to a lack of subsurface fracture data (formation micro imager (FMI) logs), minimum and average joint density values and structure-normalized joint orientation data obtained from surface analogs was applied to the subsurface fracture models.

This thesis describes valid geological explanations for observed structures along with trends in natural gas production. Production will be shown to occur along linear trends that correlate well with thrust faults and presumably with associated shear fracture swarms. The Price Formation is a well known oil and gas reservoir throughout West Virginia (Matchen and Vargo, 1996; Edmonds, 2004) and the methods used in this thesis could easily be applied to other locations.

\section{Locations}

Outcrop data were collected from exposures along I-64 in Greenbrier County, WV, at both high-strain (Caldwell) and low-strain (Alta) outcrops (Figures 2 and 3). These locations are both easily accessible by automobile and have excellent exposures of the Price Formation. The subsurface study area is located in Raleigh and Mercer 
Counties, West Virginia and contains 144 gas wells (Figure 4). Several additional gas wells have been drilled by Dominion E\&P since the start of this thesis but will not be

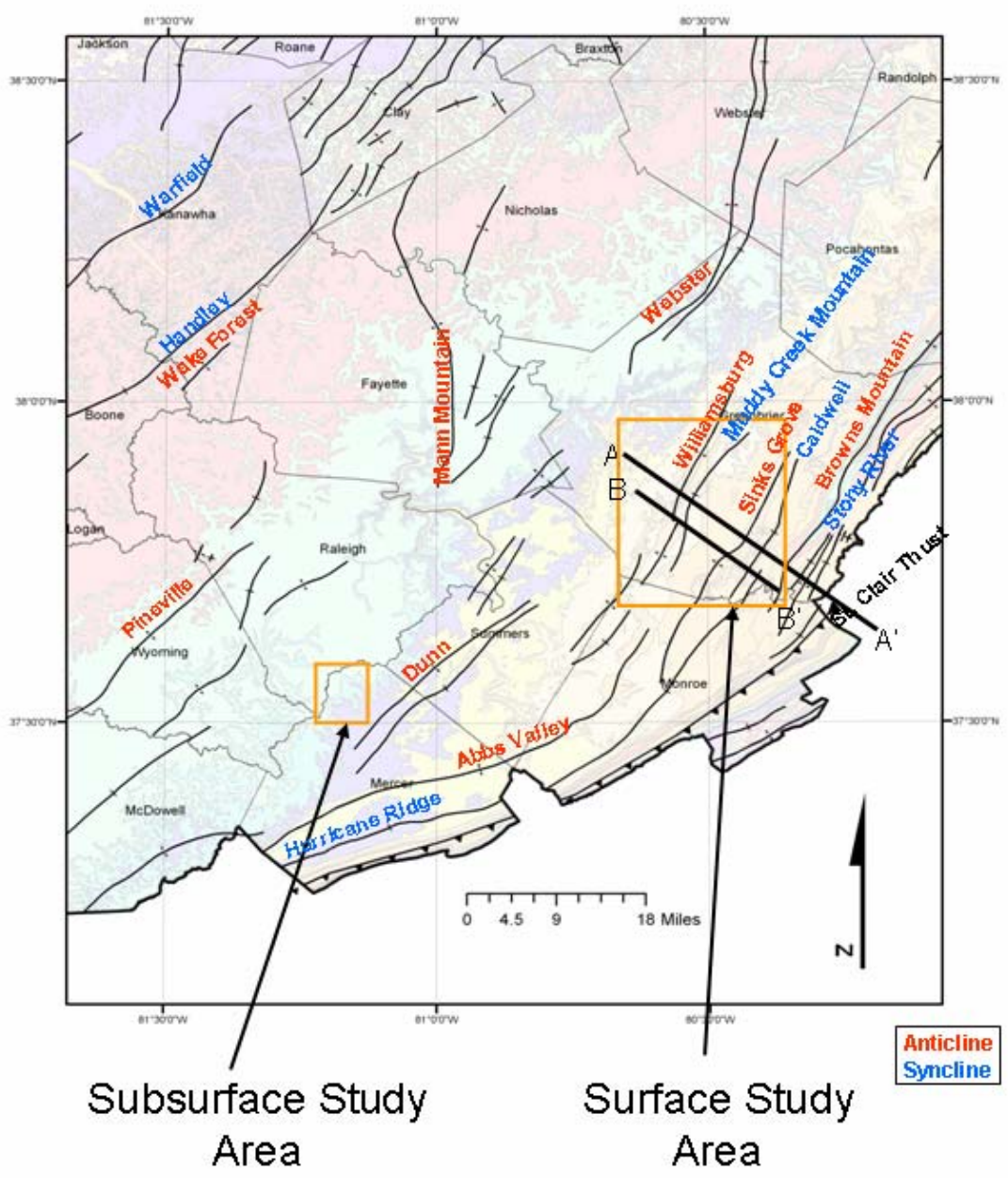

Figure 2: Major anticlines (red) and synclines (blue) of the region with subsurface and surface study areas highlighted (created using shape files from the WVU GIS Tech center and data from Cardwell, 1972 and Shumaker, 1996). Cross sections A-A' and B-B' are shown in figures 8 and 9. 

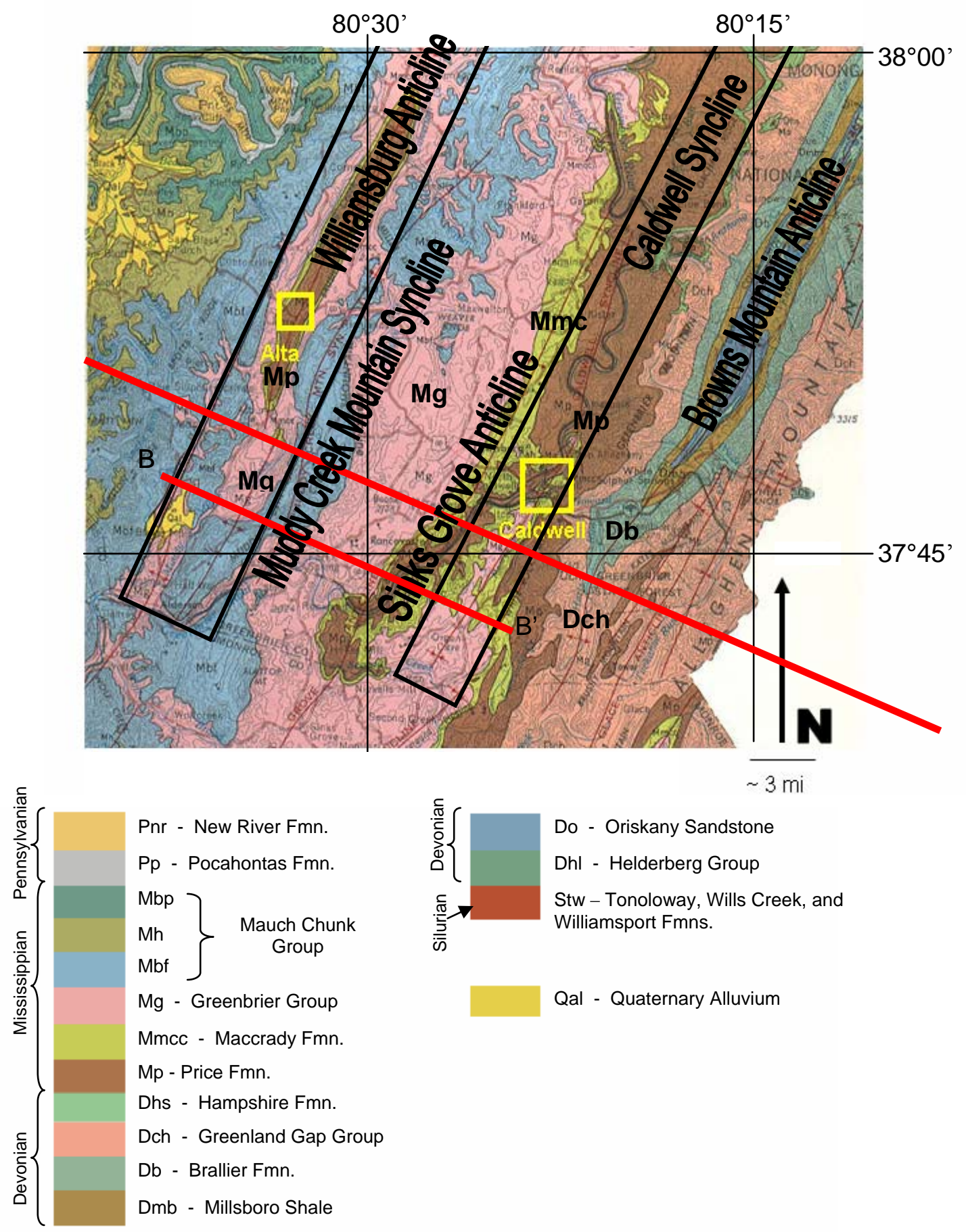

Qal - Quaternary Alluvium

Figure 3: Regional geology and study outcrop locations. The structures associated with the outcrops are highlighted in black boxes. The red lines are A-A' and B-B' as they cross the study area. 


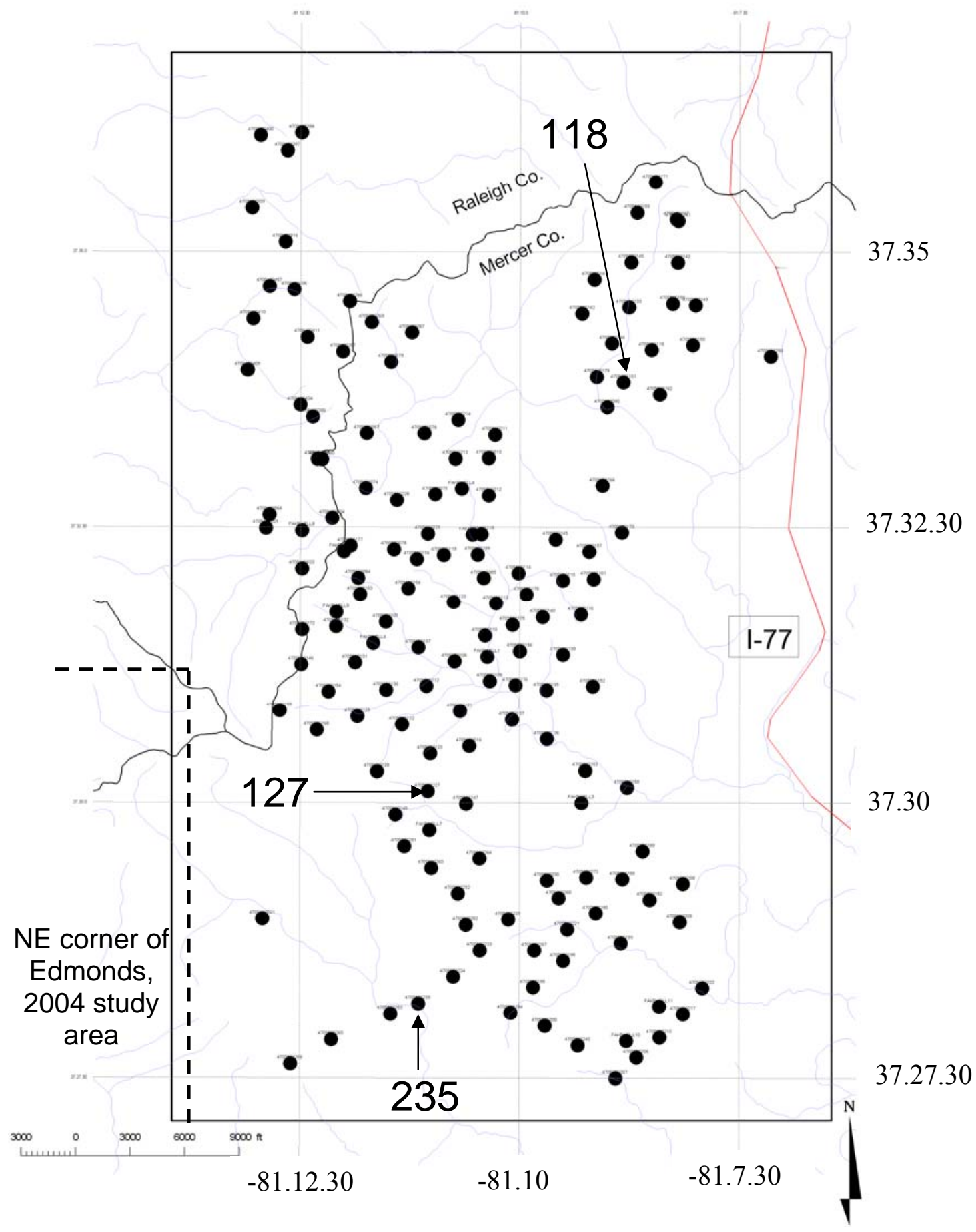

Figure 4: Well distribution and culture data in subsurface study area. As illustrated in the map, data is clustered around existing gas fields. Black lines indicate county boundaries and blue lines represent streams. Note that my study area is located adjacent to Edmonds' (2004) study area. 
included due to time constraints. The study area is 75 square miles in size, and local topographic elevations range from $2080 \mathrm{ft}$ to 3440 feet above mean sea level. Nearby communities include Odd, Egeria, Beeson, Camp Creek, and Flat Top. Beckley, the closest larger town, is located approximately 17 miles directly north of the subsurface study area.

\section{Fracturing in Sedimentary Rocks}

Fractures in sedimentary rocks are generally classified into two distinct categories: joints and shear fractures. These terms can be subdivided into the particular opening mode (I, II, III, etc.) or mixture of opening modes (Pollard and Fletcher, 2005). However, in this study the simpler terminology is used.

Joints are fractures that have no shear displacement. They are created when the tensile strength of the mechanical unit is exceeded (Davis and Reynolds, 1996). In this process joints form normal to the direction of extensional (or least compressive) strain acting on the mechanical unit (Nelson, 2001). This is often perpendicular to bedding planes. Because of the load of the overburden, true tensional regimes are rare in the subsurface, so Nelson (2001) suggests that most joints are "extensional" (where all three principal stresses are still positive) instead of truly "tensional" (in which at least one of the principal stresses is negative). The mechanisms responsible for extensional joint formation include fluid overpressure and rock expansion (Pollard and Aydin, 1988). These may occur during folding, regional extension, tectonic doming, uplift, and faulting (Price 1966; Nur 1982; Odling et. al., 1999). Joints often occur in sets where multiple joints have very similar orientations and lengths. However, whereas individual joints 
within a set are similar, the orientations of the sets themselves are often at high angles to one another (Oddling et. al., 1999).

It is natural for some variation in joint orientation to occur within an individual set due to heterogeneities in the forming stress field (Bonnett et. al., 2001). Such heterogeneities can be caused by rock heterogeneity or variation in tectonic forces. Heterogeneities in the rock unit will cause multiple joints to propagate simultaneously, thus forming a set (Bonnett et. al., 2001). Joint sets often form at a specific orientation normal and/or parallel to fold axes and are strongly related to directions of stress (Stearns and Friedman, 1972; Fischer and Wilkerson, 2001; Schwartz, 2006) (Figure 5). According to Fischer and Wilkerson (2000) three main types of fractures form along a fold: axis parallel, axis normal, and conjugate (Figure 5). 


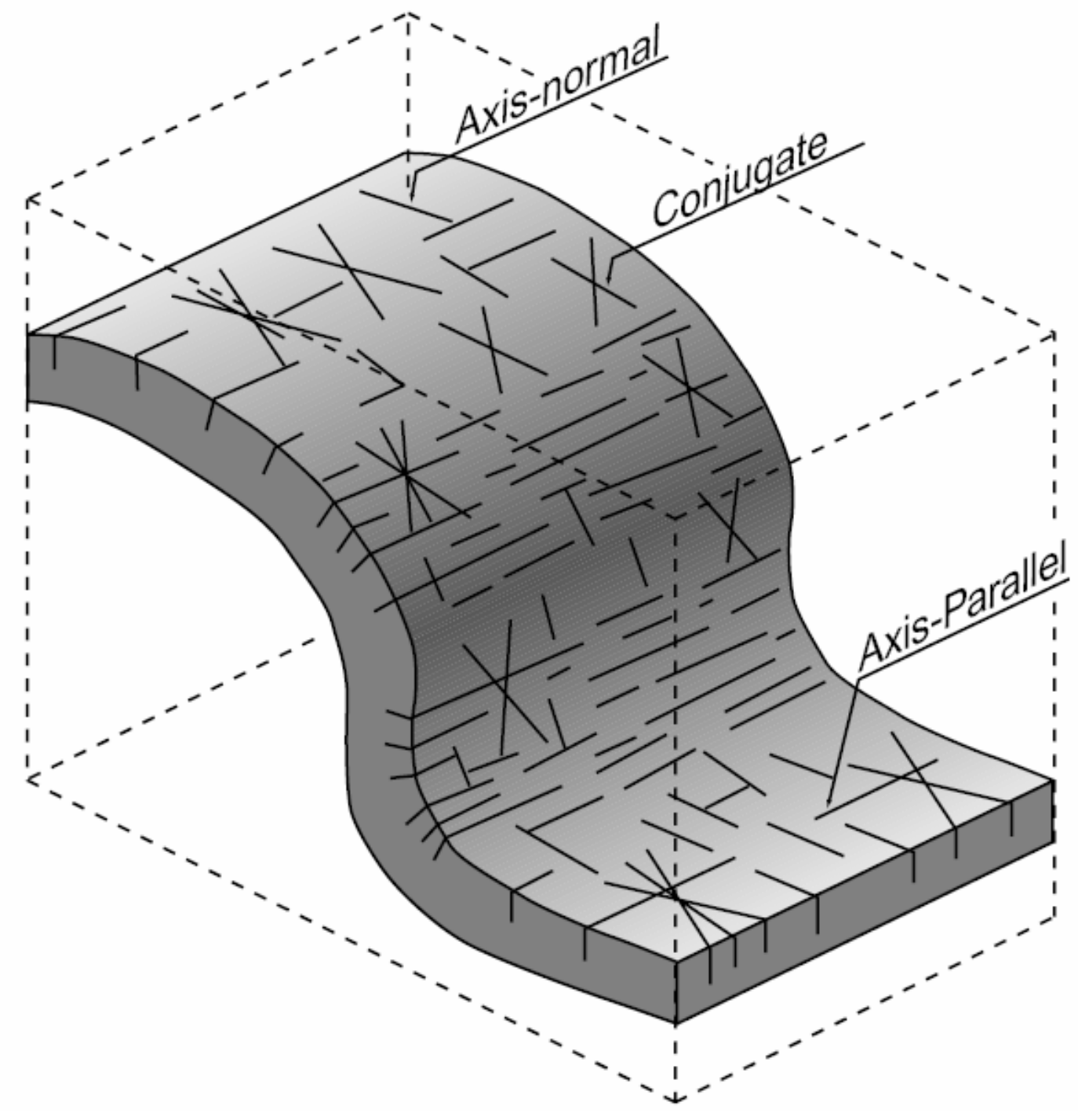

Figure 5: Idealized joint orientation in relation to folding (from Fischer and Wilkerson, 2000). 
Conversely shear fractures are fractures where the formation mechanism is shear stress. These fractures form at acute angles $\left(<45^{\circ}\right)$ to the maximum compressive stress $\left(\sigma_{1}\right)$ (Stearns and Friedman, 1972; Pollard and Fletcher, 2005). In this study, shear fractures with visible displacement are referred to as faults. Shear fractures often form in conjunction with faults and often have orientations parallel to the fault (Stearns and Friedman, 1972; Nelson, 2004) or are conjugate to the fault (Nelson, 2001; Nelson, 2004). Furthermore, shear fracture swarms often precede faulting and weaken the rock mass prior to fault propagation (Nelson, 2001). In reverse and thrust faults the majority of shear fractures occur on the hanging wall (Nelson, 2004) (Figure 6). This is due to the hanging wall passing over the irregularities on the footwall and thus undergoing more strain (Edmonds, 2004).

Fractures in sedimentary rocks, whether they are joints or shear fractures, are normally confined by mechanical stratigraphy. Mechanical units usually have fractures that completely cut that unit but do not propagate into in adjacent units. According to Shackleton et. al. (2005) "The architecture of joint networks is controlled by the ability of lithologic contacts to inhibit joint propagation..." Mechanical units are often individual sedimentary beds. In this case the joints are referred to as "stratabound" (Odling et. al 1999). In the case that multiple beds make up a mechanical unit it is referred to as "nonstratabound" (Odling et. al. 1999).

The graphical presentation of joint density data on a log-log plot (or in this case taking the $\log _{10}$ of the data and presenting it on a linear plot) allows for the accurate representation of high fracture densities in thinly spaced beds (Ladeira and Price, 1981). Using a log-log plot helps to correct the problem of high density data clustering due to 


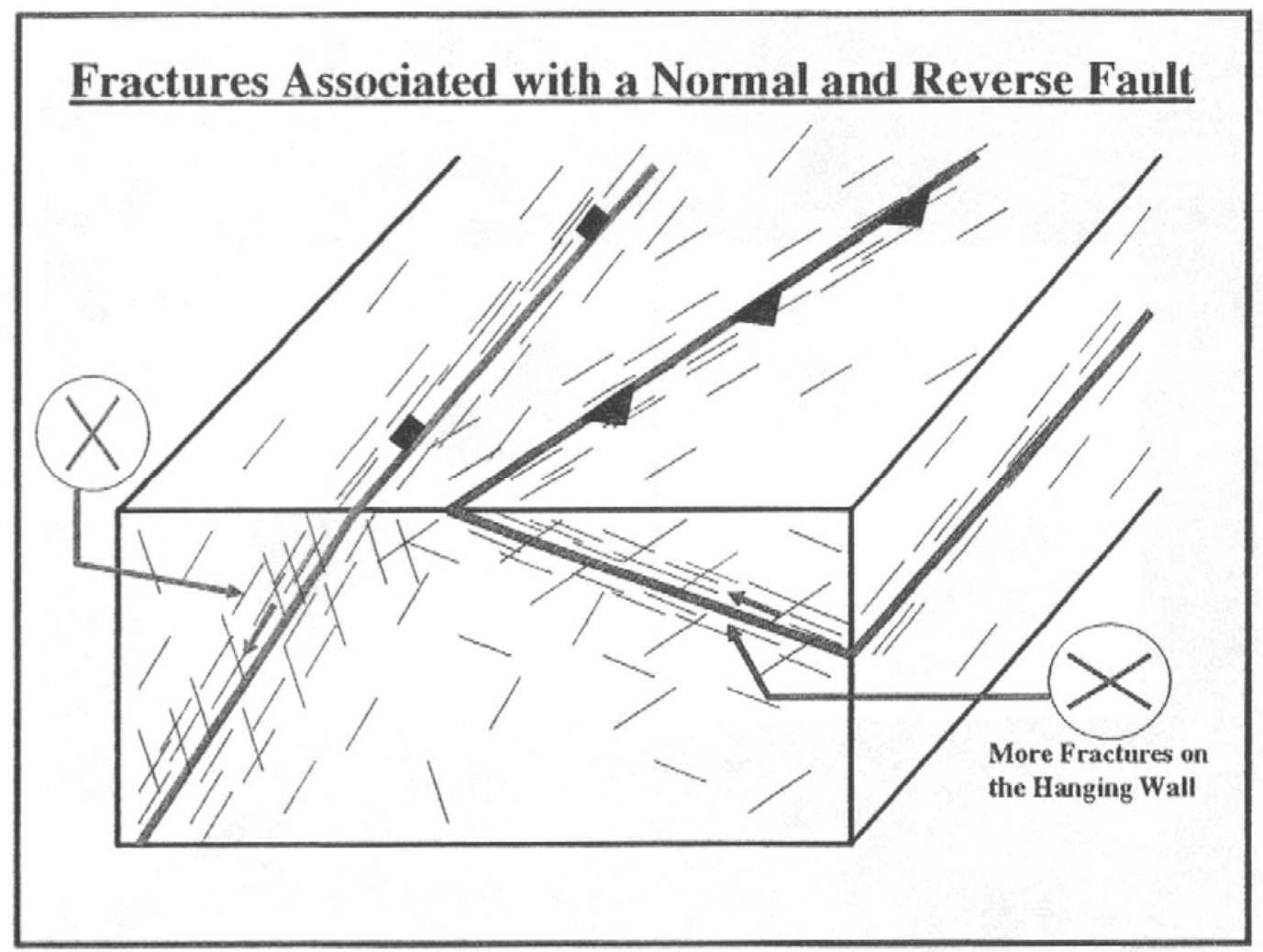

Figure 6: Shear fractures in relation to faulting. Note that most of the fractures are on the hanging wall of the reverse/thrust fault. The " $\mathrm{X}$ " intersections shown illustrate the orientations for shear fractures related to each fault type (Nelson, 2004). 
thin mechanical units near the origin (Ladeira and Price, 1981). A linear distribution is expected in a log-log plot because joint spacing data is best represented by two linear relationships which mimic a power function in a standard plot (Ladeira and Price, 1981). Joint spacing, mechanical layer thickness, and lithology are often strongly correlated. Joint spacing is also related to the thickness of non-competent layers adjacent to the competent layers where significant fracturing exists (Ladeira and Price, 1981). Shackleton et. al. (2005) found that diagenesis experienced during deformation can alter mechanical units over time so that multiple joint sets in the same rock can be mechanically bounded by separate units. This is referred to as stratabound mechanical stratigraphy and is visible in Figure 7. This suggests that deformation also has a strong control over the mechanical stratigraphy, and thus jointing of a rock unit. If two or more jointing episodes are experienced with different principal stress orientations and different amounts of deformation then the joint systems created can become quite complex with both stratabound and non-stratabound joints having different orientations (Figure7). Pore-fluid pressure can also play a significant role in the formation of fractures as it "reduces significantly the stress needed for failure" (Hubbert and Rubey 1959, Davis and Reynolds, 1996).

Natural fractures within a reservoir can have lasting positive or negative effects on production. Fractures can contribute to the non-matrix porosity and/or permeability within a reservoir. They can also create significant anisotropy that serves as a barrier to hydrocarbon flow (Nelson, 2001). In rocks where fractures provide the essential porosity and permeability, drainage areas per well can be very high and reservoirs of very poor 


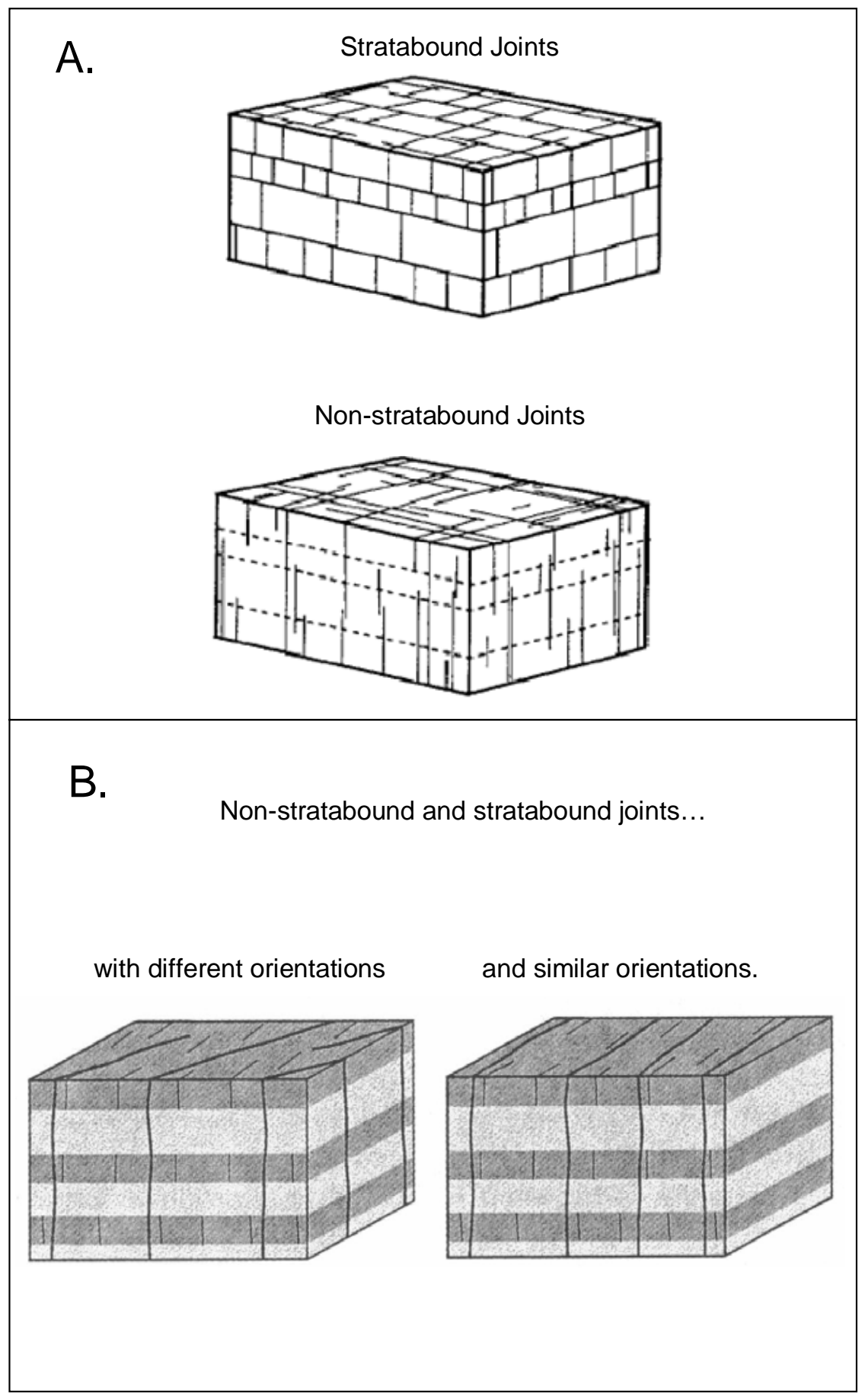

Figure 7: Top: mechanical stratigraphy in both "stratabound" and "non-stratabound" systems. Bottom: Various types of jointing and associated mechanical stratigraphy associated with differential timing of jointing. Diagrams edited from Odling et. al. 1999 an d Shackleton et. al. 2005. 
quality can be productive. However, in these areas the drainage is often difficult to model and gas production often declines rapidly (Nelson, 2001). Fractures can have a lasting negative effect on production if communication between matrix porosity and fracture porosity is inhibited. This can cause hydrocarbon recovery to be quite poor. Fractures acting as barriers to flow may also cause significant reservoir compartmentalization (Nelson, 2001). Subsurface fracture spacing is important and can be directly measured only by wells that are at a low angle to bedding planes (often horizontal wells) (Narr, 1991). FMI (formation micro imager) logs and cores are often used to detect and analyze subsurface fracture systems. Subsurface joints often exhibit similar characteristics to those observed in outcrop (Narr, 1991; Florez-Niño, et. al., 2005). 


\section{Chapter 2: The Price Formation}

\section{Modern Structural Setting}

The subsurface study area is located on the Allegheny Plateau to the SE of the Rome Trough and northwest of the St. Clair fault near the West Virginia border (Figure 1). It is also to the west-northwest of the Valley and Ridge province in southern West Virginia and is less than two miles north of the Dunn anticline (Figure 2) (Cardwell, 1976). The surface study areas are also located on the Allegheny Plateau, at folds directly west of the St. Clair fault (Figures 3, 14, and 15). The Caldwell outcrop is located near the axis of the Caldwell Syncline, a broad, south-plunging, synclinal fold that is approximately 16.5 miles long. The Caldwell Syncline was once considered to be part of the larger Hurricane Ridge Syncline (McDowell, 1982) (Figure 2). The Alta outcrop is located along the axis of the Williamsburg Anticline, a slightly narrower, doubly plunging anticline, approximately 15.5 miles long. Both structures trend NNE to SSW and are Alleghenian in age (Shumaker, 1987). Most shallow faults and folds in the area were formed by detached deformation (Shumaker, 1987), and are oriented with regional trends (southwest to northeast for folds). The Williamsburg anticline and other smaller structures were probably formed by a small detachment in the Middle-Devonian shales (Shumaker, 1987; Craig Edmonds, personal communication, 2005). Other largescale and small scale anticlines and synclines (Figures 2, 3, 8 and 9) are also located on the Allegheny Plateau (Kulander and Dean, 1986; Dean, Kulander, and Skinner, 1988). Several major, complex thrust sheets (the St. Clair Narrows sheet, the Saltville sheet, and the Pulaski sheet) along with multiple smaller sheets, control the large-scale 


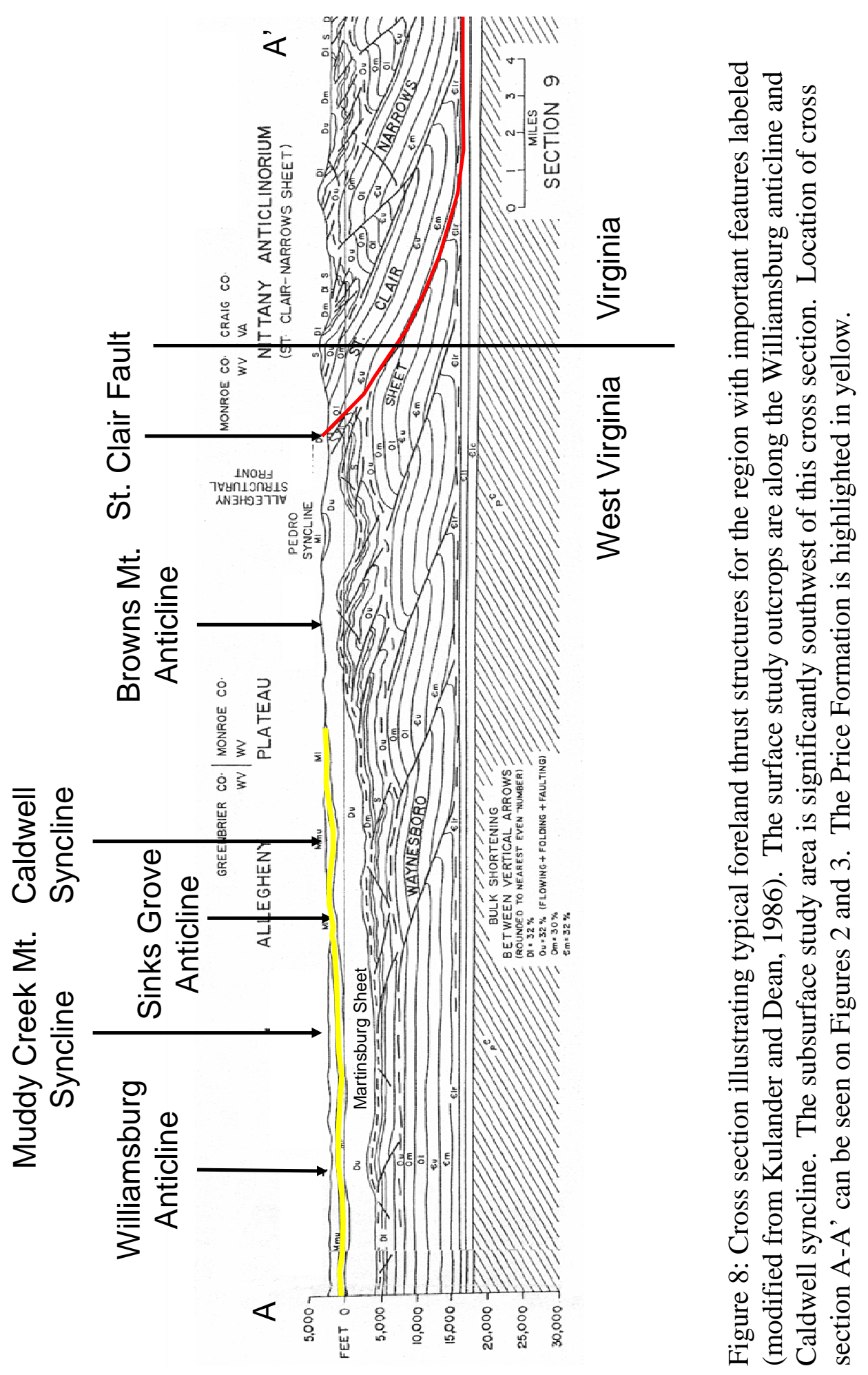




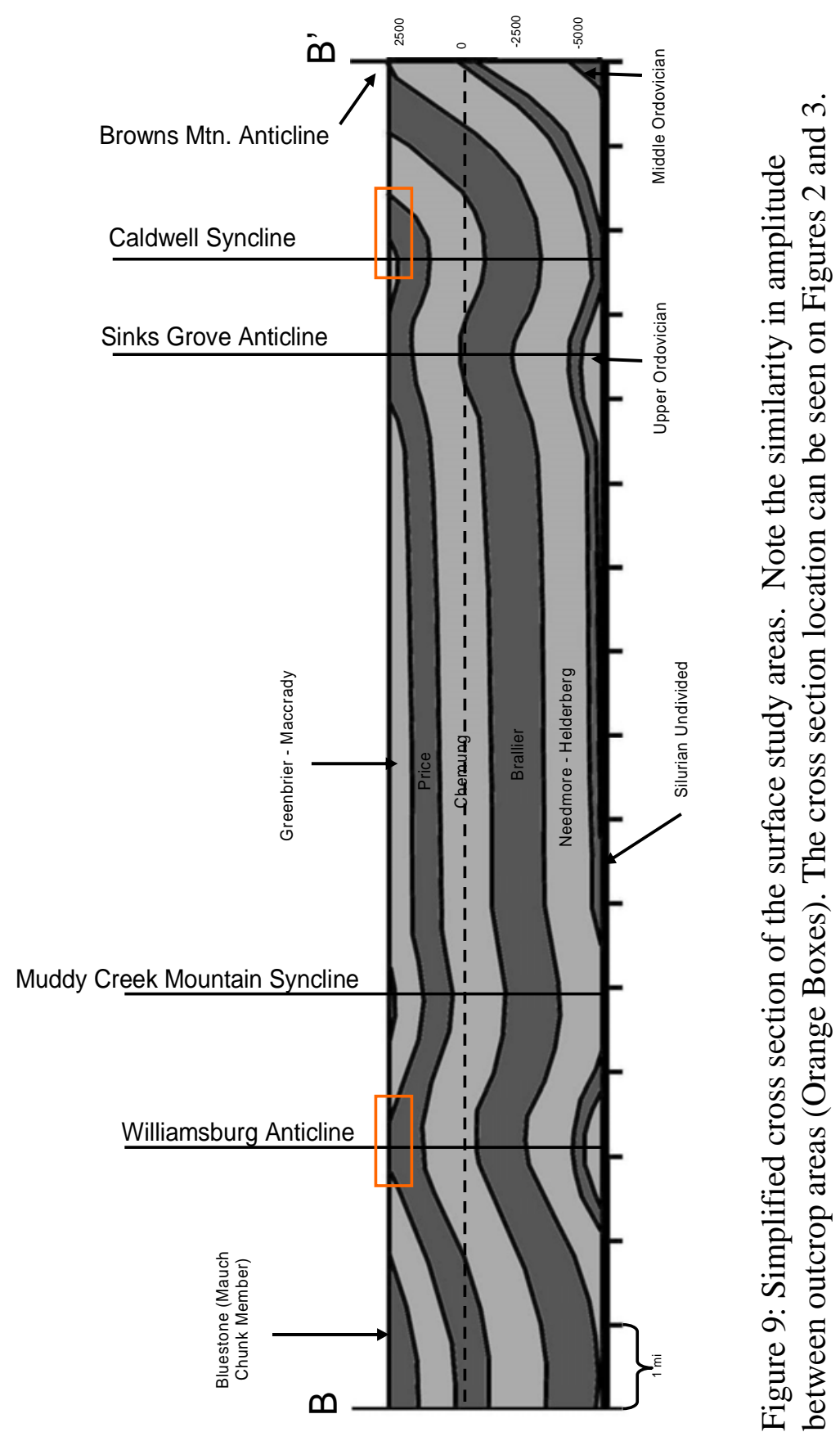


structures of the central and southern Appalachians to the east and southeast of the study areas (Figure 8) (Kulander and Dean, 1986; Jaime Toro, personal communication, 2006). Major detachment surfaces occur along the basement, in the Rome Formation, in the Martinsburg Formation, and in the Middle-Devonian shales (Kulander and Dean, 1986; Shumaker, 1987). The Martinsburg and Waynesboro sheets contain the smaller amplitude structures of the Alleghenian Plateau (Kulander and Dean, 1986; Kulander, 1987) while large-scale décollements control major structures in the Valley and Ridge Province.

Both large and small displacement thrust sheets were driven westward over underlying Precambrian basement rocks during the Alleghenian orogeny, the most recent of a series of mountain building events, which partially defines modern Appalachian topography and geologic structure (Kulander and Dean, 1986). Two major phases of deformation affected the Alleghenian foreland during this orogeny. However, the latter phase (Late Pennsylvanian - Early Permian) was responsible for the major folds and thrusts in the region (Shumaker, 1996). The mass transport of sedimentary rocks due to mountain building is generally at right angles to the fold axes within allochthonous sheets (Shumaker, 1996). The St. Clair thrust is of specific importance because it marks the boundary between the Alleghenian structural front and the Alleghenian Plateau in this area, and brings Cambrian and Ordovician rocks to the surface (McDowell, 1982; Kulander and Dean, 1986) (Figure 8). Kulander and Dean (1986) describe the Massanutten-Blue Ridge and Pulaski thrust sheets as being displaced westward between 64 to $250 \mathrm{~km}$ depending on the region being described. Displacements along major thrust décollements in the fold and thrust belt generally decrease in the northeast 
direction. Central Appalachian crustal shortening in the fold and thrust belt has been determined to be between $24 \%$ and 38\% depending upon the location (Kulander and Dean, 1986). The magnitude of Alleghenian folding and faulting decreases from east to west across the fold and thrust belt and Allegheny Plateau. Alleghenian Plateau fold wavelength increases in the northeast direction (Kulander and Dean, 1986).

\section{Stratigraphic Setting}

The Price Formation is described as the unit lying above the Greenland Gap Formation and beneath the Maccrady Formation (Table1) (Bjerstedt and Kammer, 1988). It is Late Devonian and Early Mississippian in age and consists of multiple, thinly bedded, fine- to medium-grained sandstone, shale, siltstone, coal, and conglomerate. Regional correlation for all Price members can be difficult due to lateral facies changes. In southern West Virginia, the Price Formation is deep water marine-deltaic in origin (Bjerstedt and Kammer, 1988). The Price is correlative with the Cuyahoga and Borden Formations in Pennsylvania, Kentucky, and Ohio (Table 1) (Matchen 1992; Milici, 1996). The entire Price sequence is 940 feet thick at Caldwell, WV (Matchen, 1992).

The lower portion of the Price is dominated by the Cloyd Conglomerate Member. This conglomerate was deposited by a regression -transgression sequence during the late Devonian (Bjerstedt and Kammer, 1988) in estuarine point bar and fluvial channel environments (Bjerstedt 1986). The Cloyd fines upward, has quartz cobbles up to $8 \mathrm{~cm}$ in diameter and may exhibit large-scale cross-bedding (Bjerstedt and Kammer; 1988; Matchen, 1992). 


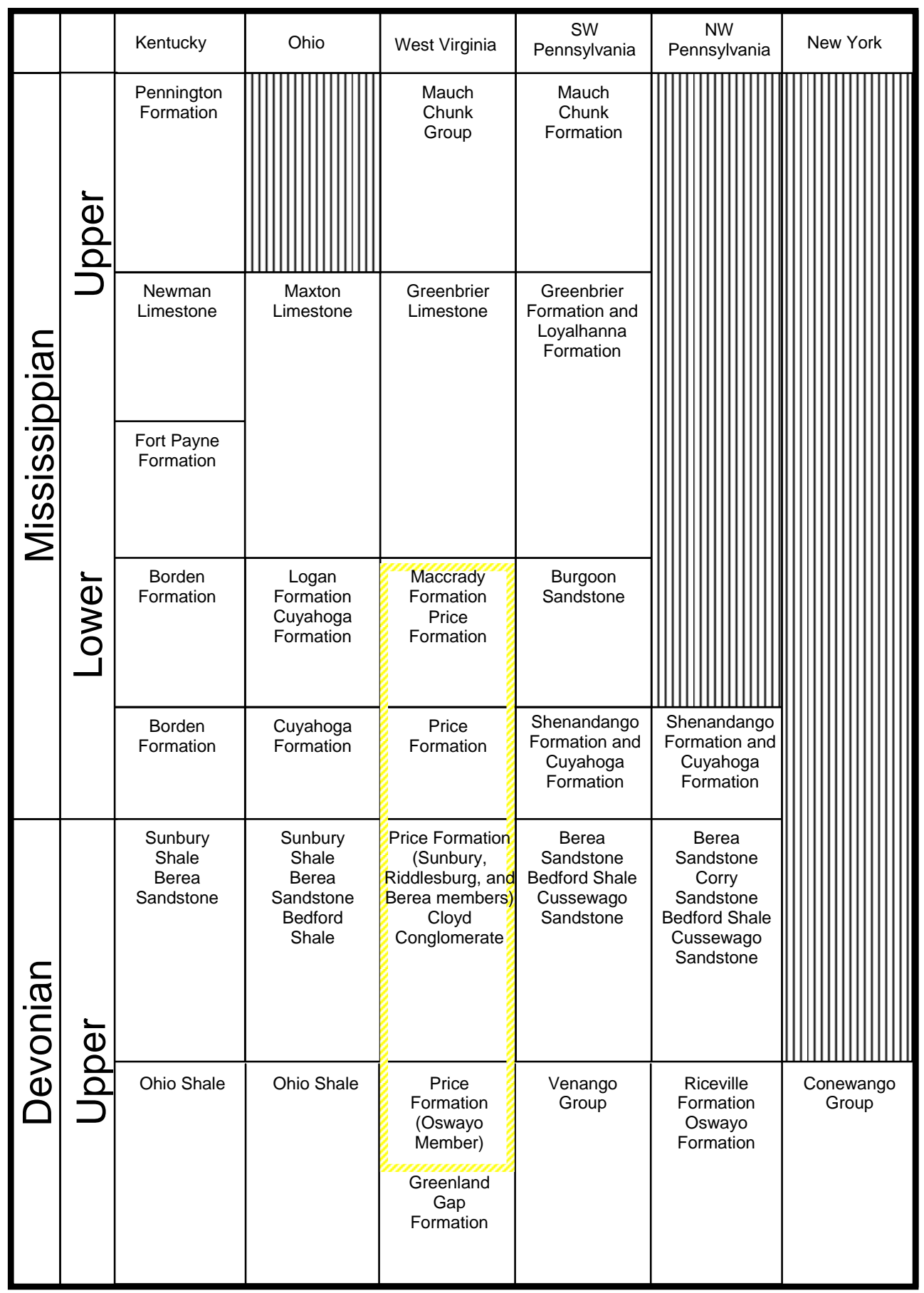

Table 1: Formations in the Lower Mississippian and Upper Devonian systems in Southern West Virginia and their equivalents in other locations (after Milici, 1996). The study interval is highlighted in yellow. 
The Sunbury shale and Berea sandstone for the purposes of this thesis are considered one unit referred to as the Sunbury Shale member (Bjerstedt and Kammer, 1987). The Sub-Berea unconformity is located within this unit which occurs at the base of the Berea sandstone. The Berea is predominantly present in Ohio and thins to the east and south (Bjerstedt and Kammer, 1988; Matchen and Kammer, 2006). Channel deposits within the Berea sandstone have been studied and developed as hydrocarbon reservoirs (Bjerstedt and Kammer, 1988; Matchen, 1992). The presence of the Berea in southern West Virginia has long been debated in literature. However, Matchen and Kammer’s (2006) latest work suggests that the Berea is not correlative throughout the region. The presence or absence of the Berea sandstone cannot be proven within my subsurface study area due to insufficient well penetration; however the Sunbury Shale top was correlated in well logs. The Sunbury Shale member consists of dark grey silty mudstones and siltstones deposited on fan slopes and deeper basinal depositional environments (Bjerstedt, 1986). This sequence marks the Mississippian-Devonian (FamennianKinderhookian) boundary in this area and also marks the upper-lower Price boundary (Zou, 1993).

The Weir sandstone is the next unit encountered and has been a target for petroleum exploration. It may occur as three distinct thin units or as one or two thicker units (Table 1 and Figure 10). Most well logs within the subsurface study area indicate the Weir as one or two massive units totaling approximately $40 \mathrm{ft}$ in thickness with shaley interbeds (labeled as the Weir Shale)(Figure 10). Thick Weir sequences follow NS trends in Southern West Virginia and production rates can be related to the presence or absence of the sandstones (Matchen and Vargo, 1996). The siliciclastic interval 


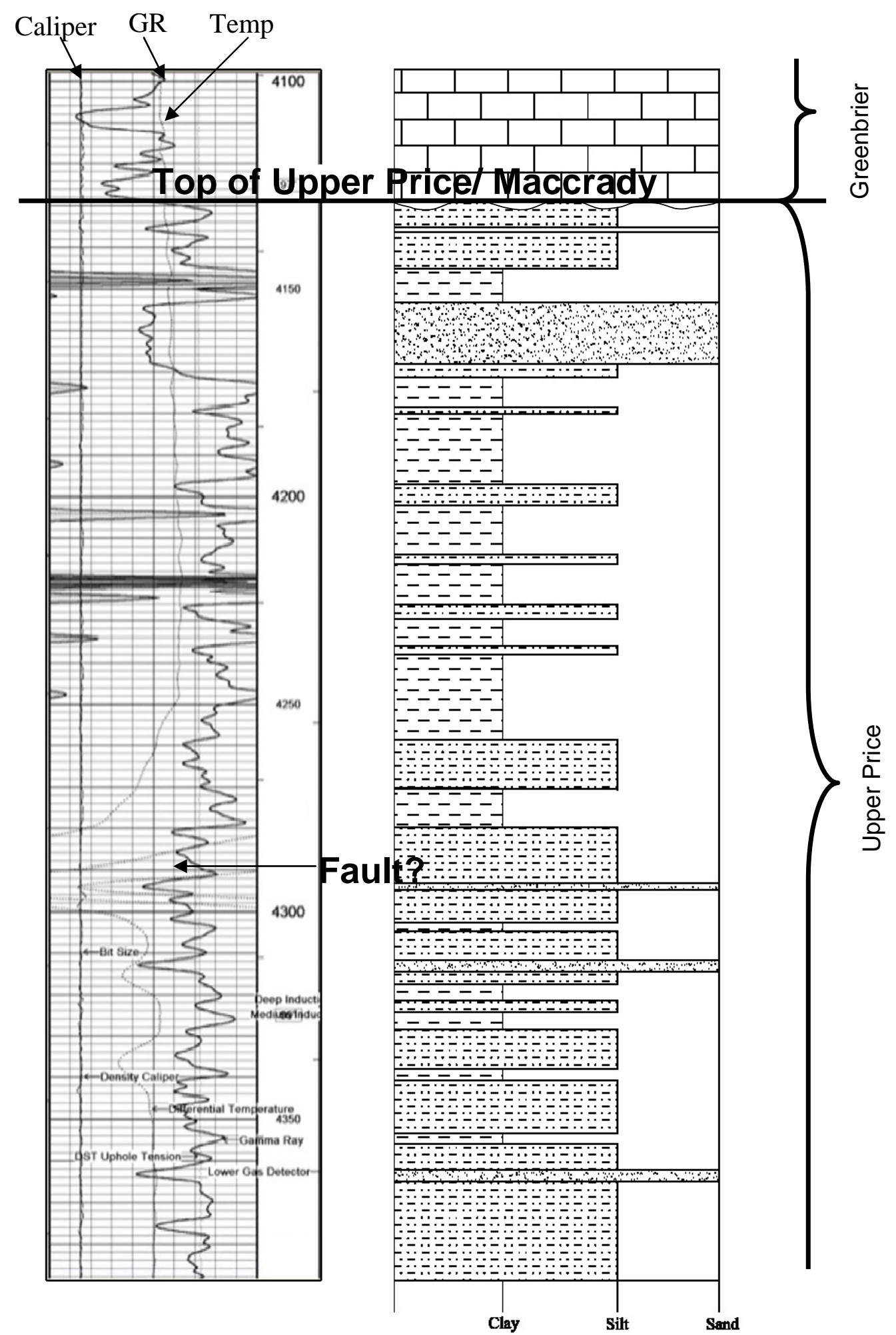

Figure 10: The Upper Price Formation as viewed in a geophysical log (API\# 4705500265) and associated markers used. Curves shown are caliper, temperature, and gamma ray. The temperature deflection shown may be illustrating gas issuing from a fault or fracture. 


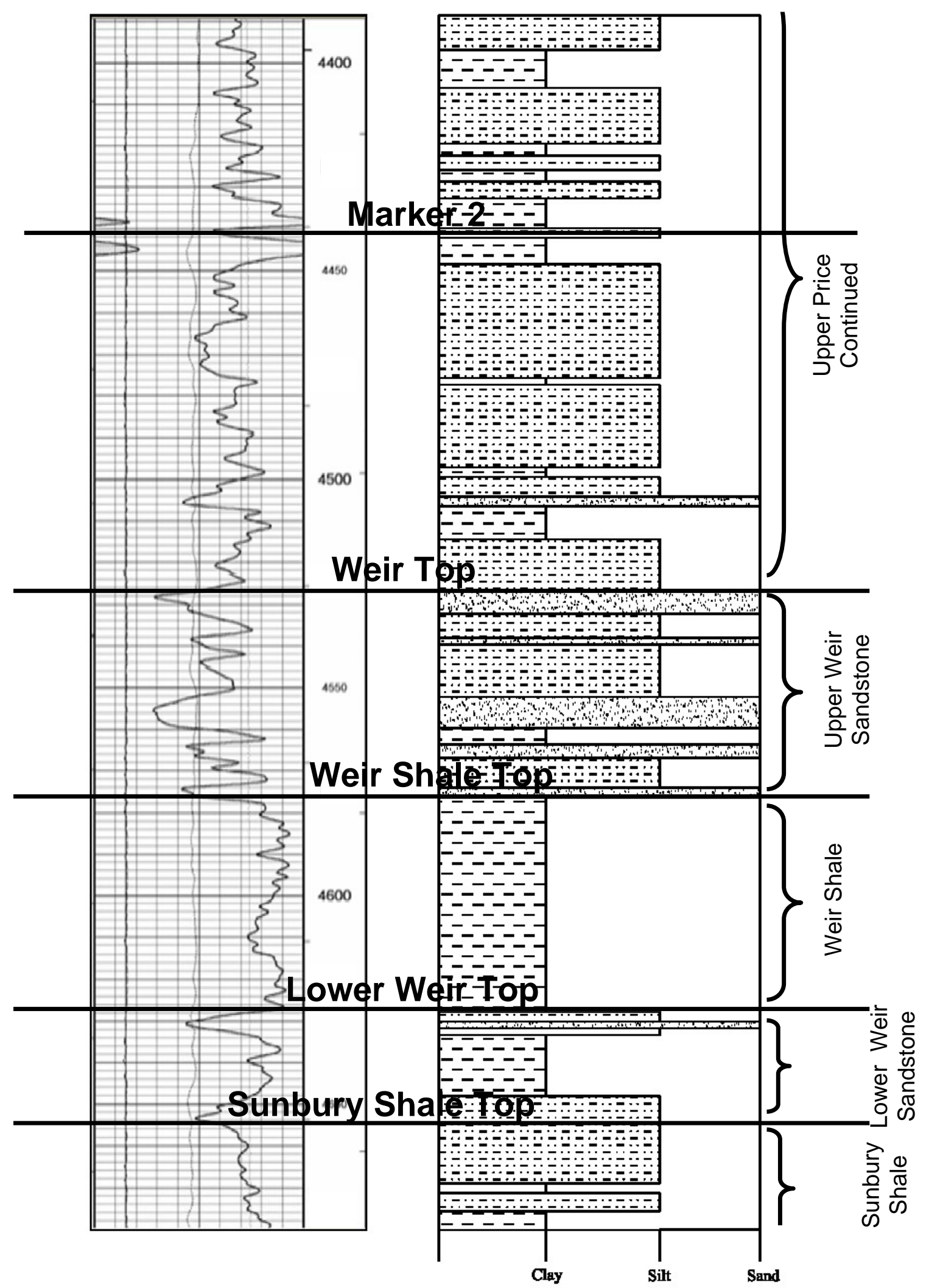

Figure 10 Continued 
bearing the Weir sandstone is approximately $370 \mathrm{ft}$ thick (Zou, 1993). The Weir is medium to coarse grained marine and is deltaic in origin (Matchen 1992). Above the Weir is a series of upward-coarsening, interbedded sandstone, siltstone and shale representing the Squaw and Big Injun (equivalent) intervals (Matchen, 1992). The Big Injun equivalent rocks are only age-equivalent to the Big Injun present in the subsurface in western West Virginia (Personal communication with Craig Edmonds, 2005). Therefore, in this study it is referred to as the Big Injun equivalent.

The units considered to be within the Upper Price are as follows: Lower Weir sandstone, Weir shale, Upper Weir sandstone, and the Big Injun equivalent units. The Sunbury Shale which, according to Matchen (1992), is not a part of the Upper Price was also examined to a limited extent where well data existed at that depth. Units below the Sunbury Shale were not studied due to a lack of well log data because most wells within the region lack sufficient depth.

The overlying Maccrady Formation, a series of argillaceous or calcareous shale (Reger and Price, 1926), is difficult to discern from the Upper Price in gamma-ray logs and may be absent in some areas due to the sub-Greenbrier unconformity (Matchen and Kammer, 1994). For this reason, it was included as part of the Upper Price interval for this study. The Upper Price/Maccrady marker (Figure 10), even though it is an unconformity surface, correlated well and was consistent structurally with adjacent markers. It was therefore assumed to be reliable marker for stratigraphic well log correlation. Formations located above and below the Price can be seen in Table 1. 


\section{Basin Development}

The Appalachian basin has a complex developmental history. Thomas (1977) states that the Appalachian Foreland Basin contains three main genetic sequences: The Precambrian and Cambrian volcaniclastics, the Cambrian and Ordovician carbonates and shales, and the Ordovician through Pennsylvanian dominantly clastic wedges. The latter of these three sequences, where the Price Formation resides, is comprised of multiple clastic wedges contained within regional scale salients (cratonward curved portions of lithosphere) (Thomas, 1977). Each of these clastic wedges represents one large depositional cycle related to an orogenic event (Thomas, 1977).

Multiple orogenic events, including the Iapetian Rift (Rome Trough - Figure 1), Taconic, Acadian, and Alleghenian orogenies, have caused uplift and supplied sediment for the various genetic sequences within the foreland basin (Milici, 1996). However, the Acadian and Alleghenian orogenies are the primary orogenic events responsible for the deposition and deformation of the rocks covered in this thesis.

The Acadian orogeny is of significant importance because it supplied the sediment for the modern Acadian Clastic wedge and Catskill Delta (Matchen and Kammer, 1994; Milici, 1996). The Acadian Orogeny began in middle Devonian time and is defined by the merging of the Avalonian terranes with Laurentia (Milici, 1996).This convergence progressed from northeast to southwest (Ettensohn, 2005). Lithospheric flexure and subsidence due to loading from the orogeny most likely created the Appalachian Basin. The Appalachian basin filled from east to west and eventually formed a large westward dipping sedimentary platform (Ettensohn, 1985). The upper 
portion Catskill Delta preserved in West Virginia is known as the Price Rockwell deltaic complex and includes the Price Formation (Milici, 1996).

The subsidence or the foreland basin and sedimentation of the Price-Rockwell deltaic complex occurred due to the oblique slip movement between the Avalon Terrane and Virginia Promontory (Thomas, 1977) during the fourth tectophase of the Acadian Orogeny (Ettensohn, 1985). All Appalachian orogenies can be broken into tectophases, a period of loading and deformation followed by large scale relaxation, whose average regional interval is about 12 million years (Ettensohn, 2005). 


\section{Chapter 3: Surface Methods and Results}

\section{Surface Outcrops Measured}

Fractures were analyzed at multiple outcrops throughout southern West Virginia and Virginia (Figure 1). After consideration of all the exposures, the Alta and Caldwell outcrops were chosen as the primary analogs for the subsurface model (Figures 11 and 12). These outcrops were chosen as analogs because of their proximity to the subsurface study area (39 and 45 miles respectively), their similar structural setting to the subsurface study area, and excellent exposure. The Williamsburg anticline and Caldwell syncline, the structures associated with the study outcrops, strongly resemble the structures observed in the subsurface in geometry. While the folds at the surface study outcrops are larger in scale than those in the subsurface, they were probably formed by similar tectonic processes and are similar in age. The deformation illustrated by these outcrops is a wide range which most likely encompasses the degree of deformation in the subsurface. Strain designations were made based on structural setting, which included distance from major faults and the amount of deformation observed in the field.

At the Alta outcrop only the Upper Price and Maccrady are exposed. However, in the Caldwell outcrop, the Price is exposed in its entirety along with partial exposure of the overlying Maccrady and underlying Chemung. Both outcrops were described stratigraphically by Bjerstedt (1986). 


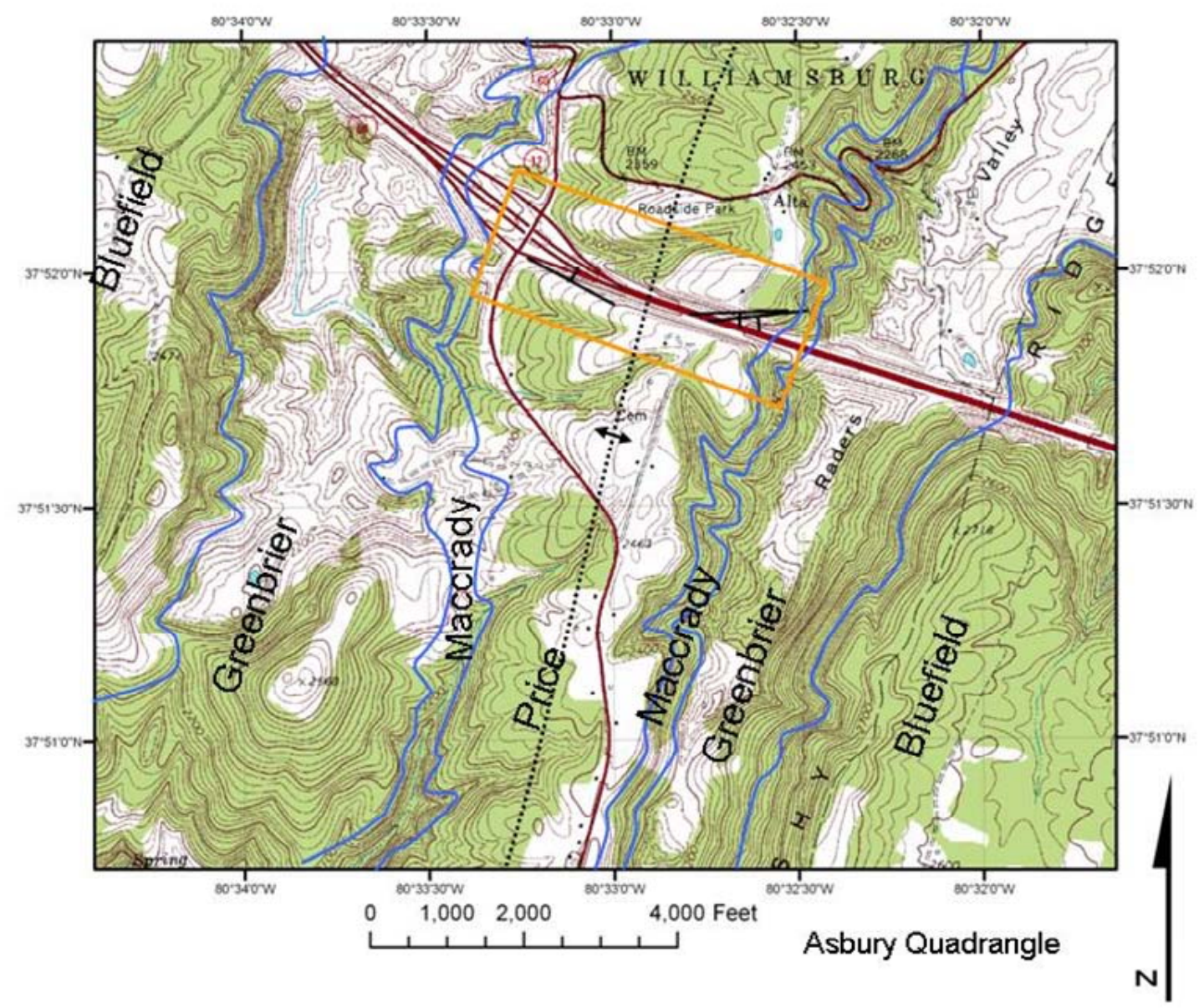

Figure 11: The Alta outcrop location (outlined in orange). The exposure is located along both sides of I-64 approximately $0.3 \mathrm{~km}$ east of exit 161 . Blue lines represent geologic contacts. Black symbols represent selected strike and dip direction measurements. Note: The Bluefield formation is part of the Mauch Chunk Group. 


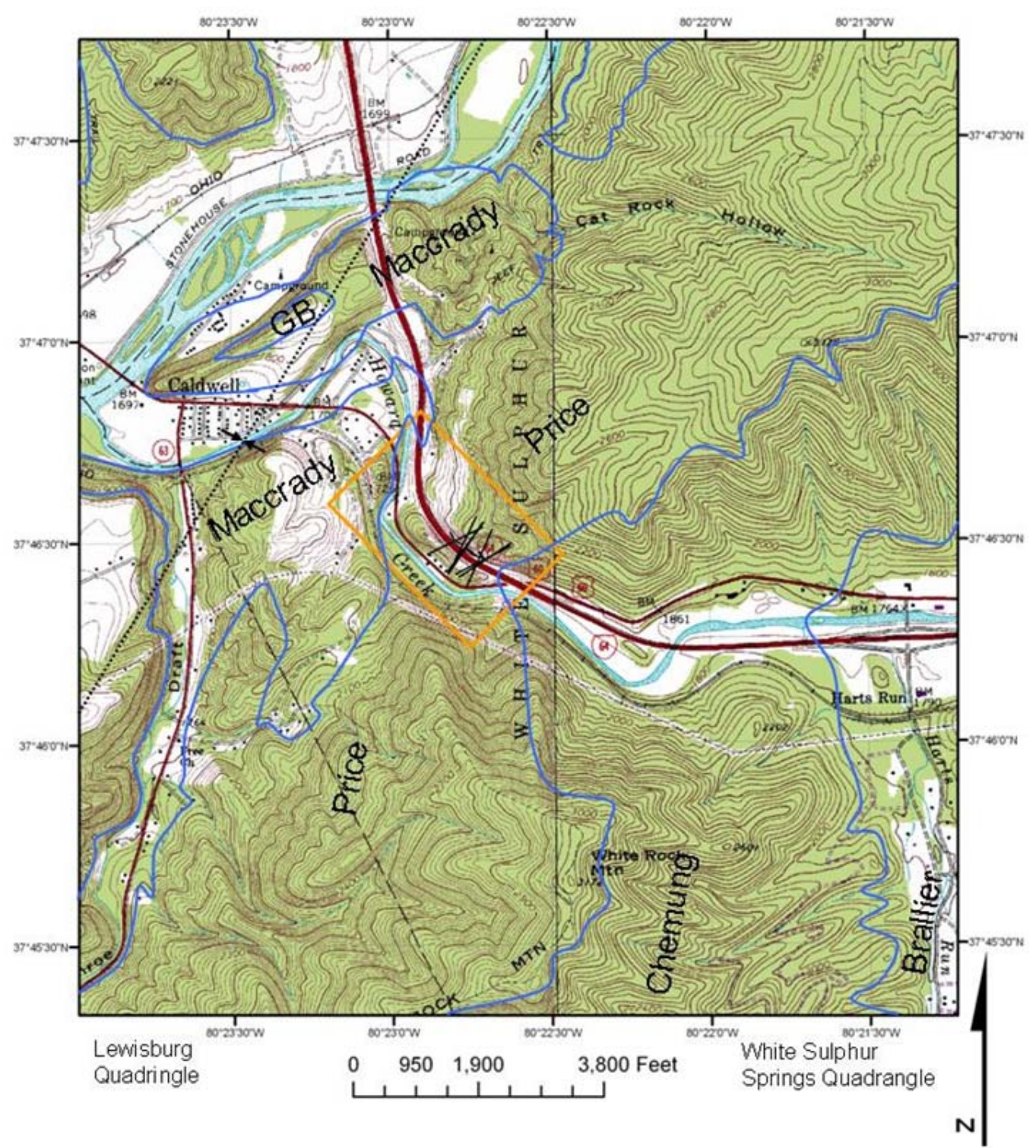

Figure 12: The Caldwell exposure location (outlined in orange). The outcrop is along both sides of I-64 approximately $1.9 \mathrm{~km}$ west of exit 175 . Note: Black symbols represent selected strike and dip direction measurements. The Brallier formation is the Devonian unit that underlies the Greenland Gap Formation (Milici, 1996). 


\section{Measurement methods}

Fractures were analyzed in outcrop in a variety of different ways. Initial fracture measurements were made using the circle inventory method outlined by Davis and Reynolds (1996) and originally created by Titley (1976). This process required exposed bedding planes with visible joints that can be measured and counted. However, due to the lack of exposed bedding planes, linear joint densities were taken instead using the method presented in Narr (1991). In the collection process length measurements are made along the side of the exposed bed and the joints are counted (Figure 13). When possible, mechanical units with at least four visible joints were measured. In this process, it is possible that not all of the joint sets are accurately represented due to joint sets that do not intersect the outcrop plane (i.e. joints that are parallel to outcrop). However, this method is still reasonable given that upon visual inspection, joint spacing for the sets in each outcrop was consistent. Strike, dip, and dip direction for both joint surfaces and bedding planes were also recorded to supplement the joint-density data.

At each outcrop, a data set representative of all structural regimes, lithologies, and bedding thicknesses was collected. Due to the thinly bedded nature of the Price, it was not feasible for this project to measure each individual mechanical unit in outcrop. There are literally thousands of mechanical units in the Caldwell outcrop alone. 


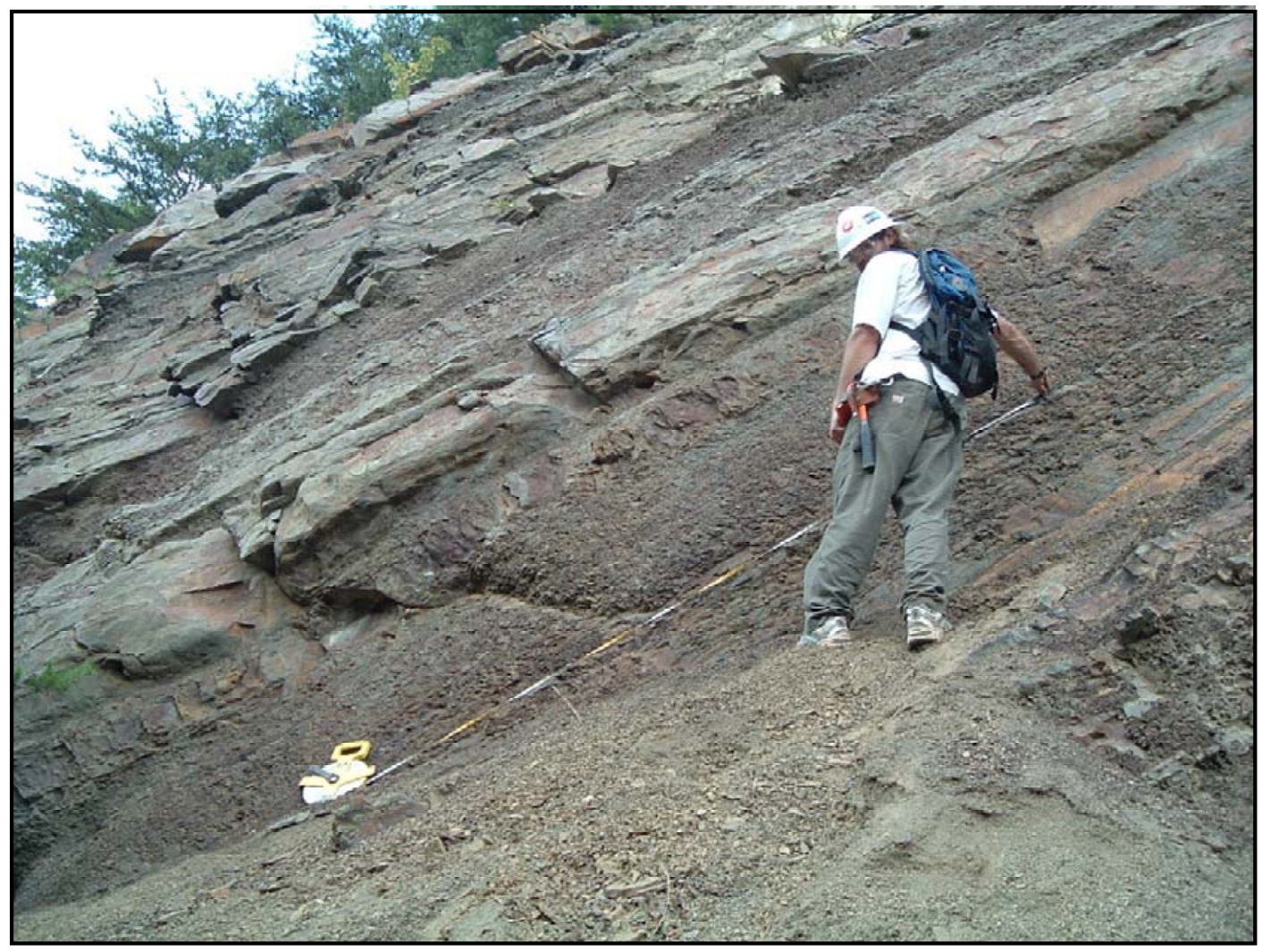

Figure 13: Photo of joint measurement at the Caldwell outcrop. 


\section{Outcrop Analysis Results}

The two outcrops measured are vastly different in many ways but serve as excellent analogs because of the joint patterns and densities observed. The Alta exposure was considered low strain whereas the Caldwell exposure was considered high strain (Figure 14) because of structures observed in the regional geologic map (Cardwell, et. al., 1986), the amount of folding or lack thereof observed in outcrop, dip angles measured at outcrop, and relative distance from the Allegheny structural front (St. Clair Fault). Fracture density in both outcrops was strongly correlated with mechanical layer thickness which is probably highly related to strain. Fracture densities and average mechanical unit thicknesses were different between outcrops. All of the joints observed in outcrop were open with no observable cement or fill. Hackle structures were visible on the surfaces of

some joints but were not prevalent. Some shear fracturing was observed at both outcrops but was not considered to constitute a significant amount of the connected fractures. A shear fracture shatter zone was noted at a small normal fault in the preliminary data gathering stage near the St. Clair Fault in Oakvale, WV (Figures 1 \& 15). The shear fractures observed at Alta and Caldwell had little to no visible displacement. The mechanical stratigraphy presented here is an oversimplification for both outcrops.

\section{Caldwell - High Strain Outcrop}

The Caldwell outcrop is located along the east limb on the Caldwell syncline. It is approximately 11 miles west from the St. Clair Thrust and 45 miles from the subsurface study area. The Caldwell outcrop contains mainly "stratabound” mechanical 

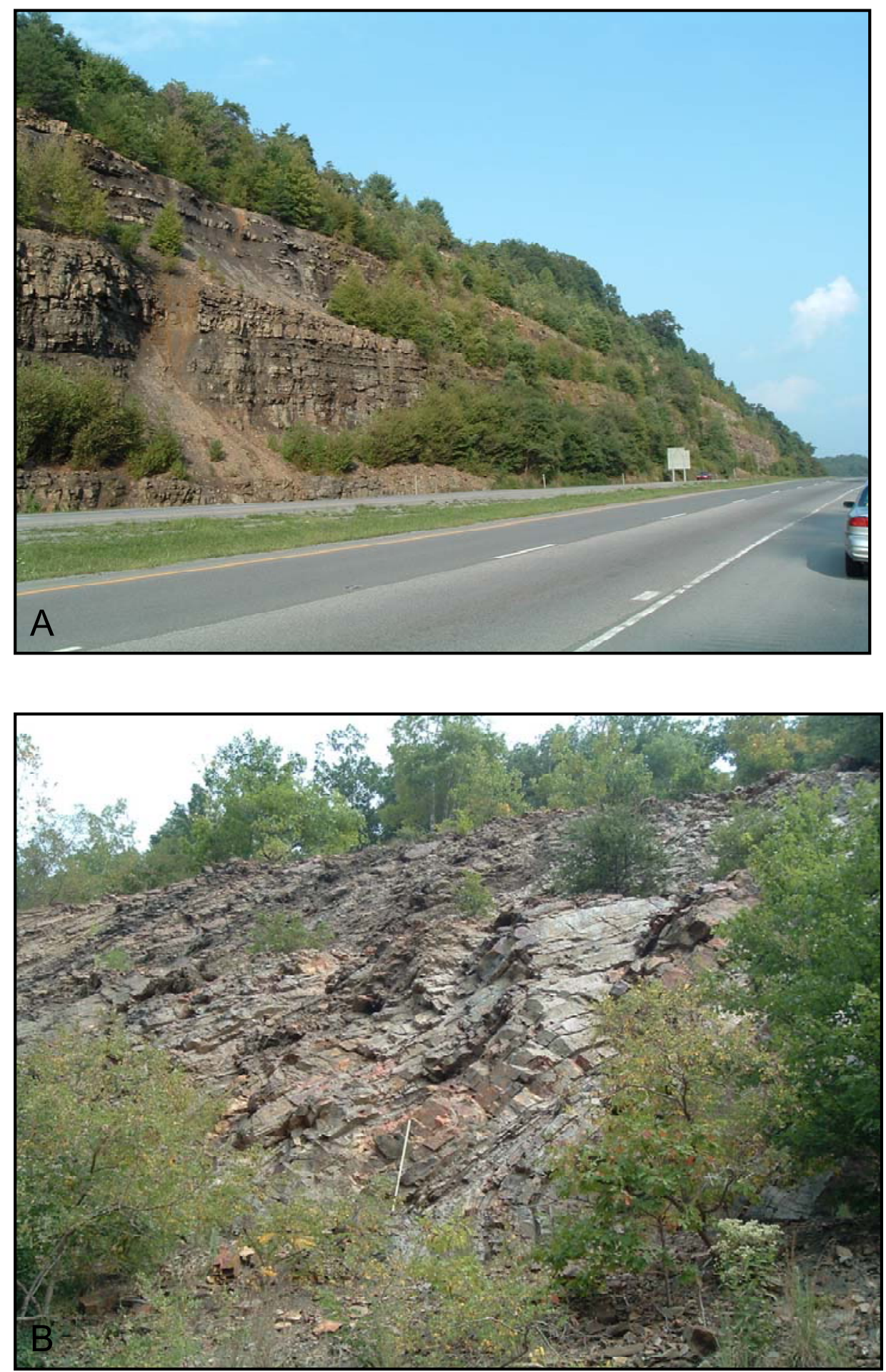

Figure 14: Outcrop photos. The Alta and Caldwell outcrops are labeled A and B respectively. Note the significant difference in dip angle between outcrops. A small slightly overturned fold is visible at Caldwell to the right of the tape measure (which is set at 3 feet). 


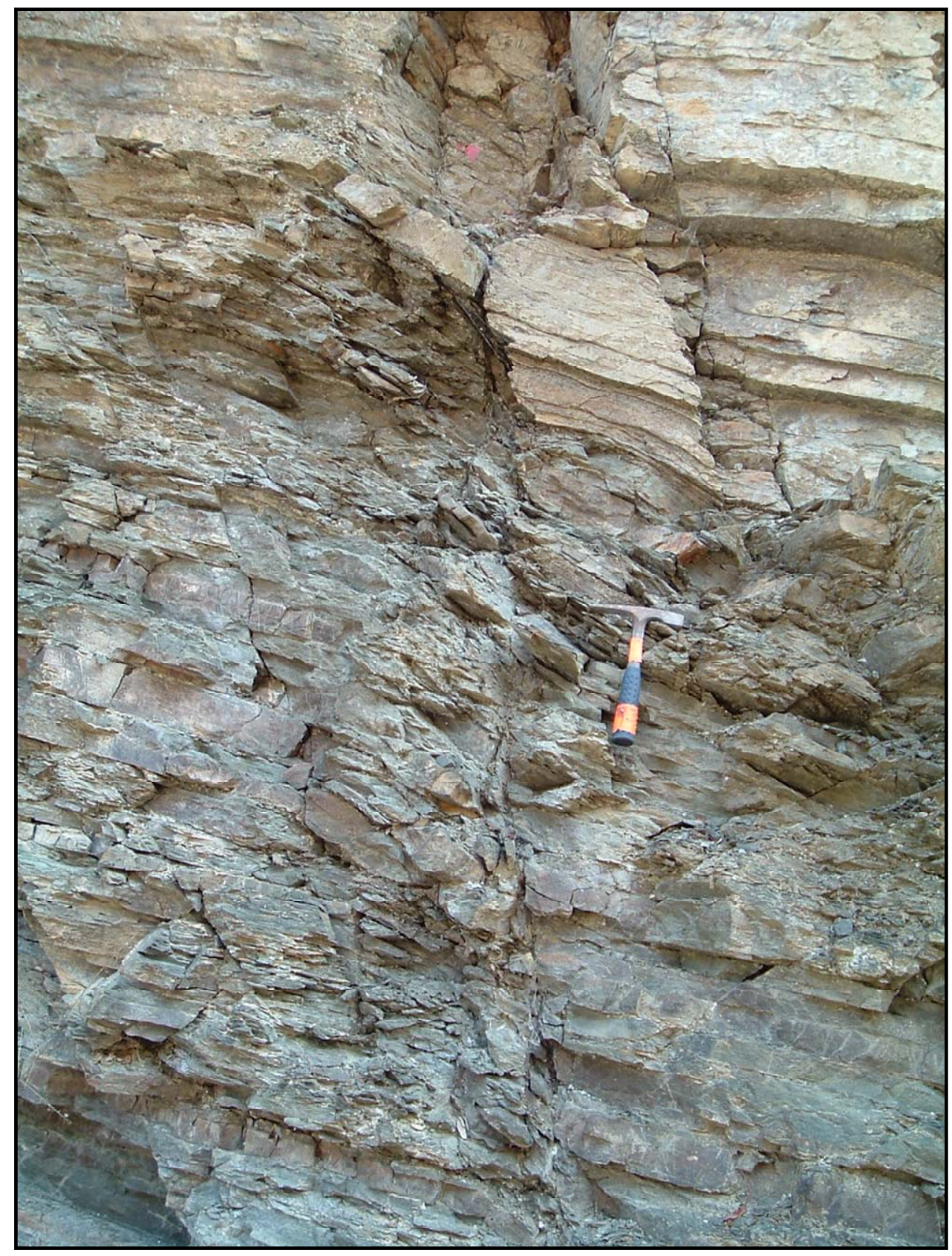

Figure 15: Photo of a shatter zone near a small normal fault in the Price Formation near the St. Clair Thrust Fault in Oakvale, WV. 
units (Odling et. al. 1999) where each depositional unit functions as a mechanical unit (Figure 7). Deformation and folding are high there with numerous small folds, some of which are slightly overturned. The outcrop-scale folds are west verging and have amplitudes of approximately 10-20 ft. Shales have significantly higher joint densities than the sandstones, and thinly bedded units have significantly higher joint densities than thickly bedded units (Figures 16 and 17). Three primary joint sets exist at the Caldwell outcrop with approximate orientations of $001^{\circ}, 045^{\circ}$, and $117^{\circ}$ (Figure 18). Secondary joints are numerous and have approximate orientations of $030^{\circ}, 063^{\circ}$, and $100^{\circ}$. Joint dip angles at the Caldwell outcrop vary significantly from $10^{\circ}$ to $90^{\circ}$. However, bedding dip angles are also quite variable here $\left(20^{\circ}-86^{\circ}\right)$. Several background shear fractures were also noted.

\section{Alta - Low Strain Outcrop}

Alta contained "non-stratabound" mechanical units (Odling et. al. 1999) and fewer mechanical units overall. The Alta outcrop is approximately 23.5 miles from the Allegheny structural front and 39 miles from the subsurface study area. Joint density and deformation are considerably lower at the Alta outcrop as compared with the Caldwell outcrop (Figure 16 and 17). The only folding observed in the Alta outcrop was the gentle curvature of the Williamsburg anticline. Bedding dips at the Alta outcrop were fairly uniform $\left(1^{\circ}-10^{\circ}\right)$. The Alta outcrop had a primary joint set oriented at $084^{\circ}$ and two secondary joint sets oriented at $015^{\circ}$ and $170^{\circ}$ (Figure 18). Joint dips at the Alta outcrop were all $82^{\circ}$ or higher. These joint set orientations at Alta did not fully fit the idealistic model produced by Fisher and Wilkerson (2000) concerning fold axes and joint orientations (Figures 5 and 18). 


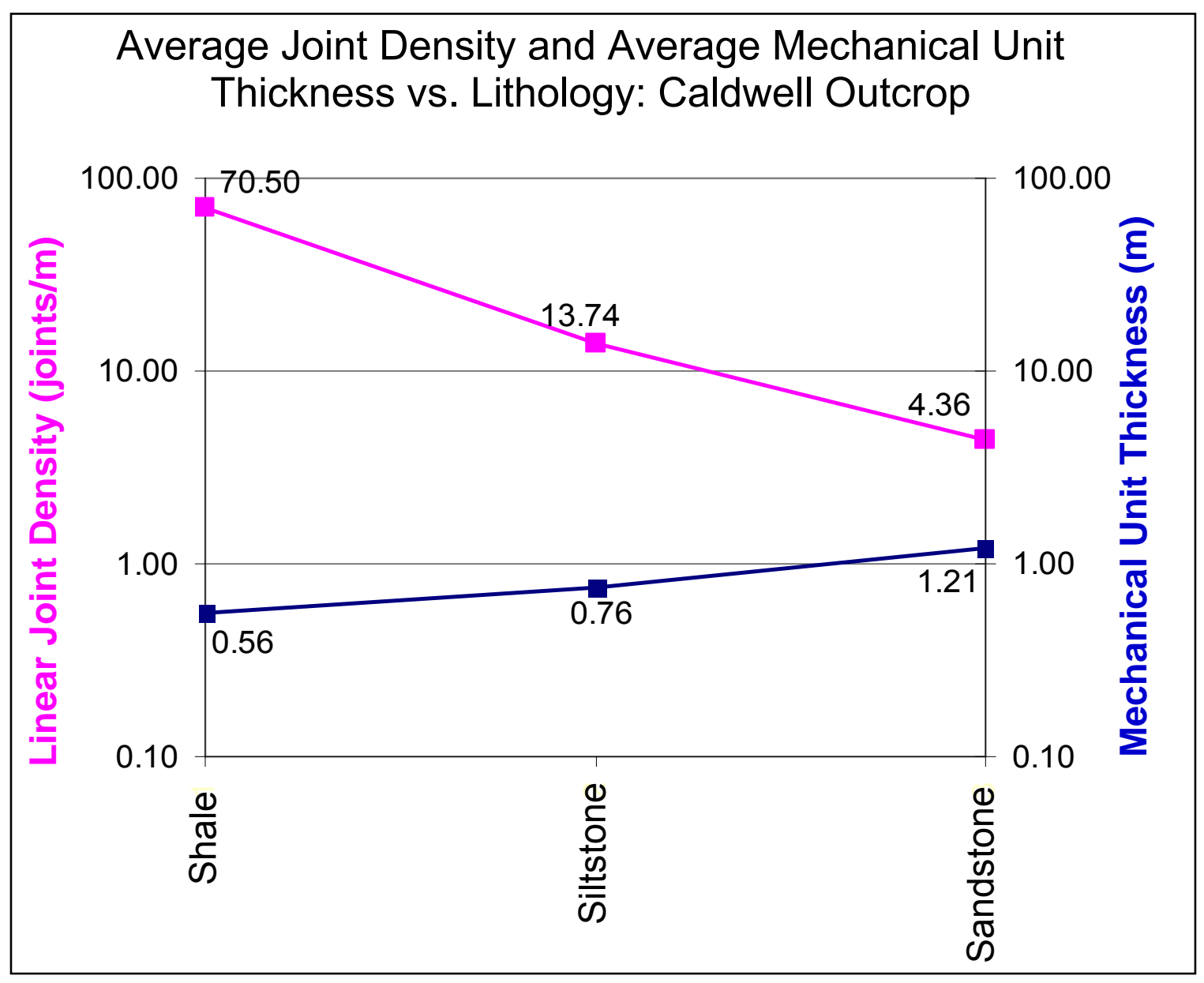

Figure 16: Joint density and mechanical unit thickness, lithology, at Caldwell. Note the changes in joint density and mechanical unit thickness with grain size. 


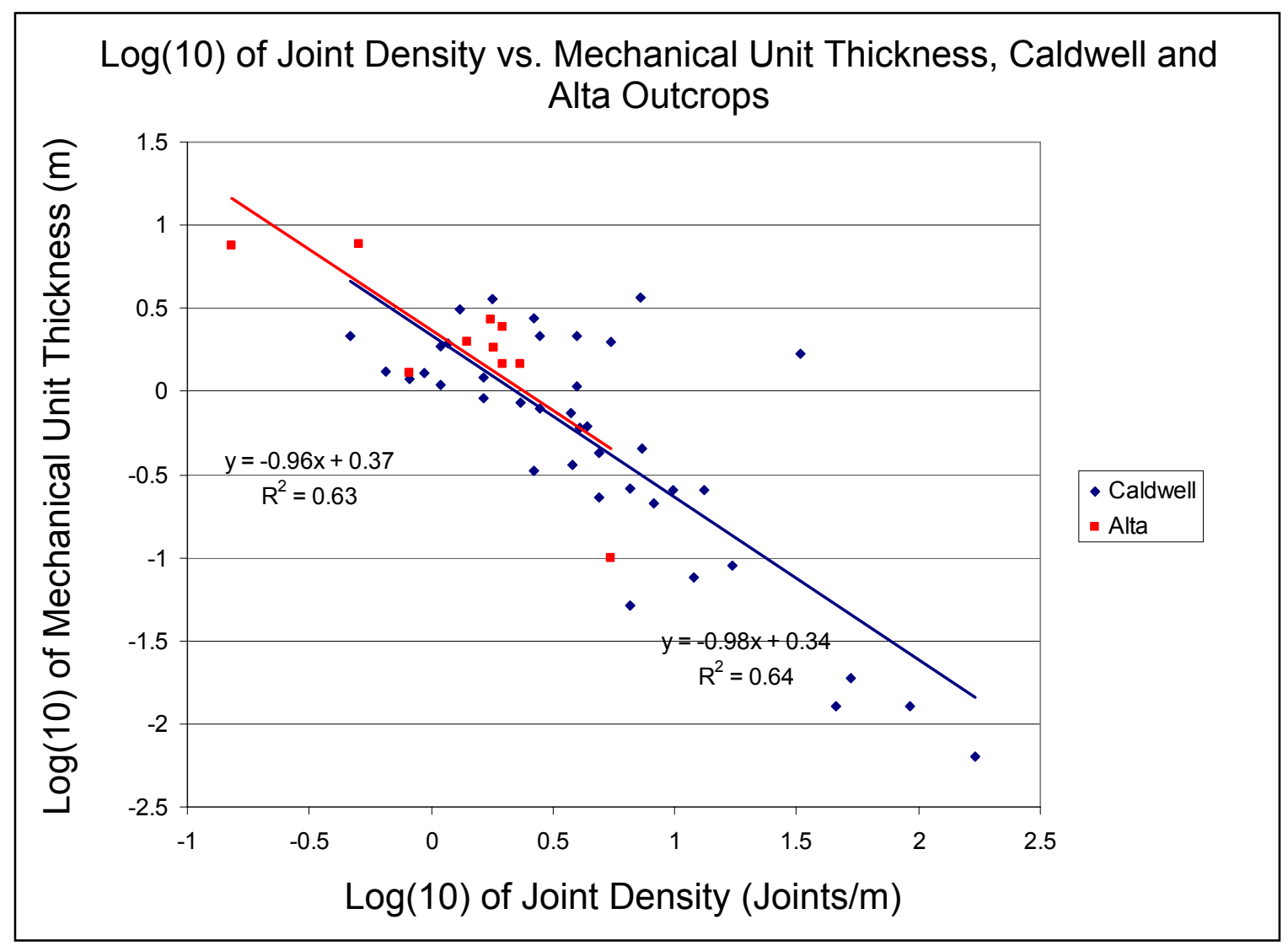

Figure 17: Joint density vs. layer thickness graph for the Alta and Caldwell outcrops. Log (10) values were used to better assign a linear fit to the data. Note that the linear trends are very similar between outcrops. 

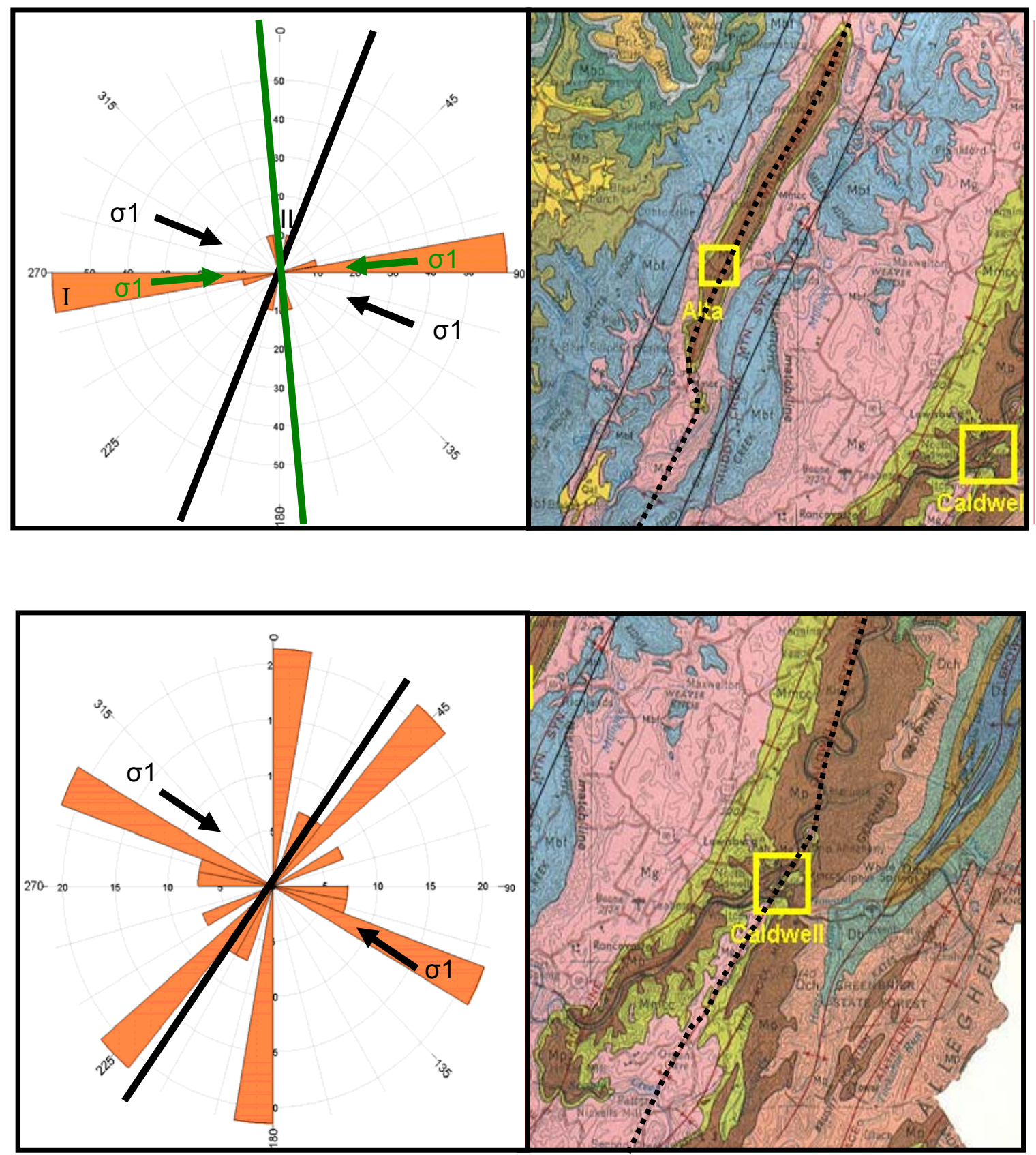

Figure 18: Rose diagrams for outcrop joint data for Alta (Top) and Caldwell (Bottom) outcrops. Diagrams are bipolar. Circles indicate percentage, and azimuths indicate strike direction of joint sets. Black lines and arrows indicate fold axes for the major structures and the stress directions responsible. Green lines and arrows indicate the idealistic fold axes and stress directions responsible for set I at Alta. The jointing complexity is significantly higher at Caldwell but better fits the fold-joint relationships described by Figure 5. 


\section{Chapter 4: Subsurface Analysis, Modeling and Results Geophysical Log Correlation}

The geophysical logs used typically included gamma-ray, caliper, temperature, audio, neutron-porosity, and density-porosity curves. All geophysical logs were raster images (TIFF) and no LAS files were used. Seven horizons were correlated primarily on gamma-ray signature. Gamma-ray logs generally registered 0-200 API units and 200-400 API units where the curve wrapped. Sandstone was picked at $<100$ API units and shale was picked at >220 API units. Correlation was done on all wells with available logs (121 total) utilizing circular correlation along with NE-SW and NW-SE trending cross sections. One dipmeter/FMI log was examined as it was the only available dipmeter log to penetrate the Price Formation (API\# 4705500118) (Figure 4). Unfortunately to quality of this $\log$ is poor.

The horizons correlated are as follows (in decreasing age): Sunbury Shale top, Lower Weir sandstone top, Weir shale top, Upper Weir sandstone top, Mid-Upper Price high-gamma marker (Marker 2), Upper Price/Maccrady top, and Greenbrier Limestone top (Figure 10). The Greenbrier top was picked to better illustrate structure within the model.

Five major thrust faults were recognized and correlated in the geophysical logs. Faults were identified by repeated intervals or anomalous thicknesses in the geophysical logs (Figure 19). Once again, gamma-ray was the primary log used, but caliper and porosity logs were also examined if a particular interval was suspected as being faulted. The faults were named using the terminology of Edmonds (2004), if correlatable, or for overlying towns or physical features and are as follows from SE to NW: Nubbin Ridge, 


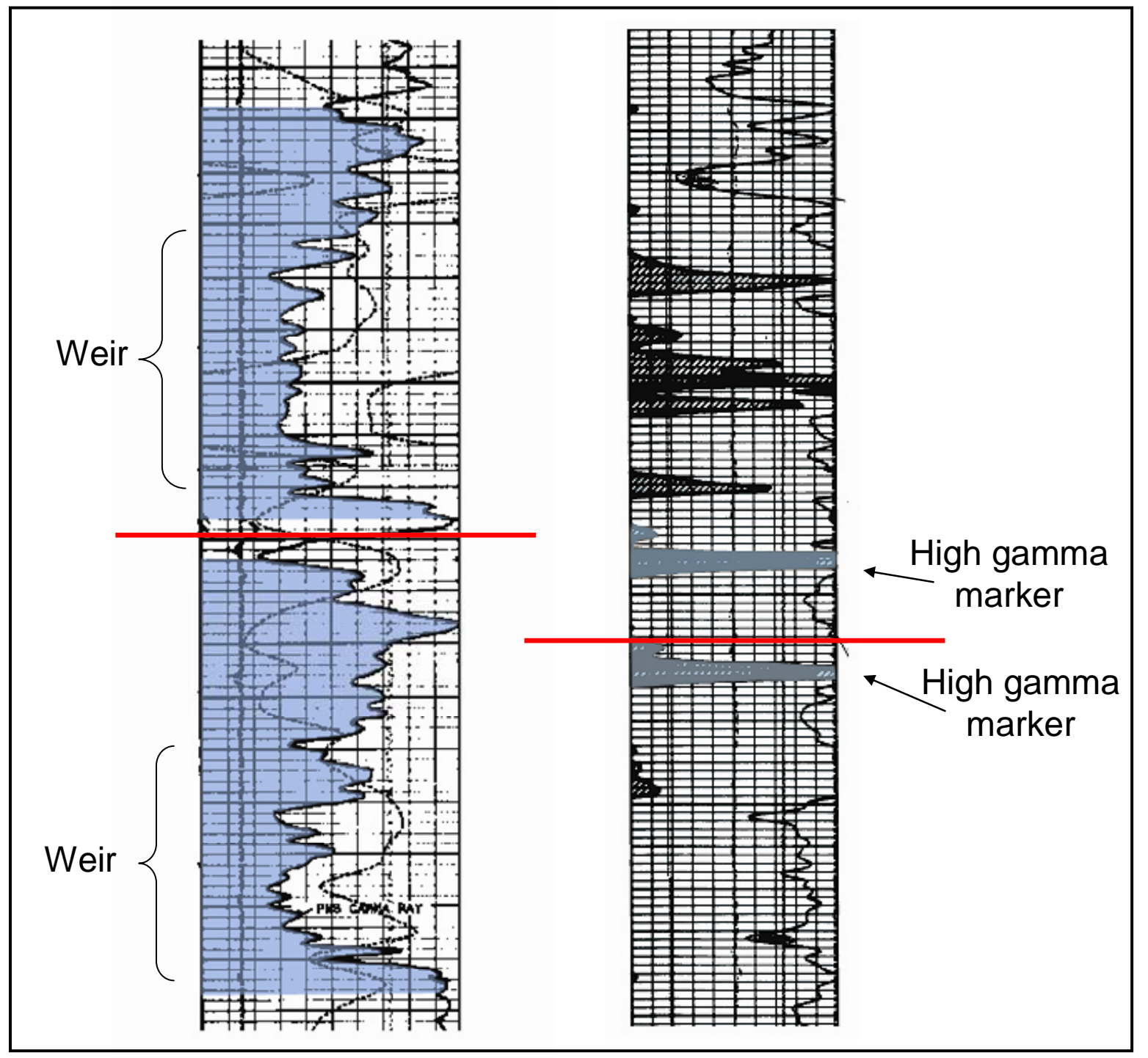

Figure 19: Repeated (faulted) intervals in the Weir sandstone (Left) and Upper Price (Right) in gamma ray logs. Red bars illustrate the approximate location of the faults. The grey highlighted intervals illustrate the sections being duplicated. The corresponding API well numbers are (Left) 4705500235 and (Right) 4705500127 and can be seen on Figure 4. 
Mash Run, Pilot Knob, Micajah, and Flat Top (Figure 20). All correlation was performed in the Landmark Geographix XSection module.

Other structural features identified included multiple small anticlines and synclines (Figure 21A-G). The overall structure deepens to the southeast. Faults, anticlines, and synclines were all found to have a northeast to southwest trend. Faults exhibited a flat-ramp type of geometry and generally were shallow dipping (Table 2). The Pilot Knob and Mash Run faults both exhibited a geometry where some sinuosity was observed on the fault plane itself (Figure 20). As observed earlier, complete duplication of units by faulting was observed. Vertical depths ranged from 4526 to 3323 for the Price Top. Isopach mapping (Figure 22) illustrated anomalous thickening which led to the discovery of faults in several wells. Total study section thickness (Upper Price Top - Sunbury Top) across the subsurface study area ranged from 438 to 597 feet. Gas effect (crossover of the neutron porosity and density porosity logs) was noted in multiple locations throughout the Price interval in multiple well logs. The dipmeter log analyzed contained interpreted drilling-induced fractures that were oriented at approximately $60^{\circ}$. This agrees with drilling-induced fractures found in Edmonds (2004). The dip and dip direction for the Price bedding planes in this well are $3.2^{\circ} \mathrm{NW}$ which agrees with local structure. The Pilot Knob Fault does intersect this well but the dipmeter log does not show the feature due to a gap in the data. 


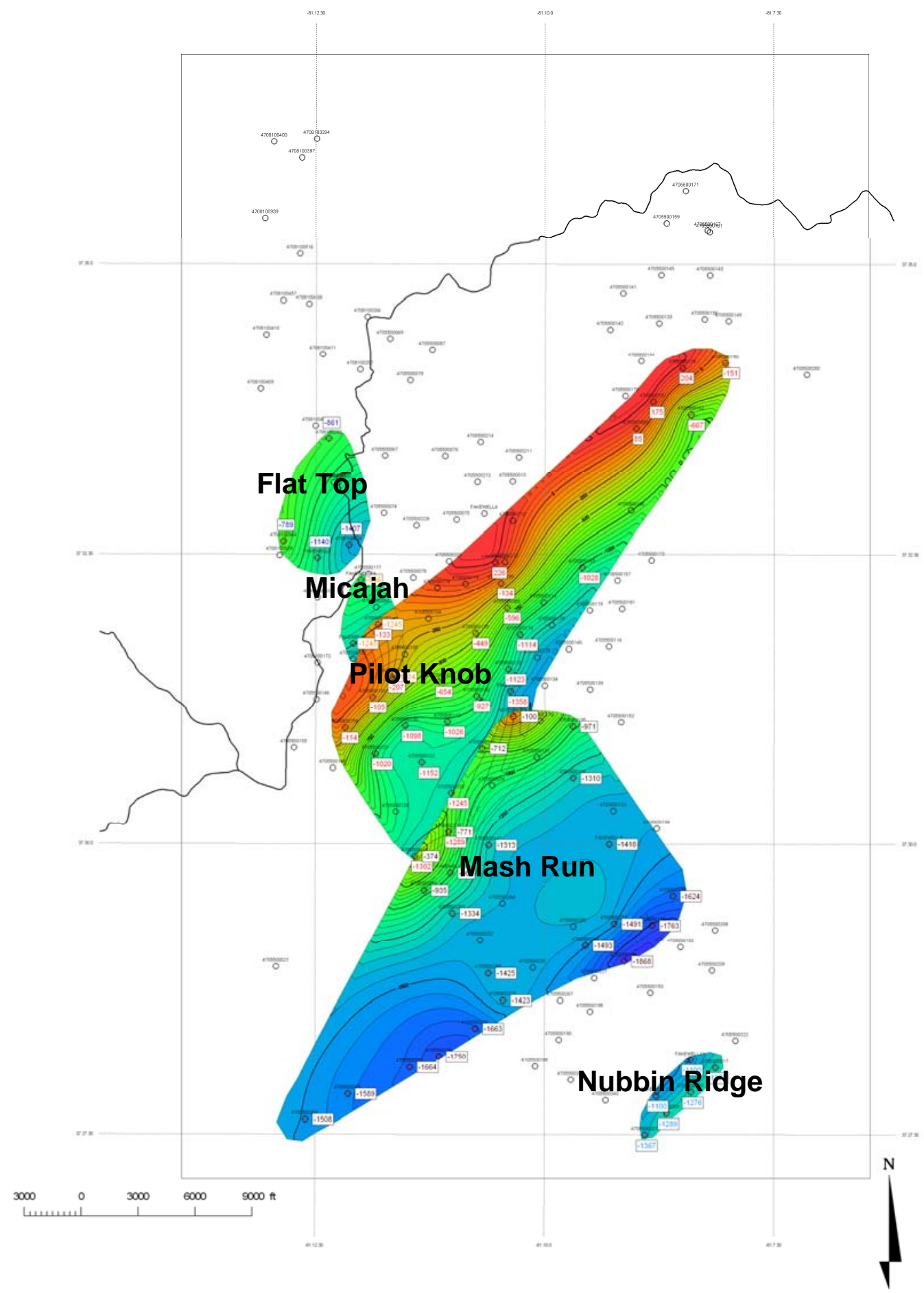

Figure 20: Map of thrust faults correlated and identified. Red = structurally high, Blue = structurally low (the default color scheme for this thesis). White boxes have subsea elevations for the fault picks labeled. The southwest portion of the Pilot Knob and Micajah faults are not visible due to overlap. The contour interval is 50ft. 


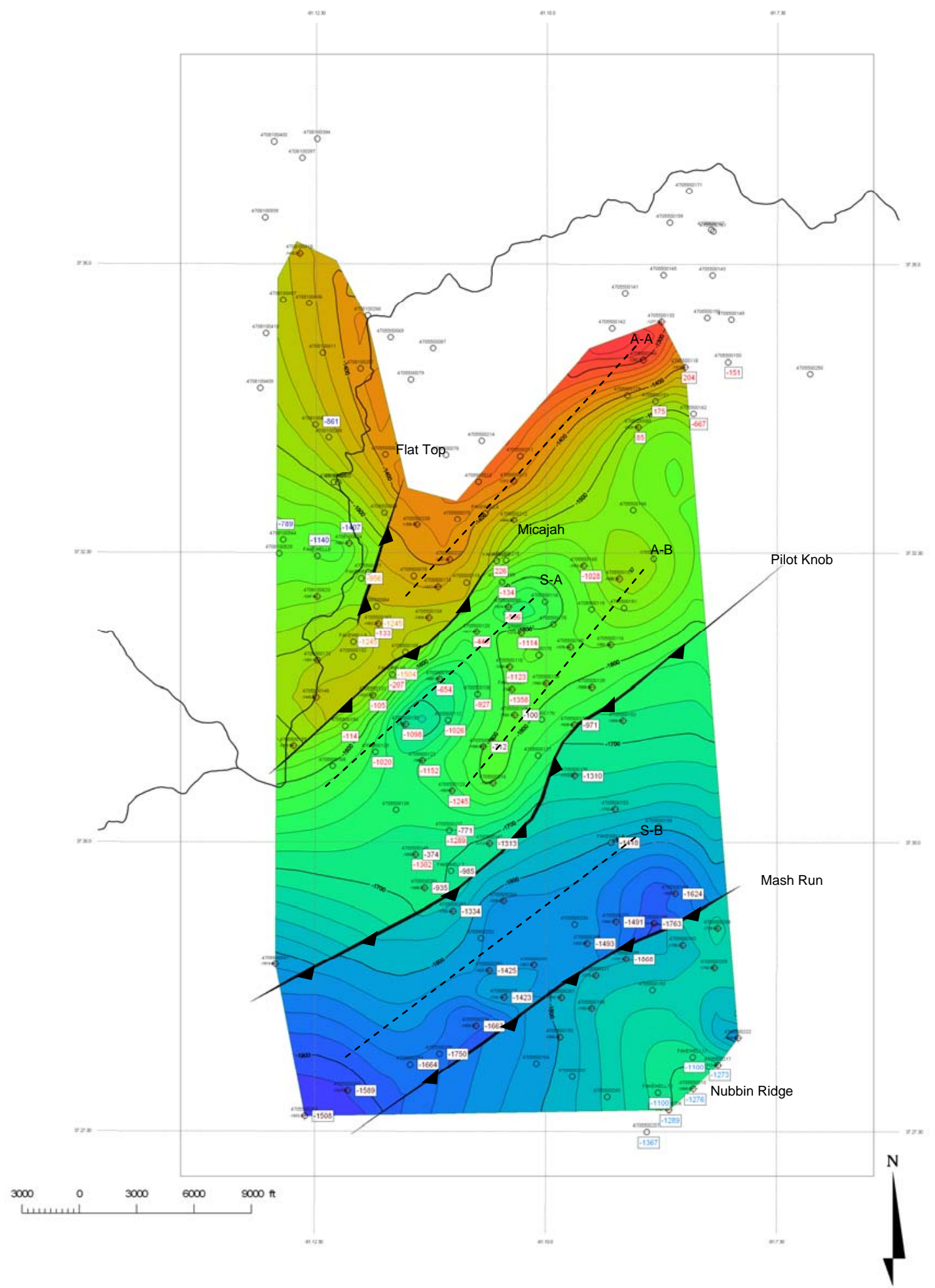

Figure 21A: Subsurface structure map of the Sunbury shale top. Blue = structurally low, red $=$ structurally high. $\mathrm{S}-\mathrm{A}=$ Syncline $\mathrm{A}, \mathrm{A}-\mathrm{A}=$ Anticline $\mathrm{A}$, etc. The contour interval is $20 \mathrm{ft}$. 


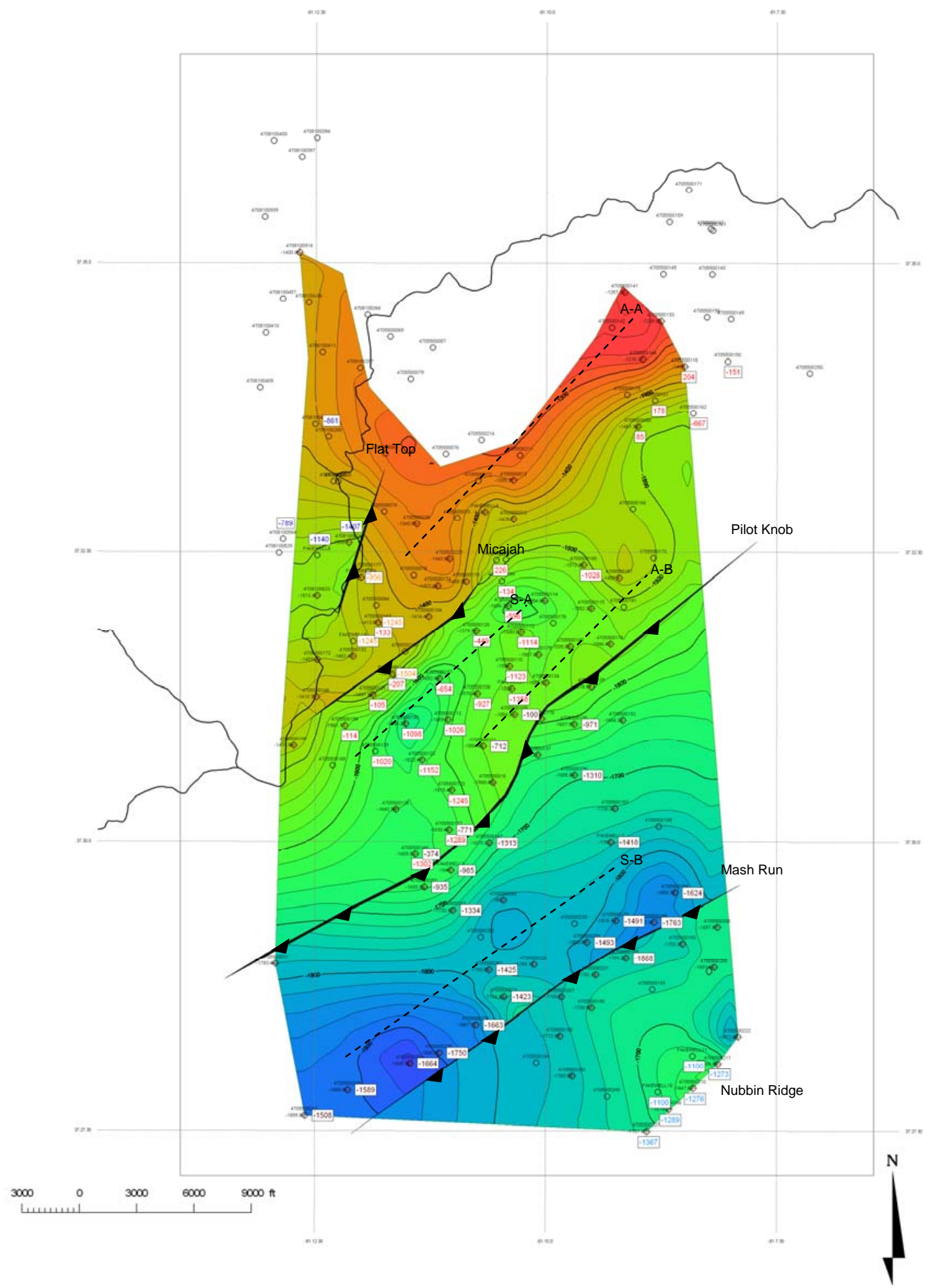

Figure 21B: Subsurface structure map of the Sunbury shale top. Blue = structurally low, red $=$ structurally high. 


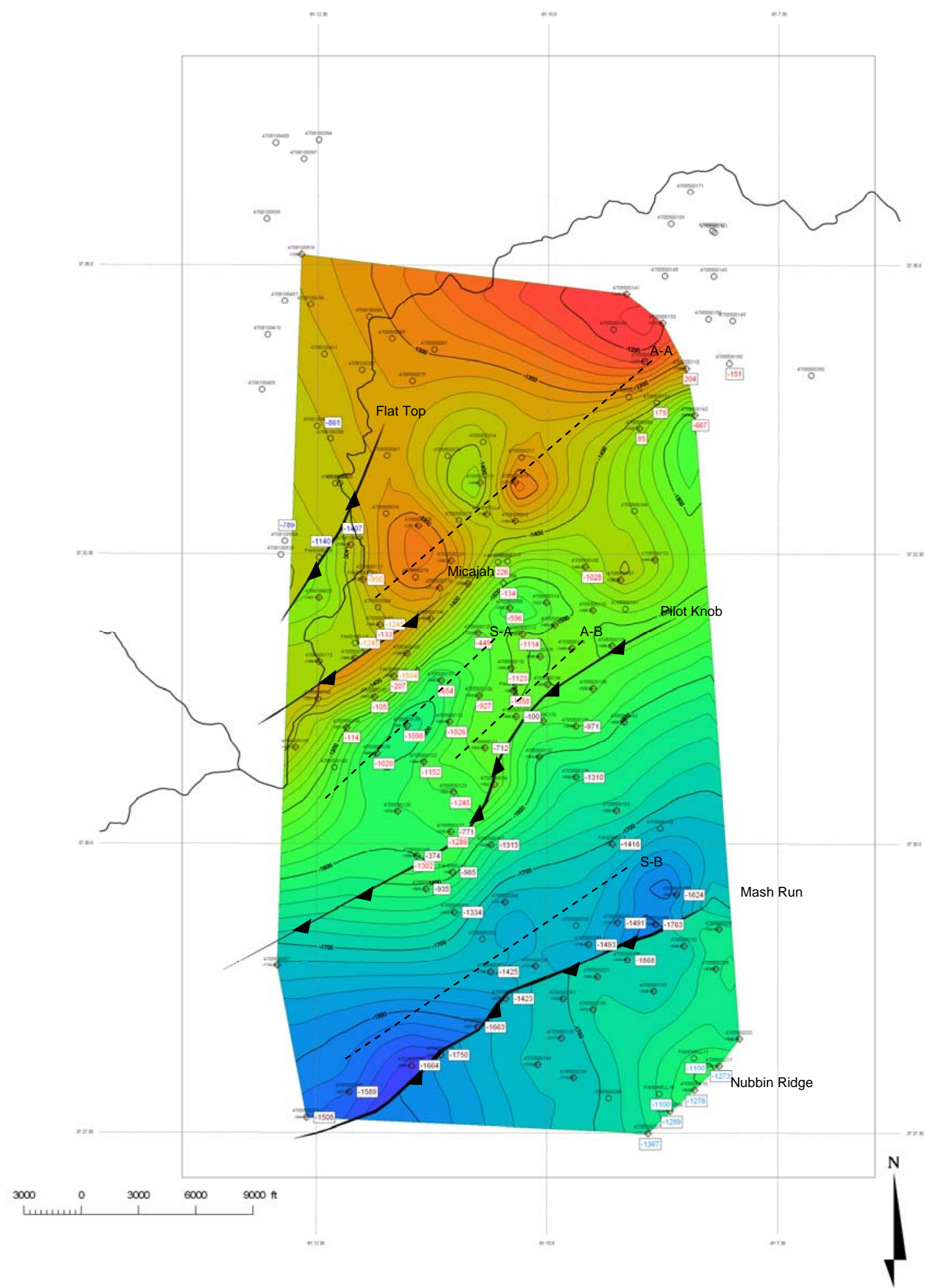

Figure 21C: Subsurface structure map of the Lower Weir top. Blue = structurally low, red $=$ structurally high. 


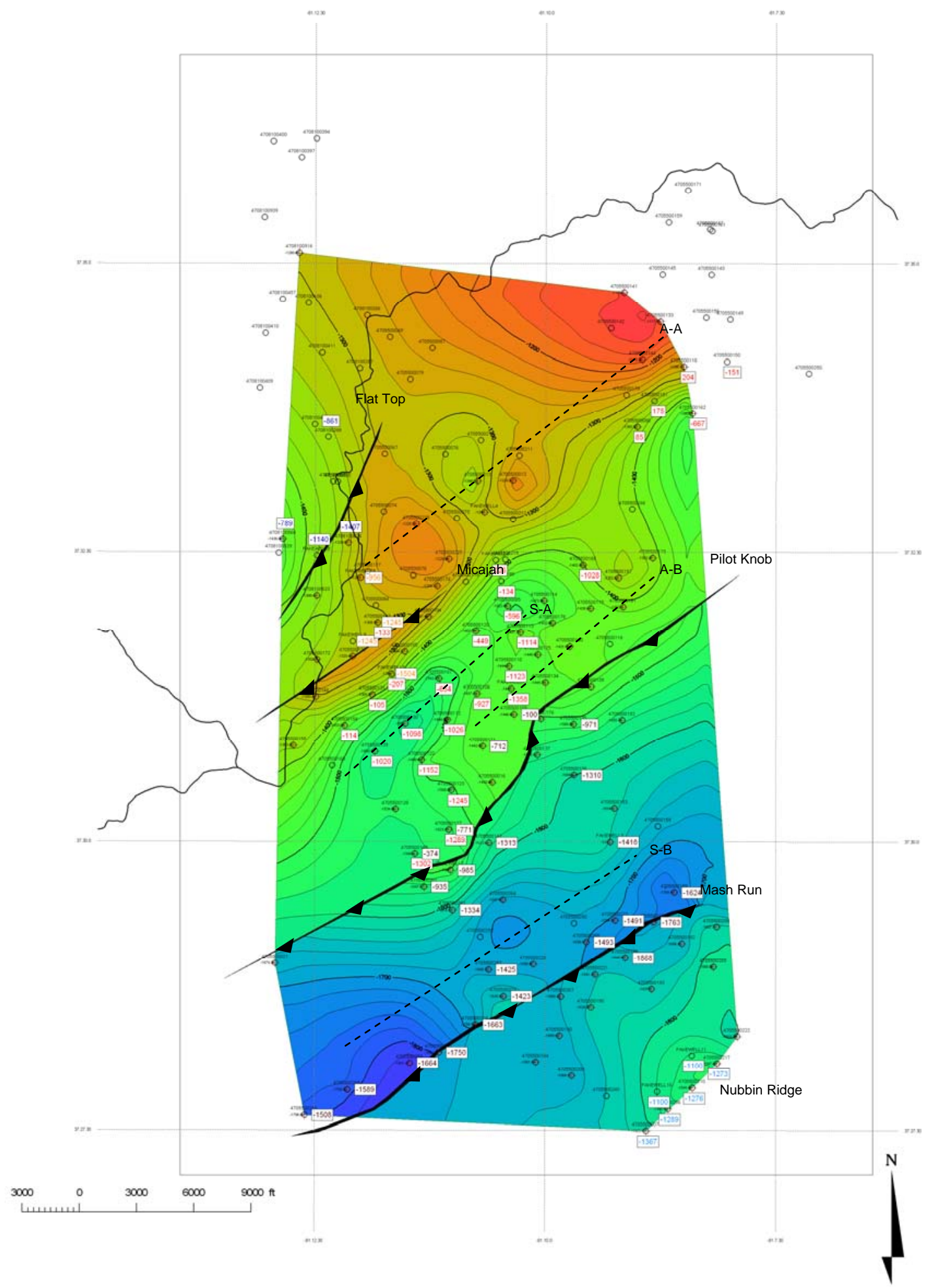

Figure 21D: Subsurface structural map of the Weir shale top. Blue = structurally low, red $=$ structurally high. 


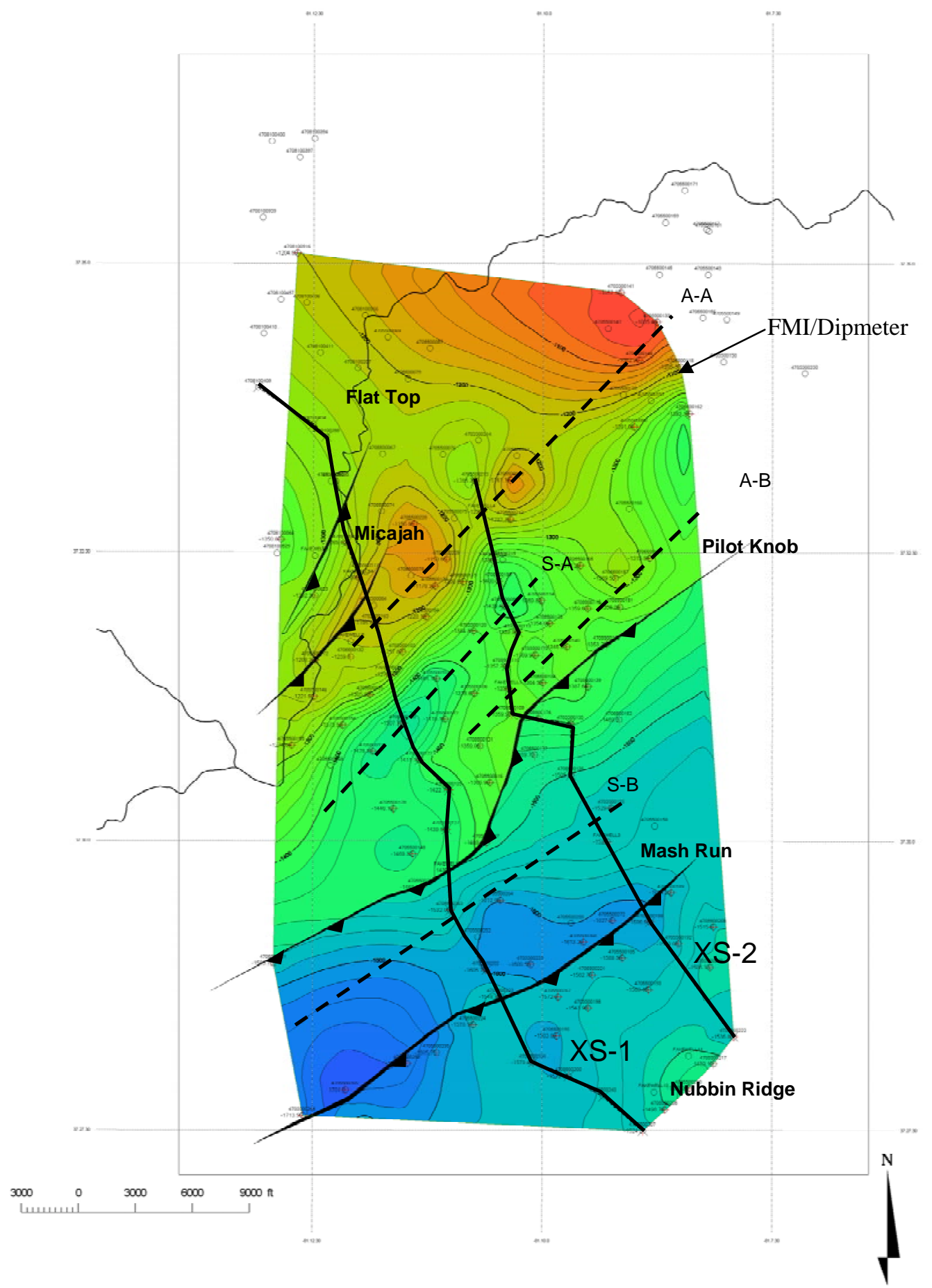

Figure 21E: Subsurface structure map of the Upper Price Marker 2. The 2D restoration cross sections are labeled. XS-2 is on Figure 27. 


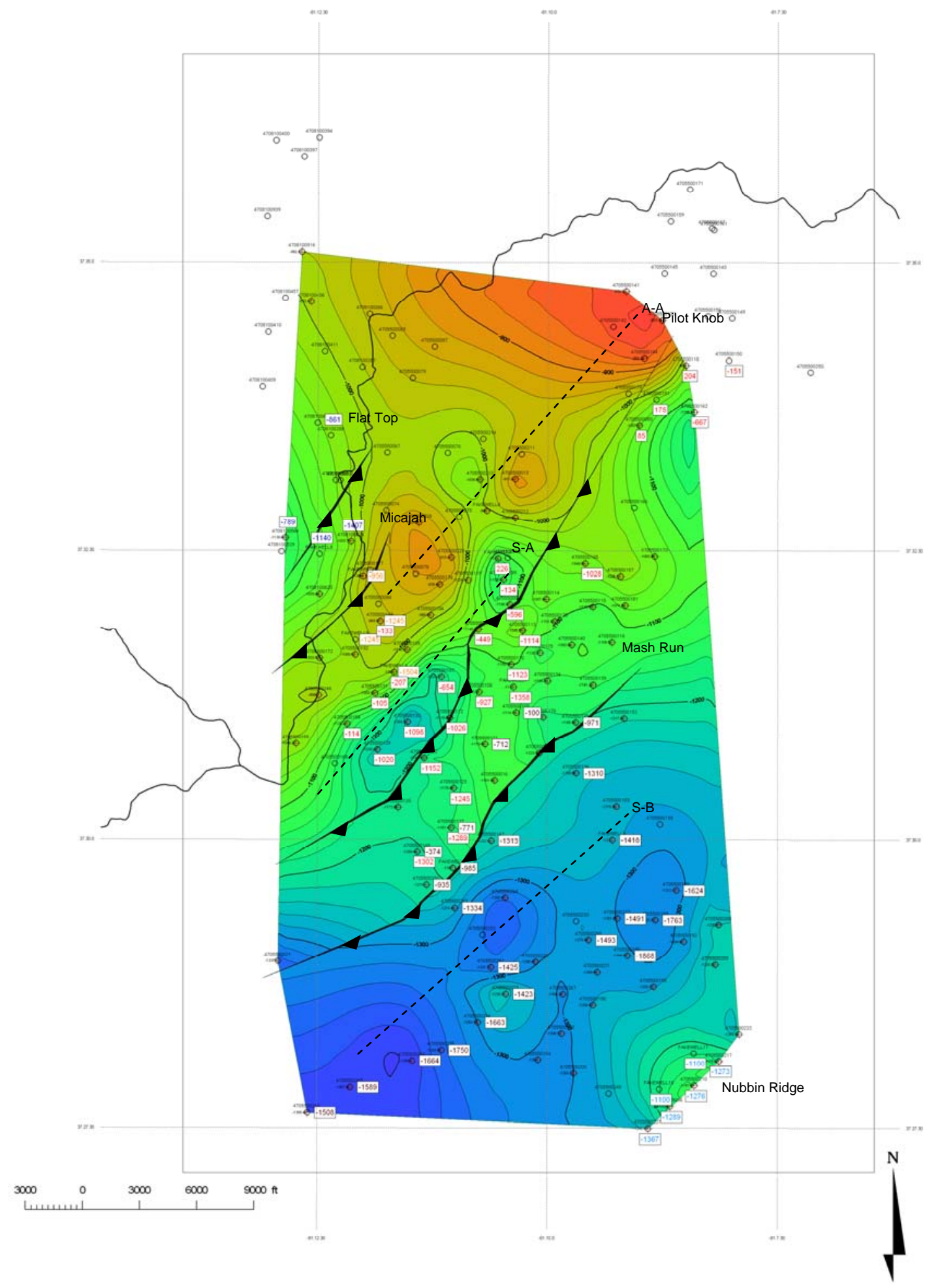

Figure 21F: Subsurface structural model mapped on the Upper Price/Maccrady top. Blue $=$ structurally low, red $=$ structurally high. 


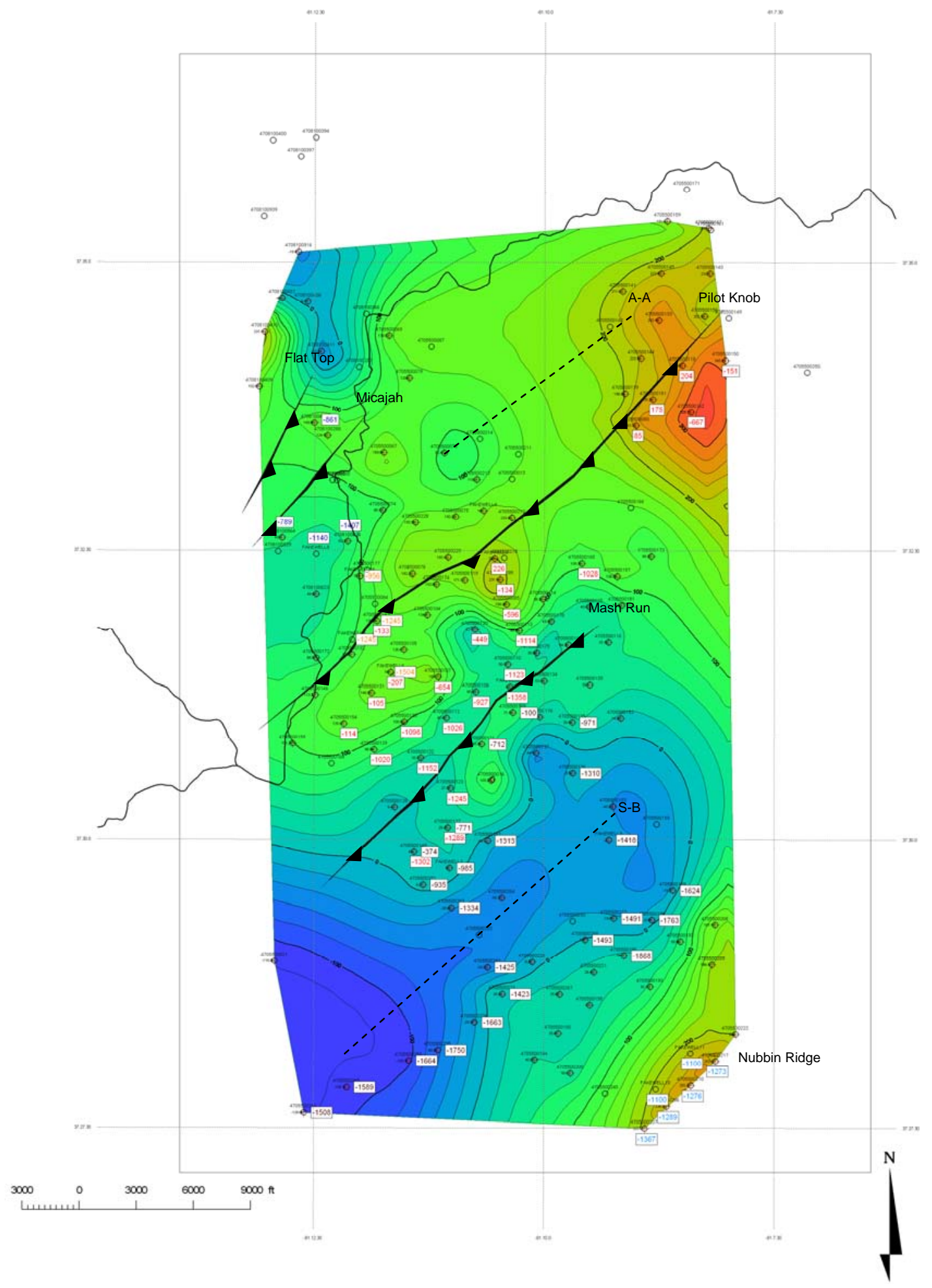

Figure 21G: Subsurface structural model mapped on the Greenbrier limestone top. Blue $=$ structurally low, red $=$ structurally high. 


\begin{tabular}{|c|c|c|c|c|c|c|c|}
\hline Method & \multicolumn{3}{|c|}{ Strike (Degrees) } & \multicolumn{3}{|c|}{ Dip Angle (Degrees) } & $\begin{array}{c}\text { Dip } \\
\text { Direction }\end{array}$ \\
\hline & Egeria & $\begin{array}{c}\text { Mash } \\
\text { Run }\end{array}$ & Flat Top & Egeria & $\begin{array}{c}\text { Mash } \\
\text { Run }\end{array}$ & Flat Top & $\begin{array}{l}\text { SE for all } \\
\text { faults }\end{array}$ \\
\hline $\begin{array}{l}\text { locally } \\
\text { measured }\end{array}$ & 47 & 41 & 20 & N/A & N/A & N/A & \\
\hline $\begin{array}{l}\text { calculated } \\
\text { average }\end{array}$ & 40.8 & 52.2 & 20.0 & 35.1 & 22.6 & 21.9 & \\
\hline $\begin{array}{l}\text { standard } \\
\text { deviation }\end{array}$ & \pm 30.0 & \pm 38.7 & \pm 13.5 & \pm 12.7 & \pm 14.0 & \pm 6.9 & \\
\hline
\end{tabular}

Table 2: Properties of faults analyzed. Calculated averages and standard deviations were taken from strike and dip values produced in GeoGraphix. Locally dip angles were not all SE. However, the overwhelming majority of dips for all of the faults were SE in nature. The variance in strike and dip can be observed in figure 20 due to the sinuous nature of the faults and flat-ramp geometry. 


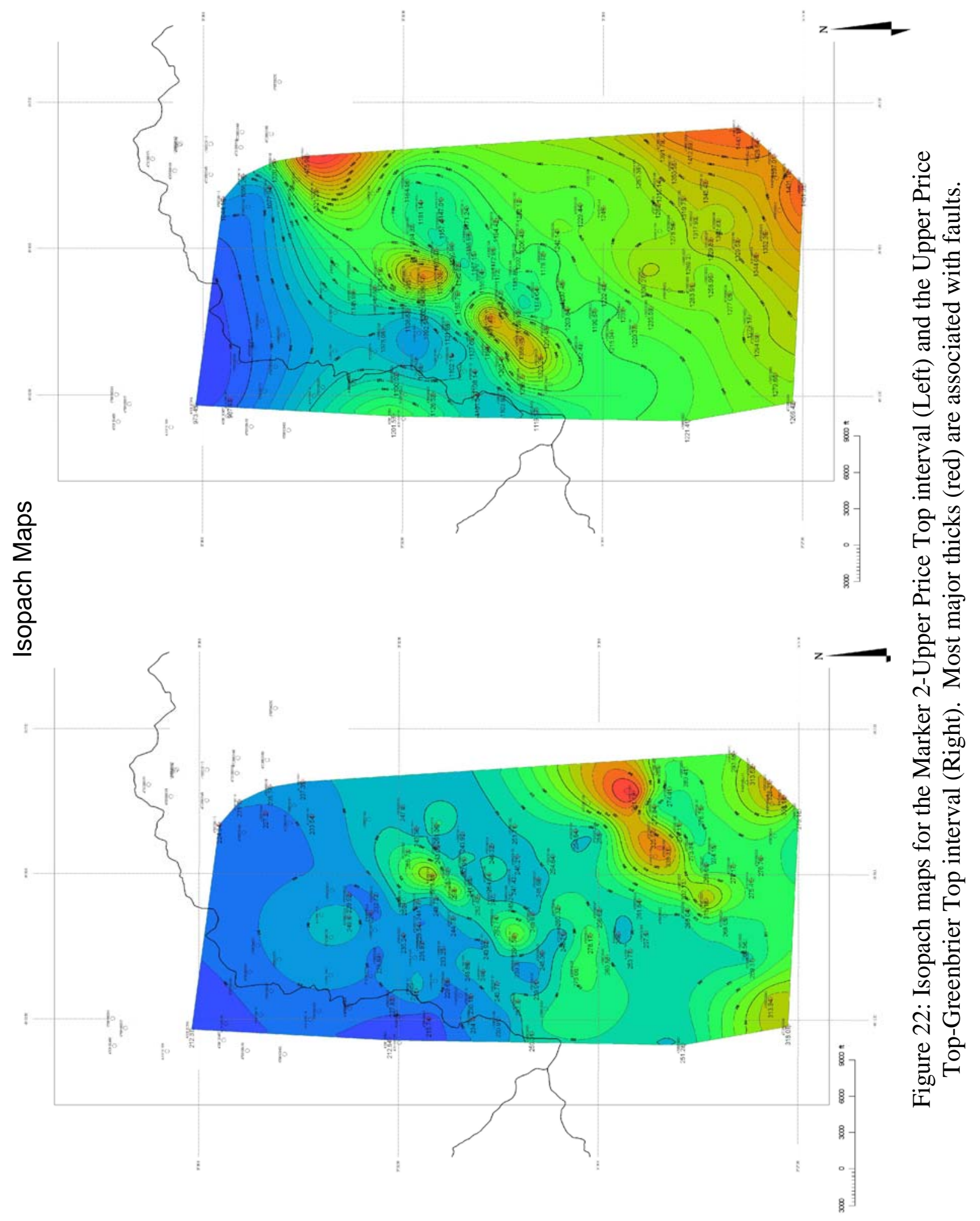




\section{Structural Model Creation}

The structural model was created by mapping the individual tops picked during correlation and converting the maps to surfaces (Figure 23). The mapping phase of this process used the minimum curvature algorithm available in GeoGraphix GeoAtlas to create a grid file and contour map for each horizon. Minimum curvature was used because it produced the most consistent and geologically feasible surfaces of all available algorithms. Contour maps and surfaces were edited manually to a small extent to produce a more realistic geologic model. Due to a slight variance in trend found in the structure, I decided not to use the geologic bias calculations available in GeoGraphix GeoAtlas. Using this option could have decreased the geologic accuracy in some areas.

Two cross sections that illustrate the geologic structure within the study area were exported to Midland Valley’s 2D Move software suite as images, were digitized, and were restored back to their pre-deformation state using fault-parallel flow and tri-shear (a zone of distributed shear) kinematic analyses (Figure 24) (Allmendinger, 1998). The 2DMove restoration process was as follows: The initial model was transferred and digitized into 2DMove (Figure 24A). Vertical throw values calculated from well logs were used to estimate vertical throws along the fault and this was transferred to the model (Figure 24B), the beds were flattened to a target flat horizon to dispatch any post faulting features (Figure 24B), the model was restored to its pre-deformation state by faultparallel flow (Figure 24C), and was restored back to its deformed state using tri-shear to check accuracy of the model (Figure 24D). This process effectively modeled faulting- 


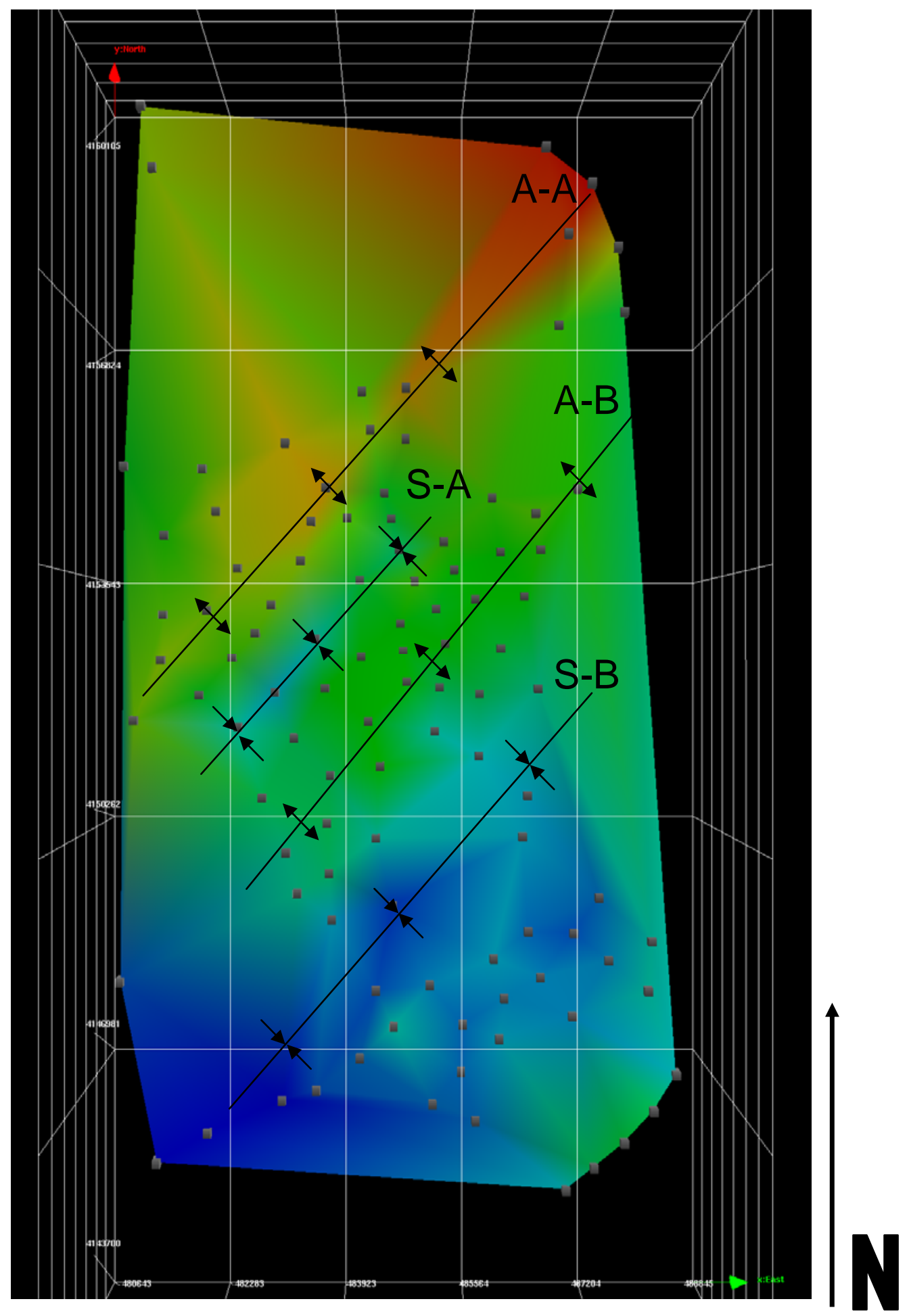

Figure 23: 3D Structure model of marker 2 illustrating major anticlines and synclines within study area. Red = structurally high, blue = structurally low. A-A = Anticline A, S$\mathrm{A}=$ Syncline $\mathrm{A}$ etc. 

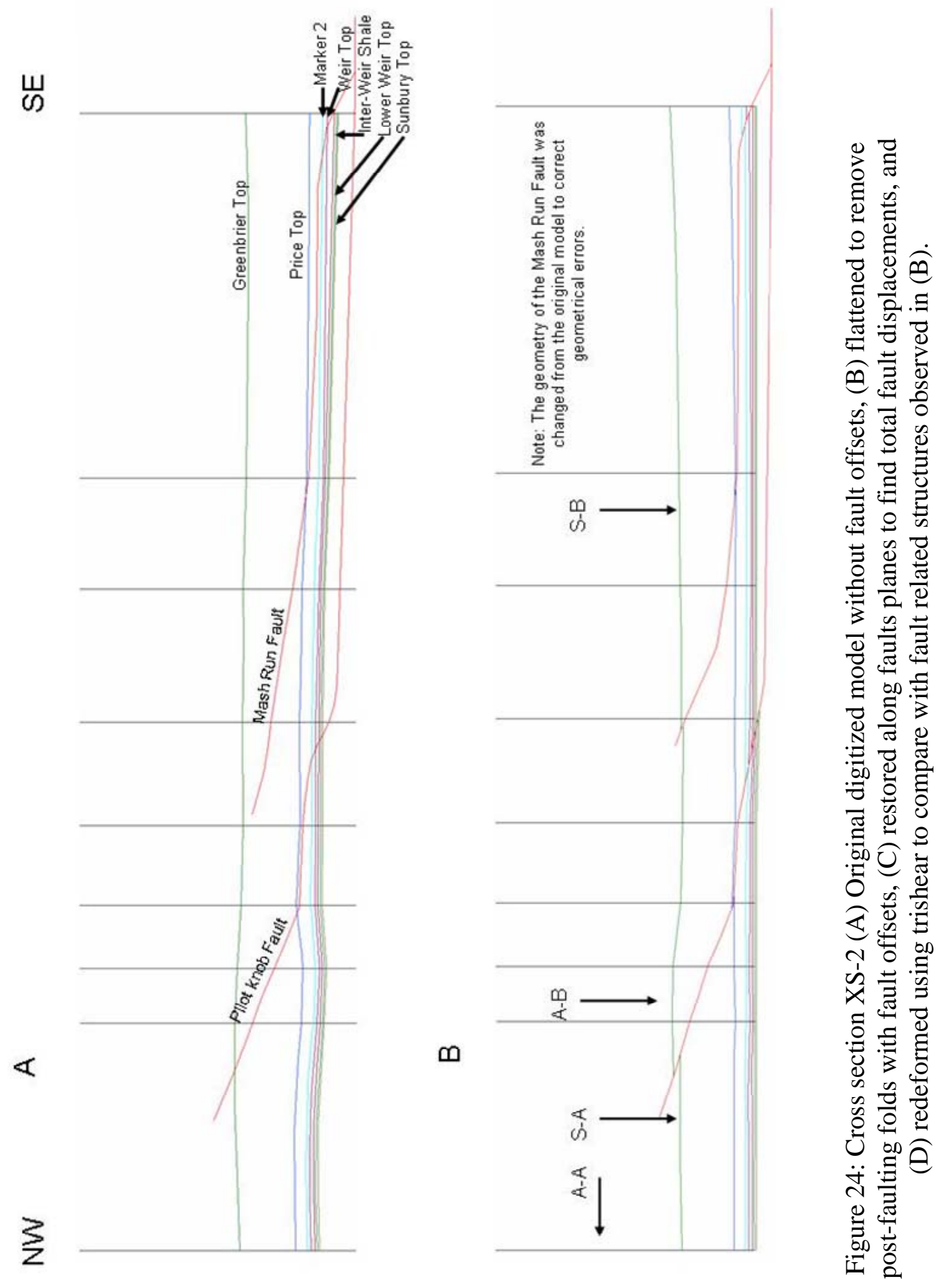


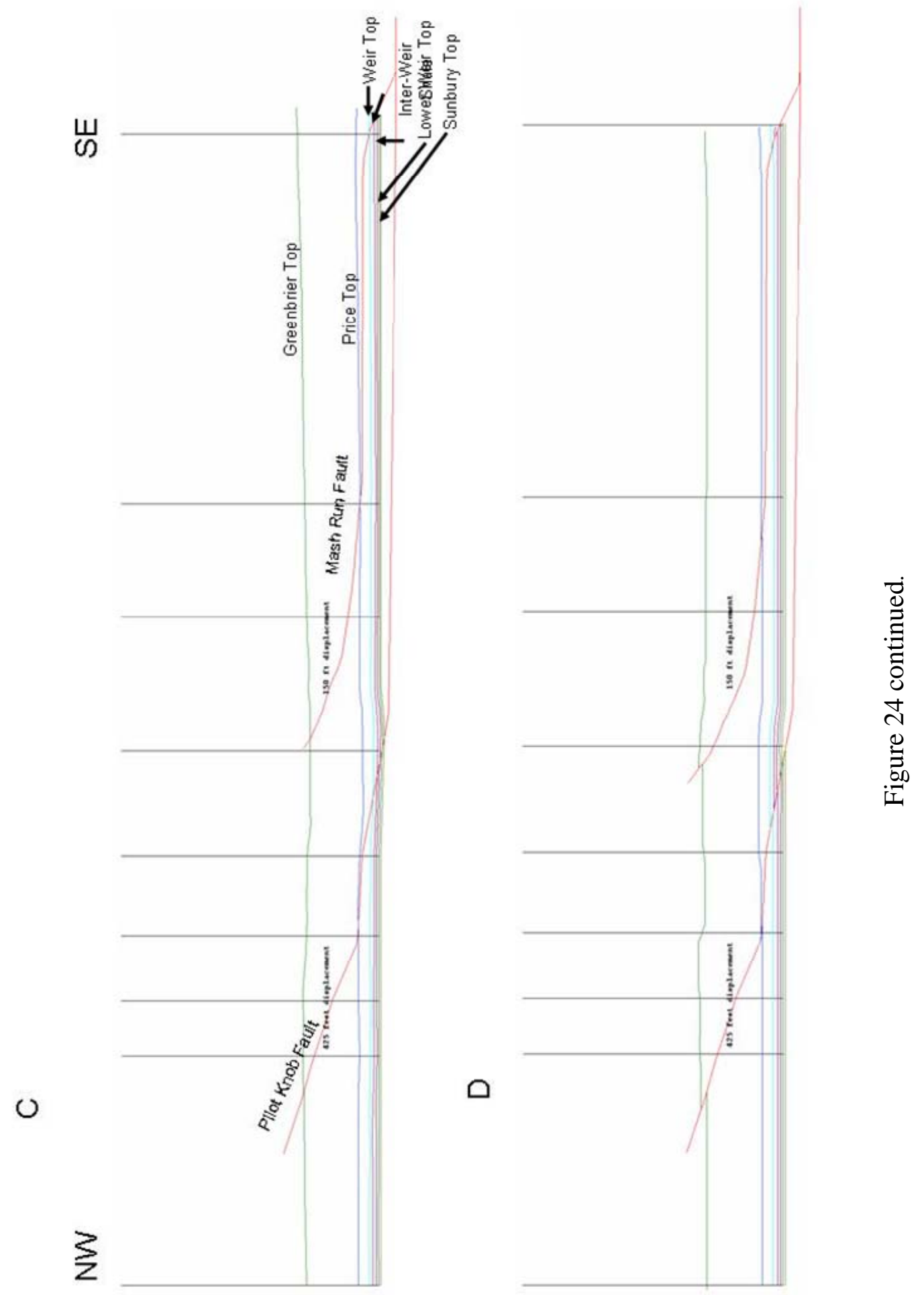


related structures for the faults within the model. Other faults or detachments (i.e. deeper regional decollements or faults not in the scope of this project) were not modeled. Seven fake wells (which consisted of well locations and tops for horizons and/or faults) were imported into the GeoGraphix model based upon the structures observed in the 2D Move restorations to improve accuracy of the gridded surfaces. These fake wells slightly altered structure to better fit the 2D Move model. Four additional fake wells were also added to increase gridding ability and accuracy for Geographix and 3DMove.

The two-dimensional restoration (Figure 24) illustrates that the displacement along the faults is relatively small. Fault displacements in the first restored cross section were 300, 425 and $150 \mathrm{ft}$ for the Mash Run, Pilot Knob, and Micajah faults, respectively. Fault displacements in the second cross section were 150 and 425 for the Mash Run and Pilot Knob faults, respectively. Vertical throw values ranged from 23 to 150 feet. Due to a lack of well data, the other faults were not kinematically modeled in this process. Postrestoration folding was minimal and was possibly an artifact of the fault parallel flow restoration process or the influence of another unknown fault. The forward-modeled restoration produced folding that was very similar to the structures observed in the original structural model (Figure 24B). 


\section{Fracture Model Creation and Analysis}

Joint and shear fracture models were created for two horizons using Midland Valley's 3DMove software suite. All of the edited data (post 2DMove restoration) were imported into 3DMove and gridded surfaces were created. The horizons used were: Lower Weir, Weir Shale, Upper Weir, Marker 2, Upper Price/Maccrady Top, and Greenbrier Top. Horizons below the Lower Weir were not imported due to geometric errors produced by gridding of partial data coverage. Joint models were created using the maximum and mean joint spacings observed for both outcrops (16ft and $0.3 \mathrm{ft}$ respectively) as the minimum fracture spacing input parameter. These parameters were used to provide a representative sampling of the outcrop data. The minimum joint spacing found in outcrop was not used as a modeling parameter because it was for microjoints in a structural regime that was unrealistic for the structures observed in the subsurface. Due to the difference in regional strike between the Alta outcrop and the subsurface study area, it was necessary to make a correction before applying surface joint orientations to the subsurface model. Orientations for joints were taken from the Alta outcrop data and corrected to regional structure by comparing the joint orientations at Alta with the orientation of the axis of the Williamsburg anticline and projecting those joint orientations onto the structural strike of the subsurface study area.

The horizons modeled were the Upper Price (Upper Price/Maccrady top- Marker 2), and Weir sandstone (Upper Weir top-Weir Shale Top) (Figure 10). Other horizons were not modeled because of their lesser importance as gas reservoirs and the underlying assumption that higher joint density in one horizon means probable higher joint density in 
all horizons, as layers in a fold will all deform similarly. Because of the uncertainty of using outcrop data in a predictive subsurface model, finding areas of modeled high joint density would most likely be a better approach than trying to create a model that truly mimics a natural system that cannot be directly measured. This was the approach taken in this project.

The fracture modeling and advanced fracture modeling modules in 3DMove require several parameters to create fracture networks. They are as follows: seed probability, seeds per step, number of steps, and orientation. Seeds are stress concentration points that generate fractures (McKeown, 2001). The probability for seeding can be generated using values from previously analyzed mapped surfaces, in this case strain and curvature. Curvature-based fracture models assume that maximum bending strain is proportional to curvature, and thus fractures are distributed across the fold based on strain (Fisher and Wilkerson, 2000). Strain-based fracture models use an interpreted folding history (restoration) to produce similar fractures (Fisher and Wilkerson, 2000).

The number of steps controls the amount of joint propagation as do seeds per step. Once fractures are seeded, they will continue to grow in steps so that this also controls fracture length. By using combinations of the above parameters, joint models were created for this thesis. The joint models created were broken into two subdivisions labeled R1 and R2 (run 1 and run 2 for each model type). The following parameters were used during R1 and R2 (Table 3): 


\begin{tabular}{lcc}
\multicolumn{1}{c}{ Parameter } & R1 & R2 \\
\hline \hline Seed probability & strain and curvature & strain and curvature \\
Minimum fracture spacing (ft) & 16 (maximum) & 0.3 (mean) \\
Seeds per step & 75 & 75 \\
Step distance (ft) & 25 & 25 \\
Number of steps (total) & 10 & $7(4$ if overcrowded) \\
Joint sets modeled & 3 & 3 \\
Joint set orientation & $\mathrm{J} 1-140^{\circ}, \mathrm{J} 2-39^{\circ}, \mathrm{J} 3-13^{\circ}$ & $\mathrm{J} 1-140^{\circ}, \mathrm{J} 2-39^{\circ}, \mathrm{J3}-13^{\circ}$ \\
Joint set priority & $\mathrm{J} 1>\mathrm{J} 2>\mathrm{J} 3$ & $\mathrm{~J} 1=\mathrm{J} 2=\mathrm{J3}$ \\
Intervals modeled & Weir and $\mathrm{M} 2-$ Price Top & Weir and M2-Price Top
\end{tabular}

Table 3: Parameters for 3DMove fracture creation.

The number of steps and number of seeds per step were estimated by comparison with the 3DMove tutorial (Midland Valley, 2004A) and geologic feasibility. Curvature and strain values were created using their respective analysis tools in 3DMove. For the curvature calculation, 3DMove was utilized to assign each existing data point a curvature value (rate of change in dip across the surface (Midland Valley, 2004A)). Operations for standard and Gaussian curvature were available, but standard curvature was chosen for this project. Gaussian curvature is better at measuring curvature on non-cylindrical folds such as domes where significant curvature exists in both directions (Lisle, 1994). Strain was modeled by flattening each horizon to a datum (the lowest elevation value for that horizon) and refolding the horizon back to its original shape. Using the strain tracker tool in 3DMove allowed the assignment of strain values to each exiting data point as well. 3DMove produces strain values in three different formats: Area Dilatation, Absolute Value of the Area Dilatation, and Root Mean Square (RMS) of the Area Dilatation. Strain values produced in this thesis are all RMS-Area Dilatation values because this format makes recognition of trends simple and easy to map. Both curvature and strain 
values were mapped and used in joint generation. All joints modeled were vertical as this was a limitation of the software.

Fracture models were also created representing shear fractures so that potential shear-fracture orientations could be visualized. Orientations for shear fractures were taken from FMI analyses in Edmonds (2004), a similar study adjacent to and southwest of my subsurface study area (Figures 1 and 4). Significantly less attention was paid to shear fractures than joints in this thesis than by Edmonds (2004) because no surface analogs of the thrust faults and their related shear fracture swarms were available. 3D Move will create non-extensional fractures only if exact specifications of size, distribution, and orientation are given. Because only potential orientation was known, the shear models were created just for orientation visualization purposes. Shear fractures are difficult to model and I am unaware of any software that can accurately do so.

Curvature values for the Upper Price ranged from 0.11-0.01. Curvature values for the Weir ranged from 0.11-0.02. RMS-Area Dilatation strain values for the Upper Price ranged from 0.044-0.0021. RMS-Area Dilatation strain for the Weir ranged from 0.0670.000055. RMS-Area Dilatation maximums were probably anomalously high due to edge effects with the griddling calculations (Figure 25). Areas of high joint density were similar between runs (R1 \& R2) and were also similar between curvature and strain based models (Figure 26). As anticipated, the highest joint density areas were generally found to be located along synformal and antiformal structures (Figure 27). R1 joints illustrate 


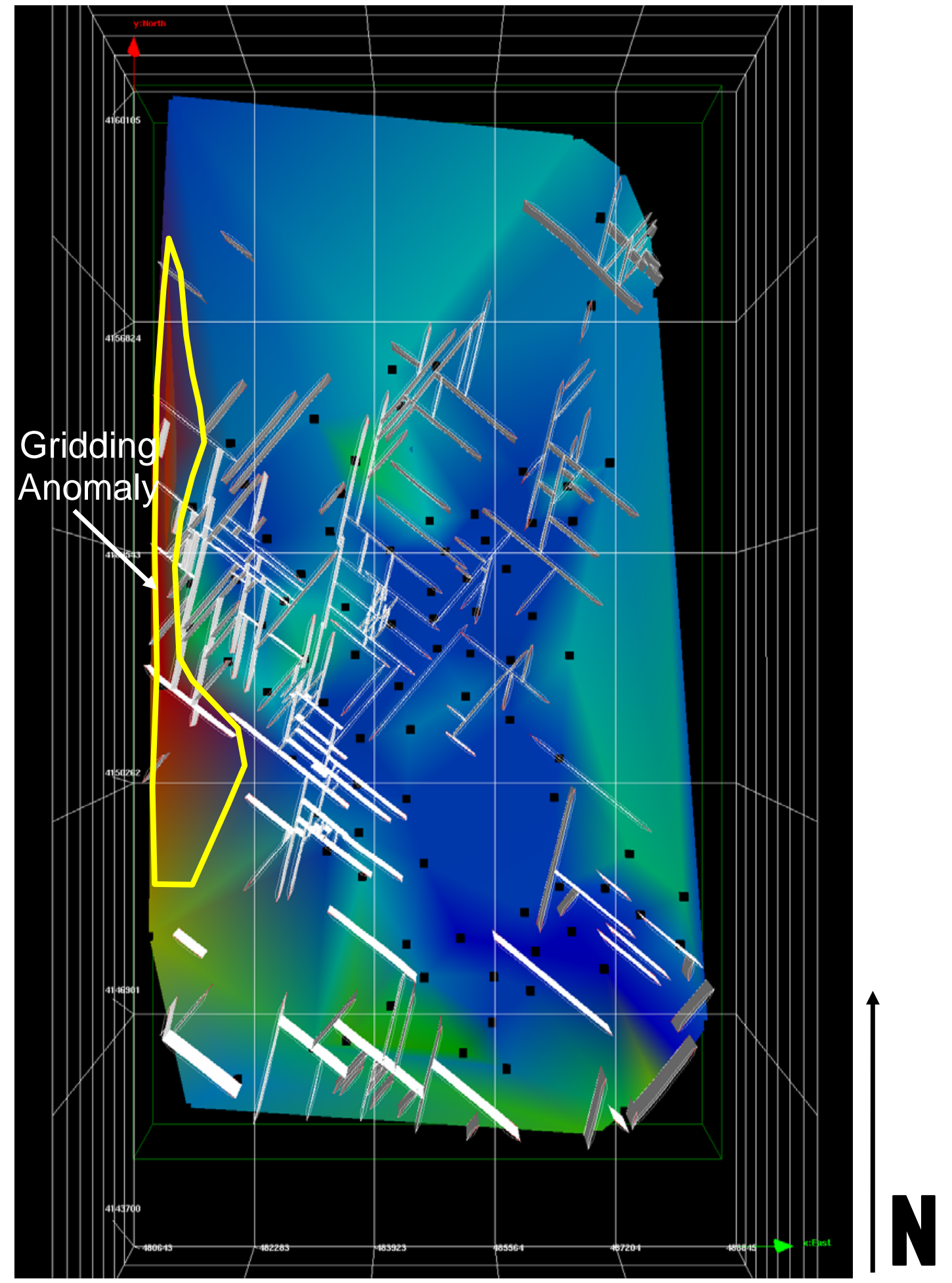

Figure 25: Strain based fracture model and gridding errors. Strain is mapped using color (Red=high strain, blue=low strain). The surface being mapped is Marker 2 . 


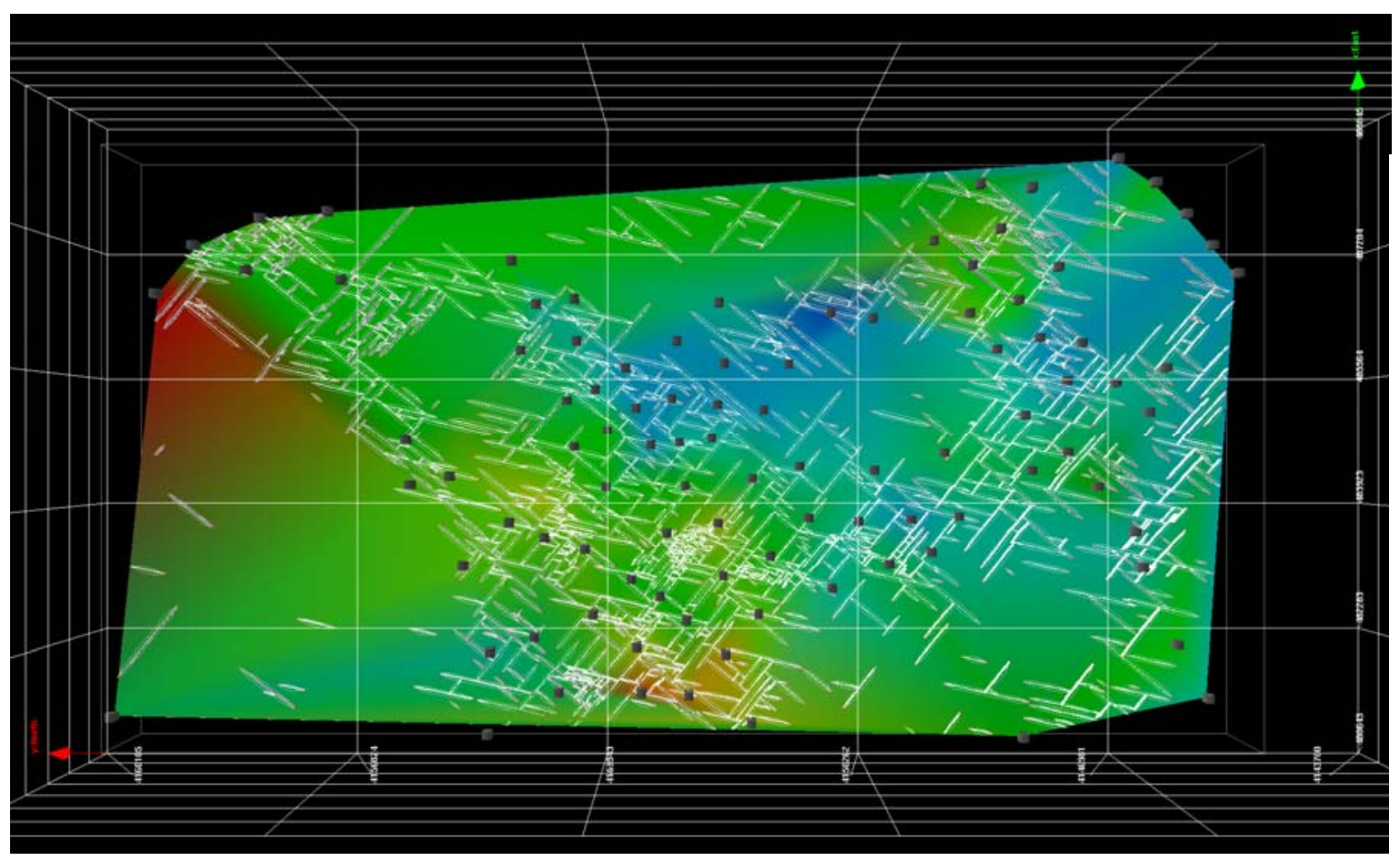

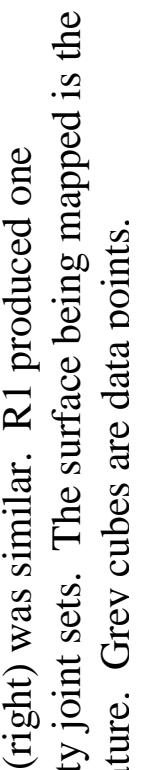

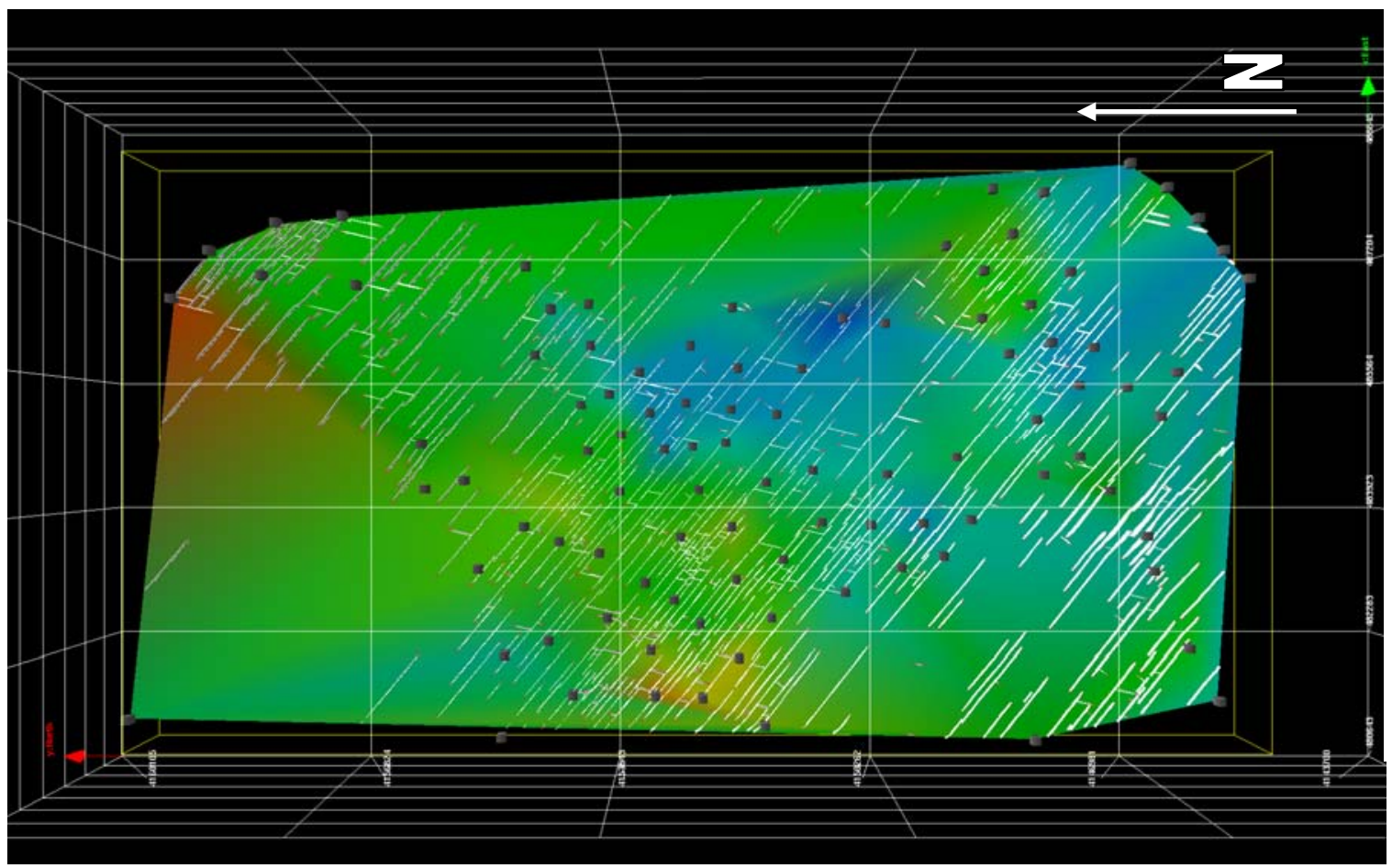
오를 들 己 즈응

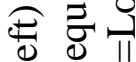
$\underset{0}{-1}$ 조음 ت نه む党 3 중 을 $B \div$ 羿 \& $\Rightarrow$ क 을. ض் 的 光当 


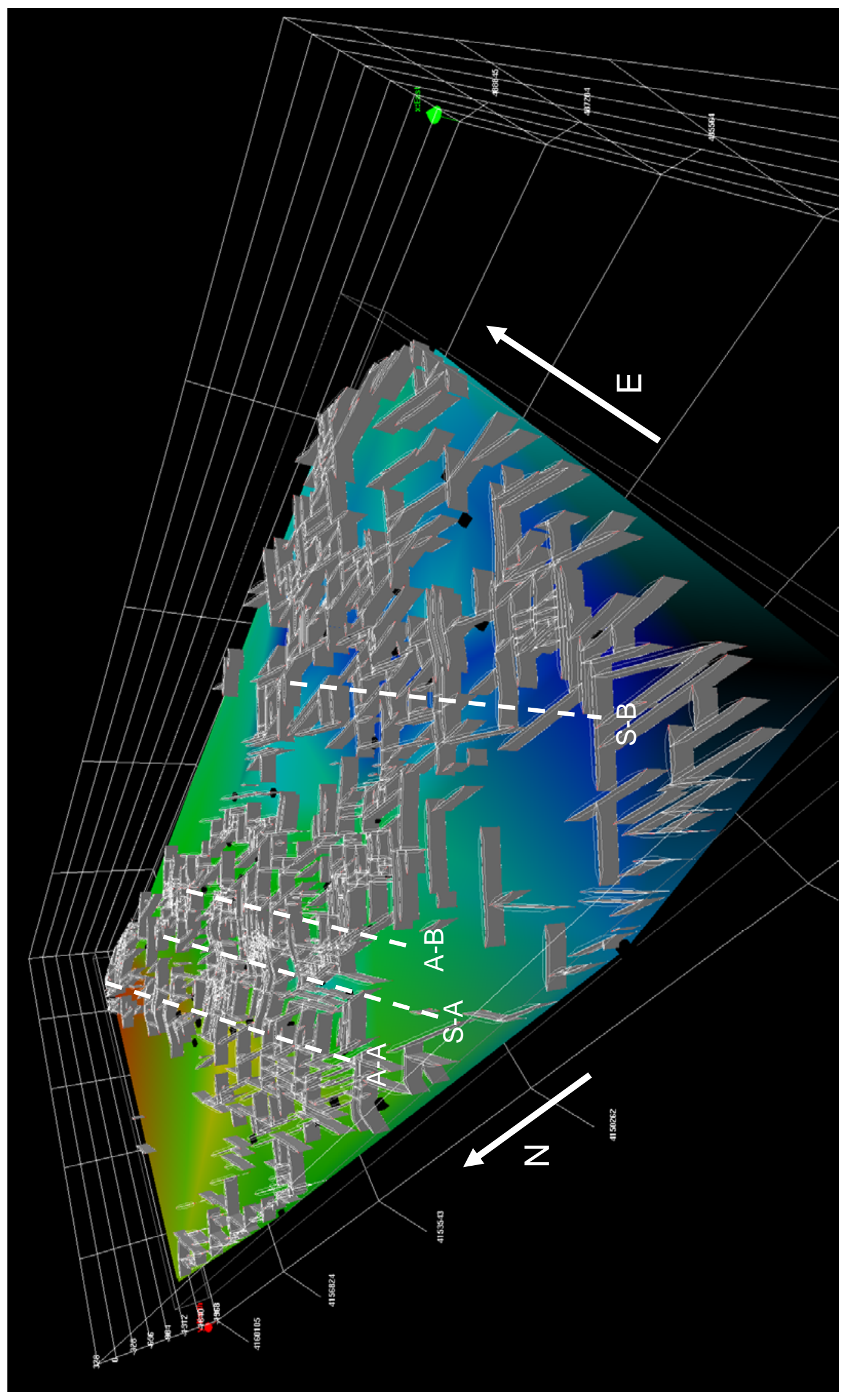

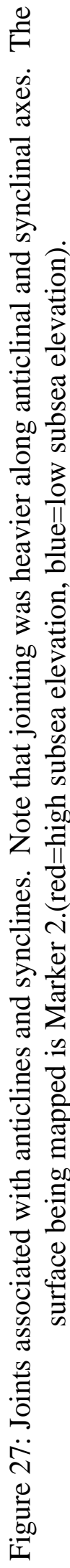


one dominant joint set and two secondary sets, whereas R2 joints illustrate three sets of equal magnitude(Figure 26). The zones containing higher fracture density were in similar locations on all of the joint models (Figure 28). Several other areas were found to have significantly less or no jointing. Four step runs generally illustrated predicted areas of jointing better than seven or ten step runs because of less crowding.

Shear fracture swarms or shatter zones most likely occur along faults (Edmonds, 2004). Porosity spikes are often encountered in faulted intervals on geophysical logs during correlation. These spikes are possibly related to fault shatter zones or shear fracture swarms associated with faulting. Edmonds (2004) found fracture zones in FMI logs that were oriented at approximately N35E in a nearby study area. This orientation suggests that these shear fracture zones follow the same strike as structures observed in this thesis (Figures 29, 30 and 31). The shear fracture model produced illustrates potential shear fracture zones based on a Fisher distribution of fractures with orientations found in the Pocahontas Land \#5384 FMI log by Edmonds (2004) (Figures 30 and 31) This well is to the southwest of my study area and located within the project extents of Edmonds (2004). 


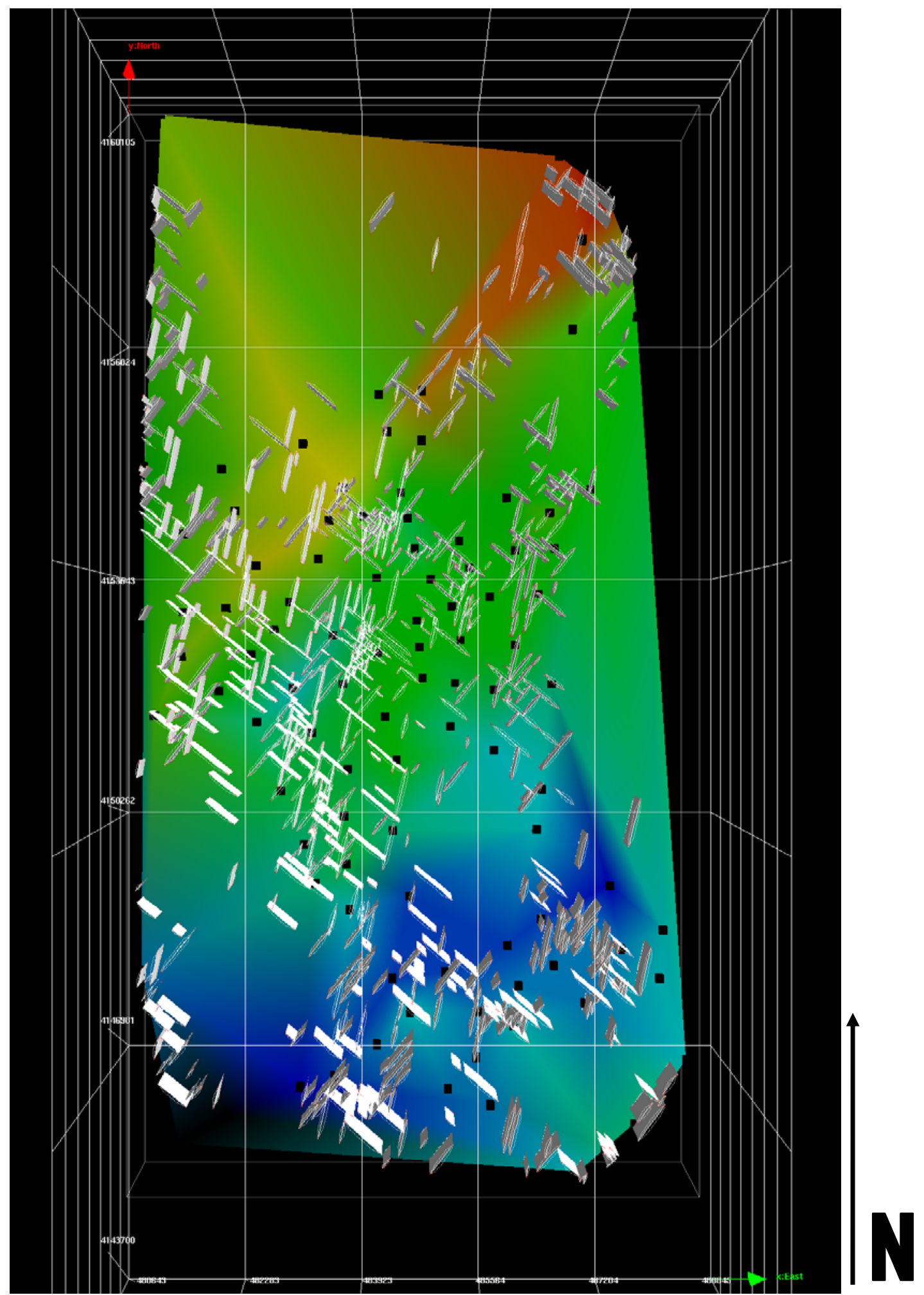

Figure 28: R2 (4 step) fracture model for the Upper Price/Big Injun Equivalent illustrating typical high joint density areas observed in most of the models. Background colors illustrate structure on Marker 2 (red=high subsea elevation, blue=low subsea elevation). Black squares indicate data points (well locations). 


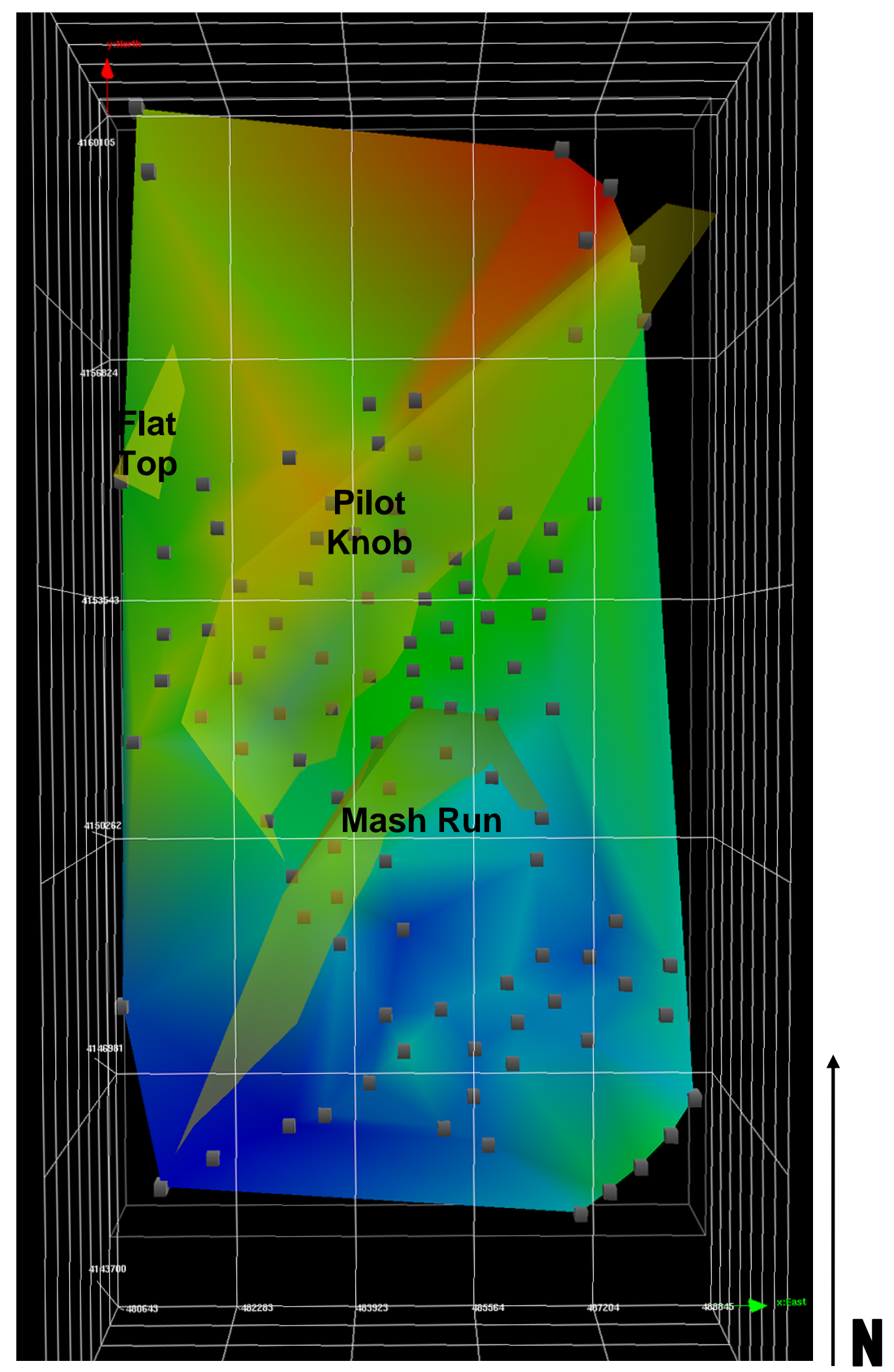

Figure 29 Map view of structure model in 3DMove for Marker 2 showing faults (red=high subsea elevation, blue=low subsea elevation). Faults are semi-transparent yellow. 


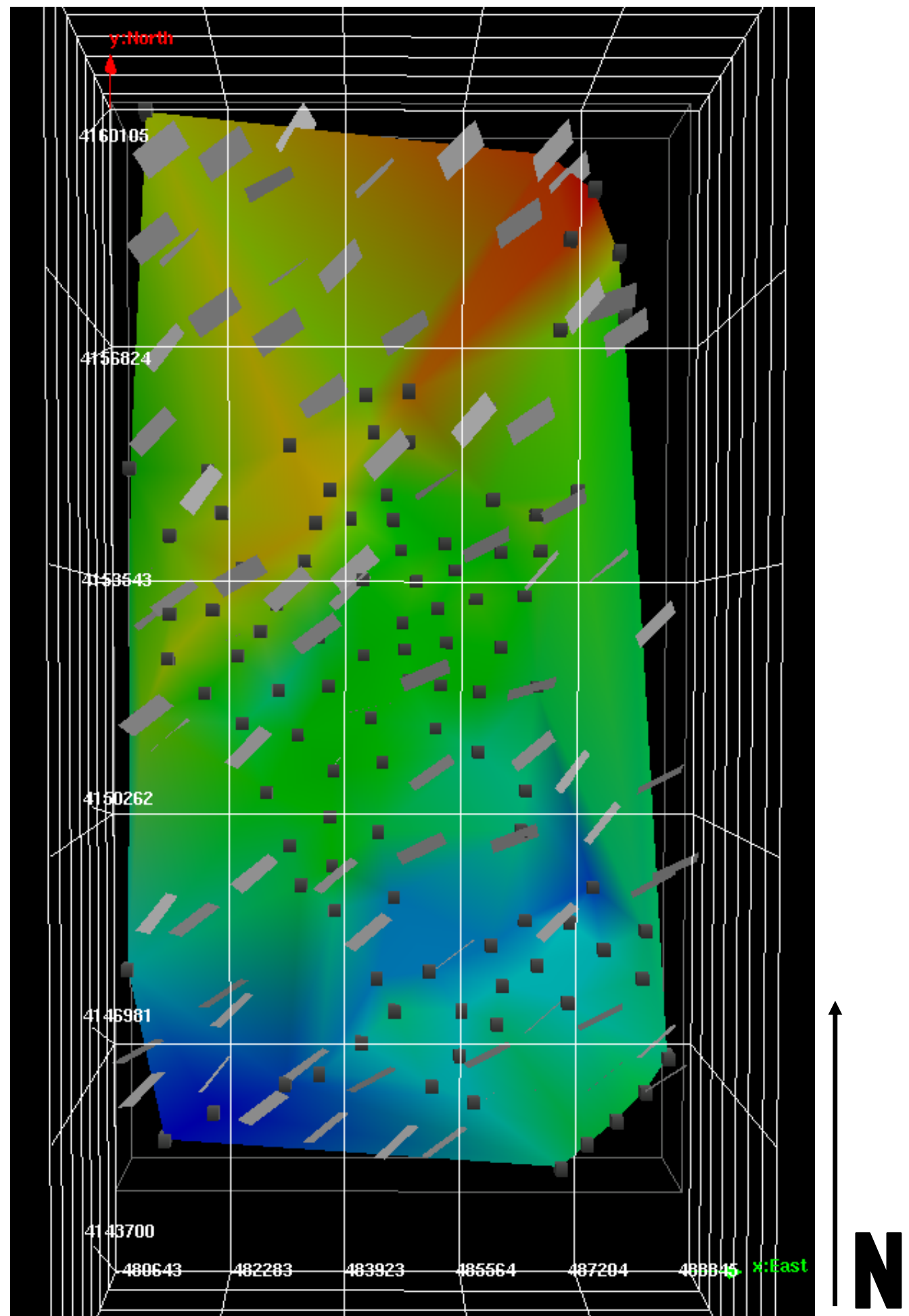

Figure 30: Shear Fractures created using a Fisher distribution and orientation data from Edmonds, 2004. This diagram illustrates orientation of shear fractures from FMI data in Pocahontas Land \#5384 (used in Edmonds, 2004) (Figure 31). Note the similarity between the orientation of these fractures and faults within the subsurface study area in figure 29. This diagram is meant to accurately portray orientation only and not distribution. 


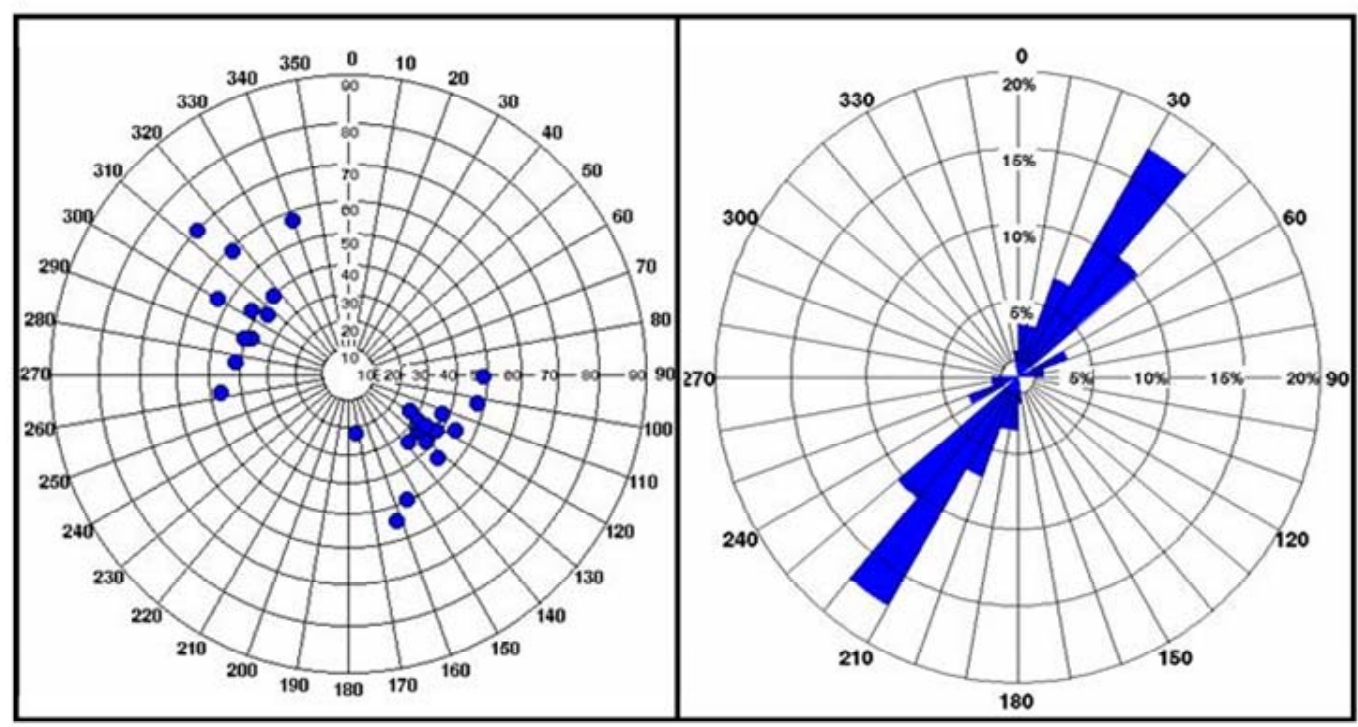

UPPER HEMISPHERE - WULFF PROJECTION

Top Dip $=3384.03 \mathrm{ft} \quad$ Top $Z$ Zone $=3427.00 \mathrm{ft}$ Bottom Dip $=3792.15 \mathrm{ft} \quad$ Bottom Zone $=3500.00 \mathrm{ft}$ Geological Objects:

\begin{tabular}{|lccc|}
\hline Set Name & A Dips & $\begin{array}{c}\text { Great Circle } \\
\text { (Dip and Azimuth) }\end{array}$ & $\begin{array}{c}\text { Mean Orientation } \\
\text { (Dip and Azimuth) }\end{array}$ \\
\hline OPEN FRACTU... & $\mathbf{4 0}$ & $\mathbf{8 8 . 4 1} / \mathbf{5 0 . 7 8}$ & $\mathbf{4 9 . 9 0 / 1 4 2 . 1 1}$ \\
\hline
\end{tabular}

Figure 31: Shear fracture orientations in an FMI log from Pocahontas Land \#5384 (Edmonds, 2004). 


\section{Production Data Mapping and Analysis}

Monthly production data supplied by Dominion E\&P corporation was compiled into total production per well for the first month, three months, and twelve months for each well with available data. Many wells that were drilled prior to the 1980 s had no early production data available. Gas was commingled from reservoirs in the Greenbrier Limestone, Price Formation, and Mauch Chunk Group (Maxton Sandstone). Unfortunately, this is the nature of the data and production by formation was not available. However, the study interval production seems to be enhanced by fracturing (Craig Edmonds, personal communication, 2006).

Of 144 wells, 101 had viable production data that was mapped in GeoGraphix based on the aforementioned compilation of one, three, and twelve months. These maps were then compared with the structural and fracture models produced in GeoGraphix and 3DMove. Production data was also compared against curvature and strain data at the well locations gathered from 3DMove.

Each map offered a different insight into the early production history of the wells. In general, high production was centered on wells that were close to or intersected the major interpreted faults. Both high and low production values, especially in the 3-month and 12-month maps, were located along NE-SW trends which correlated with regional structural strike (Figure 32). Gaps in the linearity of production trends were in some cases due to lack of data.

The plot of production versus curvature had no discernable trend even though the data distribution was semi clustered (Figure 33). The highest production values were not 


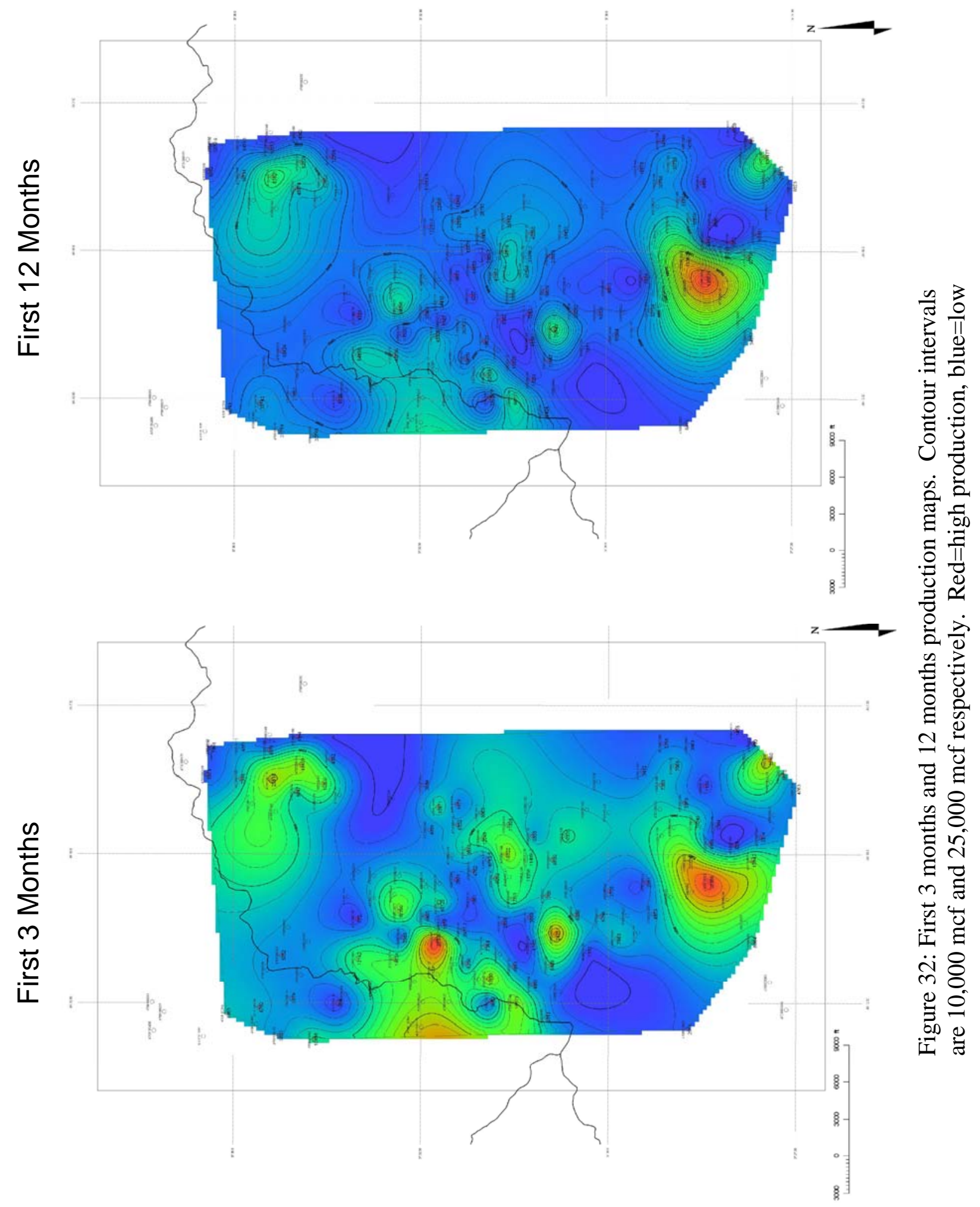




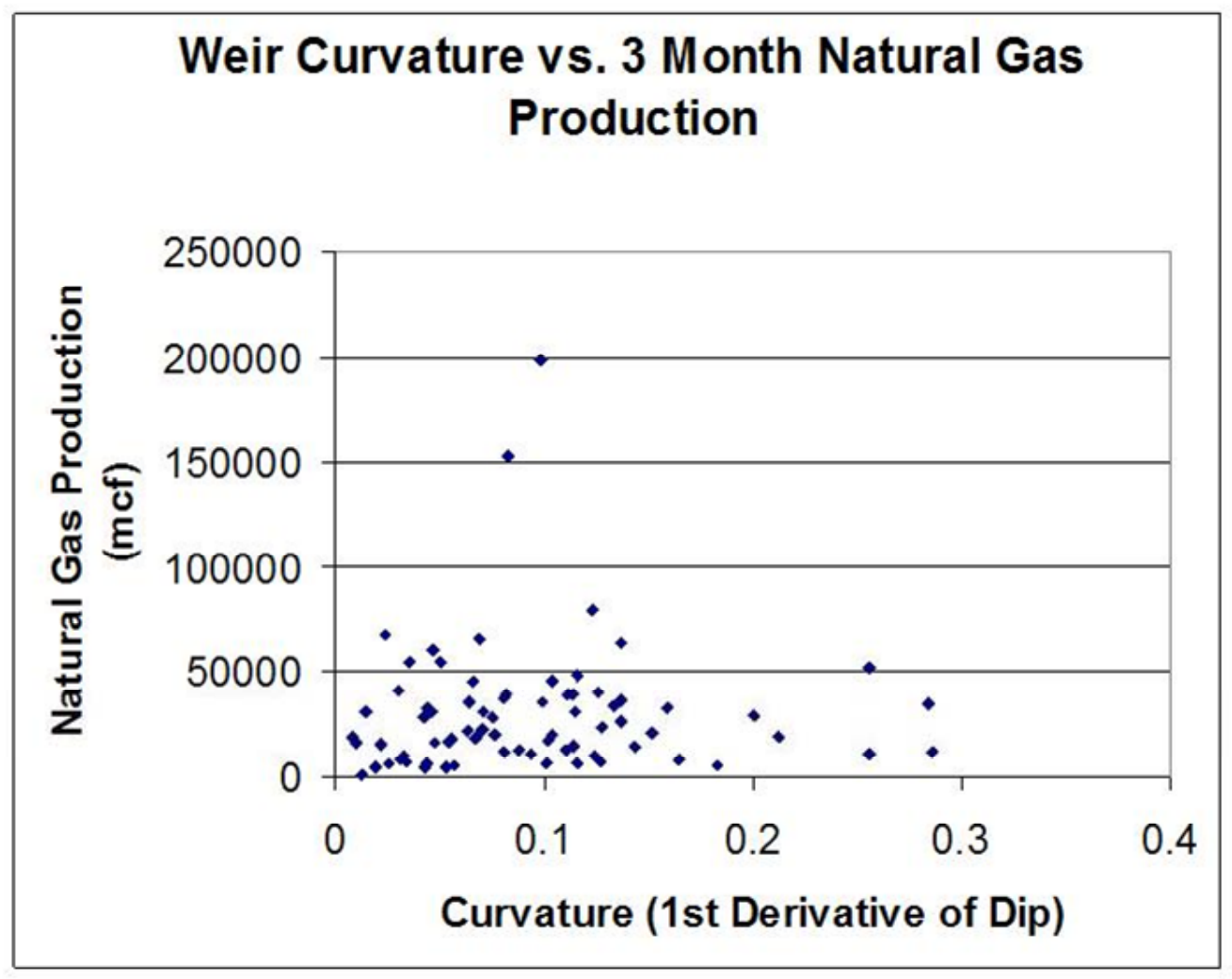

Figure 33: Curvature and 1st 3 months of gas production from each well. 
associated with the highest degree of curvature as expected. Production highs were centered on a curvature of 0.1. Extremely high curvatures (>2.5) had 3- month production vales that were no different then the vast majority of the data.

Highest Production

\begin{tabular}{|c|c|c|}
\hline Time interval & Well ID & Production (mcf) \\
\hline 1st Month & 4705500078 & 18101 \\
\hline 1st 3 Months & 4705500250 & 34667 \\
\hline 1st 12 Months & 4705500223 & 198824 \\
\hline \multicolumn{3}{|c|}{ Lowest Production } \\
\hline Time interval & Well ID & Production (mcf) \\
\hline 1st Month & 4705500193 & 46 \\
\hline 1st 3 Months & 4705500190 & 624 \\
\hline 1st 12 Months & 4705500217 & 981 \\
\hline
\end{tabular}

Table 4: Highest and lowest production by well for each time interval analyzed. 


\section{Chapter 5: Discussion}

This study has several limitations that should be briefly outlined. First, linear joint density data are less accurate than data collected using methods where joint density in measured per area. However, this is not thought to significantly hamper this thesis for two reasons: 1) Upon visual inspection at outcrop joint spacings in multiple directions were similar and 2) minimum joint density had only a small effect as a parameter in 3DMove. No studies were found in background research that effectively transferred outcrop joint data to a subsurface model. It is a difficult task that requires assumptions and interpretations to be made.

Another limitation is the lack of both seismic and FMI data in the subsurface. Seismic data (assuming the faults would have been visible in such data) would have allowed greater constraint to be placed in the structure and thus the modeling. Well data density in this thesis was semi-clustered and thus could have missed areas of high curvature. Seismic data could have corrected for this. FMI data could have been a primary data source for fracture information or could have served as a bridge between fractures in outcrop and the subsurface. However, because joints are expected to be nearly vertical even FMI logs would not provide useful constraints on joint density unless they were collected in deviated wells. It is because of the lack of subsurface fracture data that the fracture models produced in thesis are at best, difficult to test.

The final limitation that should be outlined is the commingled nature of the gas production. Production values are taken at the wellhead and include gas from the Mauch Chunk Group, Greenbrier Formation, and Price Formation. Production data for the Price alone would have illustrated production trends more accurately. However, these data do 
not exist in the area. Because the structure of the producing intervals is approximately parallel to that of the Price Formation, fracture prediction models based on curvature would yield similar results for those layers. Thus the commingled production data remains a useful way of validating the fracture modeling procedure.

For clarity, I will briefly reiterate selected results from the previous sections throughout the discussion. Multiple faults and folds were found in the subsurface modeling. Vertical displacements along the faults ranged from 150 to 450 feet. All of the faults modeled are believed to be thrust faults due to the repeated intervals, thickening of section, and shallow angle observed in the structural models. The Pilot Knob and Mash Run faults are the most continuous and correlate best across the data set. These faults most likely have a main detachment surface in the Devonian (Craig Edmonds, personal communication, 2006) and continue above the Greenbrier. The faults do illustrate a flat-ramp type of geometry. The sinuosity observed along the fault planes may be due to differential local paleostresses during fault propagation. This could potentially give the faults curvature. Another explanation may be the presence of small transform faults not observed in well logs. In the case of Pilot Knob, the presence of a second parallel thrust fault in very close proximity to the Pilot Knob fault could also be causing the sinuous appearance (Craig Edmonds, personal communication, 2006). All of the faults observed probably extend outside the areas of high data density.

Vertical throws ranged from 23-150 feet. Vertical throw for the faults was almost always greater in the Greenbrier than in the Price. This suggests that the faults most likely flatten throughout the Price and steepen in the Greenbrier. Displacement along the Mash Run generally decreases to the northeast. This agrees with the regional trends of 
major fault displacement of Kulander and Dean (1986). However, displacement magnitudes for the observed faults are far smaller than those along major Appalachian thrust faults such as the St. Clair.

It is apparent that the same paleostress directions that created the folds in this study area also created the faults. A more reasonable explanation is that the folds observed are fault-propagation and fault-bend folds. However, this idea is not fully explained by the structural models presented. Anticline A (Figure 34) is not readily aligned with, or impacted by, any observable fault. The most logical explanation is that another fault does exist at depth and anticline $\mathrm{A}$ is a fault propagation fold for that fault. The potential location of the mystery fault is certainly beneath anticline A and it possibly extends through all horizons, even though there are no well data to test this idea. Most of the wells in the region are too shallow to show the underlying fault and show only the structure it produces. Furthermore, the restored cross sections were focused upon movement of the Pilot Knob and Mash Run faults. The mystery fault could correlate with the Micajah fault observed in this study and Edmonds (2004), in which case XS-1 illustrates 150 feet of displacement. This however seems improbable considering the scale of anticline A. The fault with the largest displacement, Pilot Knob, most likely produced anticline B, a structure that is dwarfed by Anticline A (Figures 35 and 36). Therefore for anticline A to have been created by the Micajah fault, displacement would need to significantly increase in the northeast direction. Anticline A could also be a detachment fold in which there is a basal décollement zone within a highly incompetent rock (Davis and Reynolds, 1996). This would explain the lack of faulting observed in 


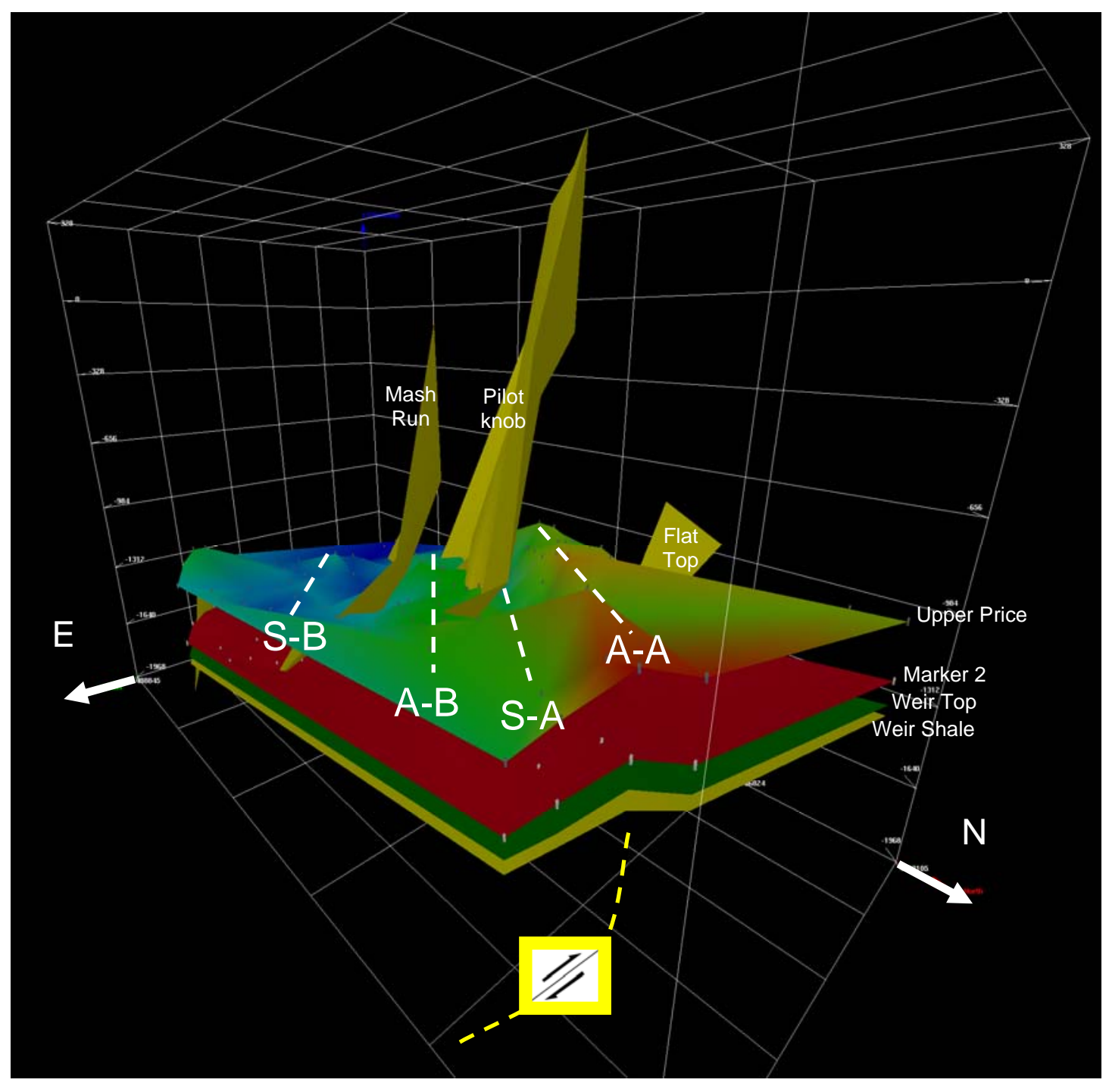

Figure 34: Structure model with faults as seen Looking SW,. Vertical exaggeration $=5 \mathrm{X}$. Grey rectangles represent data points. 


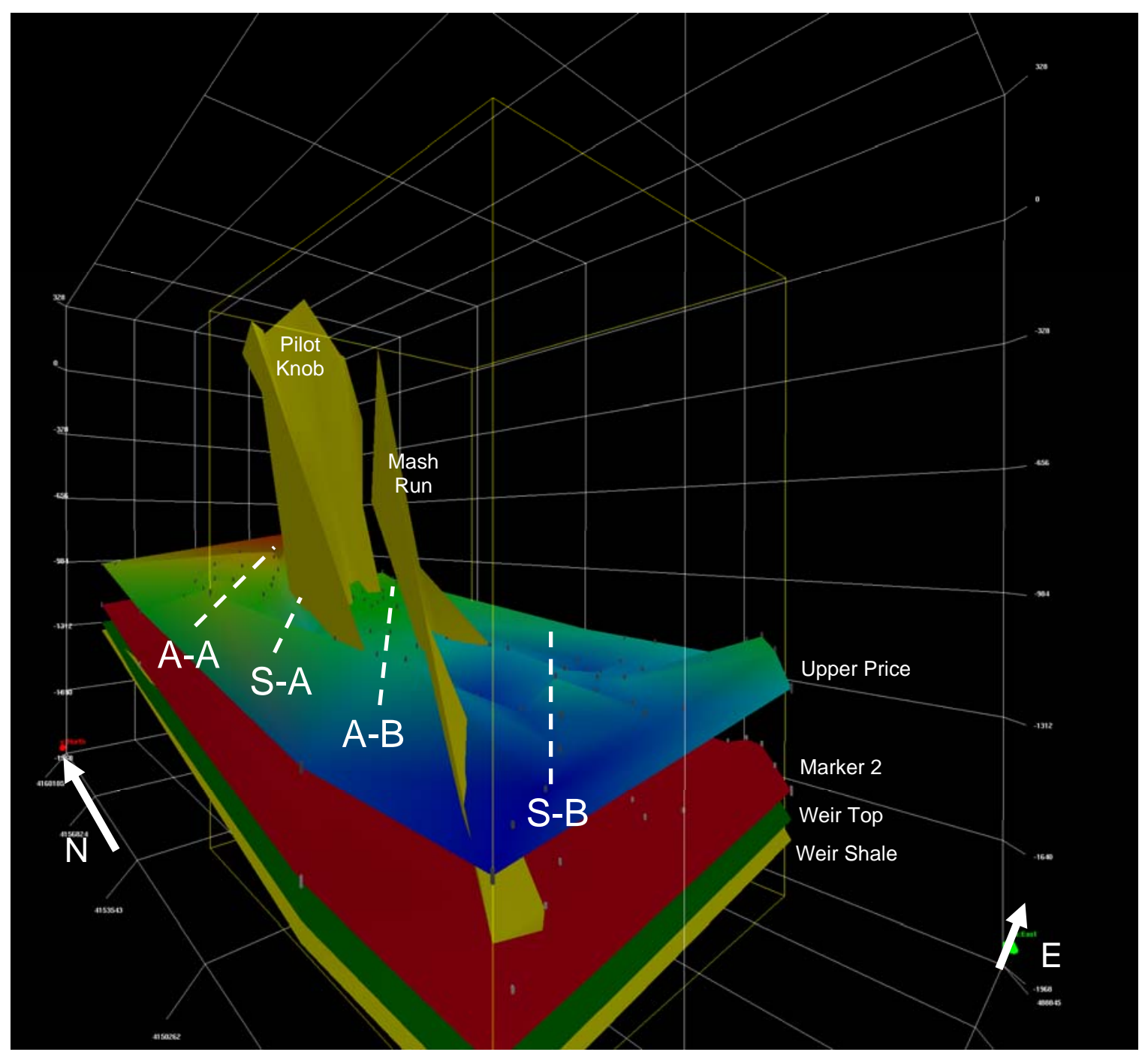

Figure 35: Structure model with faults as seen Looking NE. Vertical exaggeration $=5 \mathrm{X}$. Grey rectangles represent data points. 


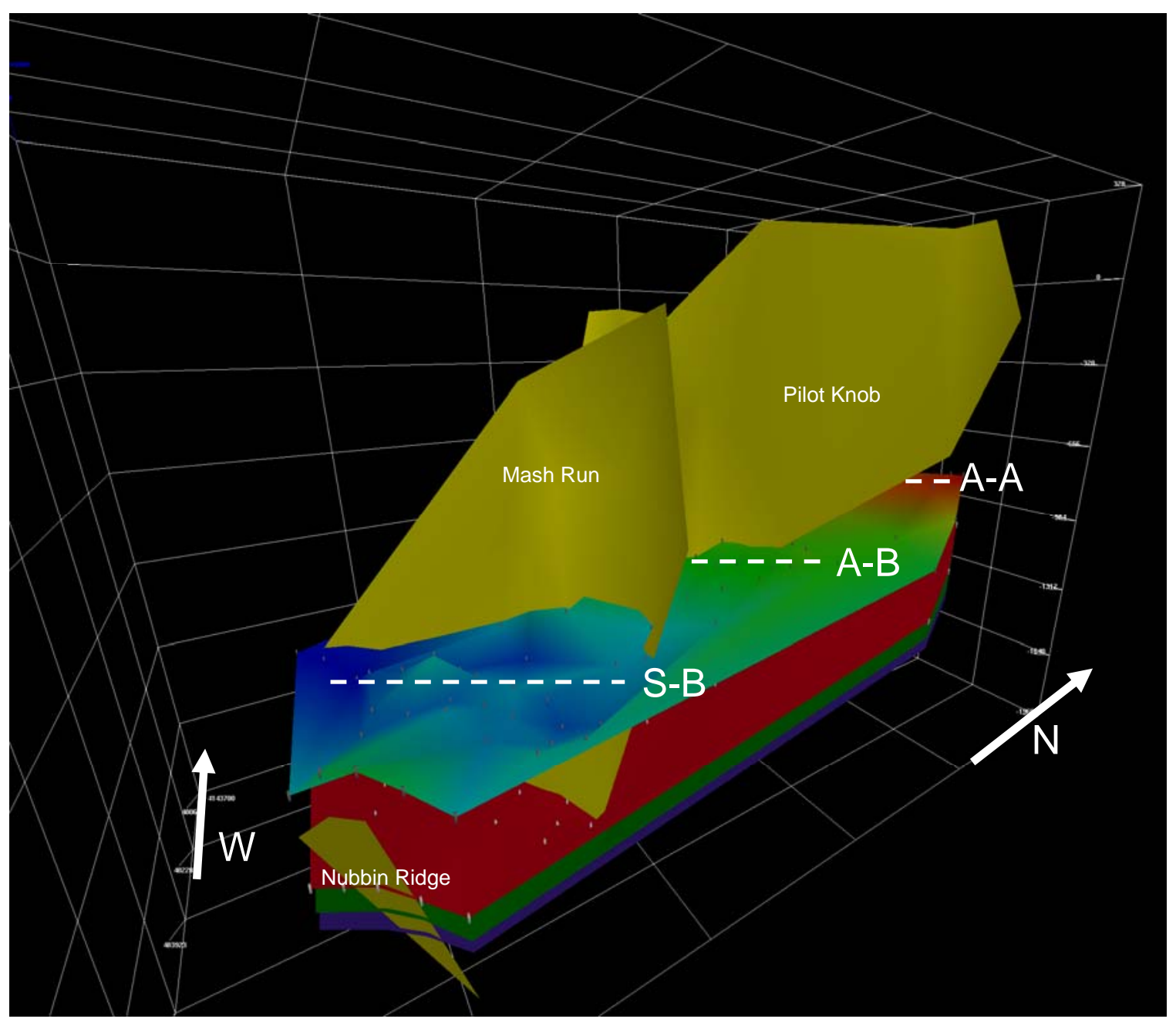

Figure 36: Structure model with faults as seen Looking NW,. Vertical exaggeration = 5X. Grey rectangles represent data points. 
well logs for this area. Syncline A and syncline B were most likely derived from the Pilot Knob and Nubbin Ridge faults, respectively.

Several inferences can be gained from the surface data analysis. Alta was found to have simple jointing patterns with one dominant and two secondary sets. These sets did not fit the typical model presented in figure 5 for joints in relation to folding. Alta contained both stratabound and non-stratabound joint sets. In contrast Caldwell contained three primary joint sets and at least three secondary joint sets. These sets were closer to the joint-fold model in figure 5 but were also more numerous and more complex in nature. The joints at Caldwell were dominantly stratabound.

Mechanical stratigraphy in outcrop was often joint dependent. A singular set of joints in a particular outcrop may define one mechanical unit while within that unit another set of joints may define a completely separate unit (Figure 7). This was particularly true for the Alta outcrop. This is a timing issue as all joints probably did not form simultaneously. Joint propagation timing can be determined by observing the cross cutting relationships (Engelder, 1984). The secondary joint sets most likely formed after the primary joint set as in most cases they did not cut across it. The timing and cross cutting relationships were more difficult to determine for Caldwell due to the complex nature of the jointing.

The fractures observed in outcrop were highly complex so it is reasonable to assume that complexity also exists in the subsurface jointing. The outcrop work suggests that mechanical stratigraphy (mechanical unit thickness) is most likely strongly related to lithology, and deformation. This work further suggests that the primary controlling factor of jointing in both outcrops is mechanical unit thickness (Figures $16 \& 17$ ). Shakleton et. 
al., (2005) states that fracture density is strongly correlated with lithology, deformation, and diagenesis. While diagenesis was not directly studied at either of the surface outcrops it is safe to assume that the higher strain rocks at Caldwell have most likely undergone diagenesis to a further degree than their counterparts at Alta due to increased tectonic stress. In the subsurface, fracture intensity of both joints and shear fractures most likely increases within the vicinity of the faults. This statement is supported by Nelson's (2004) model for shear fractures in relation to faulting and the joint density trends illustrated by the outcrop data. Fractures such as those observed at the Caldwell outcrop could significantly enhance permeability if present in the subsurface allowing wells to drain a significantly larger area.

The fracture trends produced in the subsurface models are likely similar to fracture trends present in the subsurface. Florez-Niño et. al. (2005) found similar orientations and patterns between surface and subsurface joints in the Bolivian fold and thrust belt. These similarities are not without limitations however. Unloading probably causes fracture development at the surface not present in the subsurface thus over representing subsurface fractures within these models. Unloading fractures generally form perpendicular to the unloading direction due to the release of stored stress (Nelson, 2001). Narr (1991) noted that unloading could cause increased fracture density until the rocks became saturated with joints. After this, increased strain would only result in aperture growth. Once again however, several studies, including Narr (1991) and FlorezNiño et. al. (2005) have noted similar characteristics between surface and subsurface joint systems. At least areas of high fracture density in the models represent areas of higher probable jointing within the subsurface due to increased strain and curvature. 
The paleostress directions responsible for creating orthogonal or near orthogonal joint sets in the surface and subsurface were most likely parallel to the joint azimuth. Therefore, for truly perpendicular joint sets to exist along a fold, paleo- $\sigma 1$ would have reversed with paleo- $\sigma 3$. The paleo- $\sigma 1$ responsible for fault and fold formation was most likely perpendicular to structure trend (fold axis) or fault strike. In this scenario paleo- $\sigma 1$ was oriented approximately $\mathrm{N} 38 \mathrm{~W}$ in the subsurface study area. The fractures observed at Alta did not follow this idealistic model however. The joints here deviated from perpendicular to the fold axis of the Williamsburg anticline by approximately 21 degrees. The most reasonable explanation for this is that the joints observed are preserved from an earlier time in fold development. This being the case the joints would have formed close to the termination of the fold so that their orientations would not have been truly perpendicular to the fold axis. The idea that joints at the edges of folds may not be truly axis perpendicular is further explained in Fischer and Wilkerson (2001).

Natural gas production was highest in linear trends that correlated well with the faults (Figure 37). The faults most likely have a large catchment area and produce wide shatter zones which capture gas from matrix porosity within the reservoir rock. The shatter zone observed at Oakvale was several feet wide and may represent the density of fractures in the subsurface along the faults modeled. Because high areas of curvature and strain are located near the faults, it is difficult to determine the magnitude of the impact that jointing has on production (Figures 38, 39 and 40). However, it is a fair assumption that the faults themselves are gas conduits. This is also supported by neutron/density 


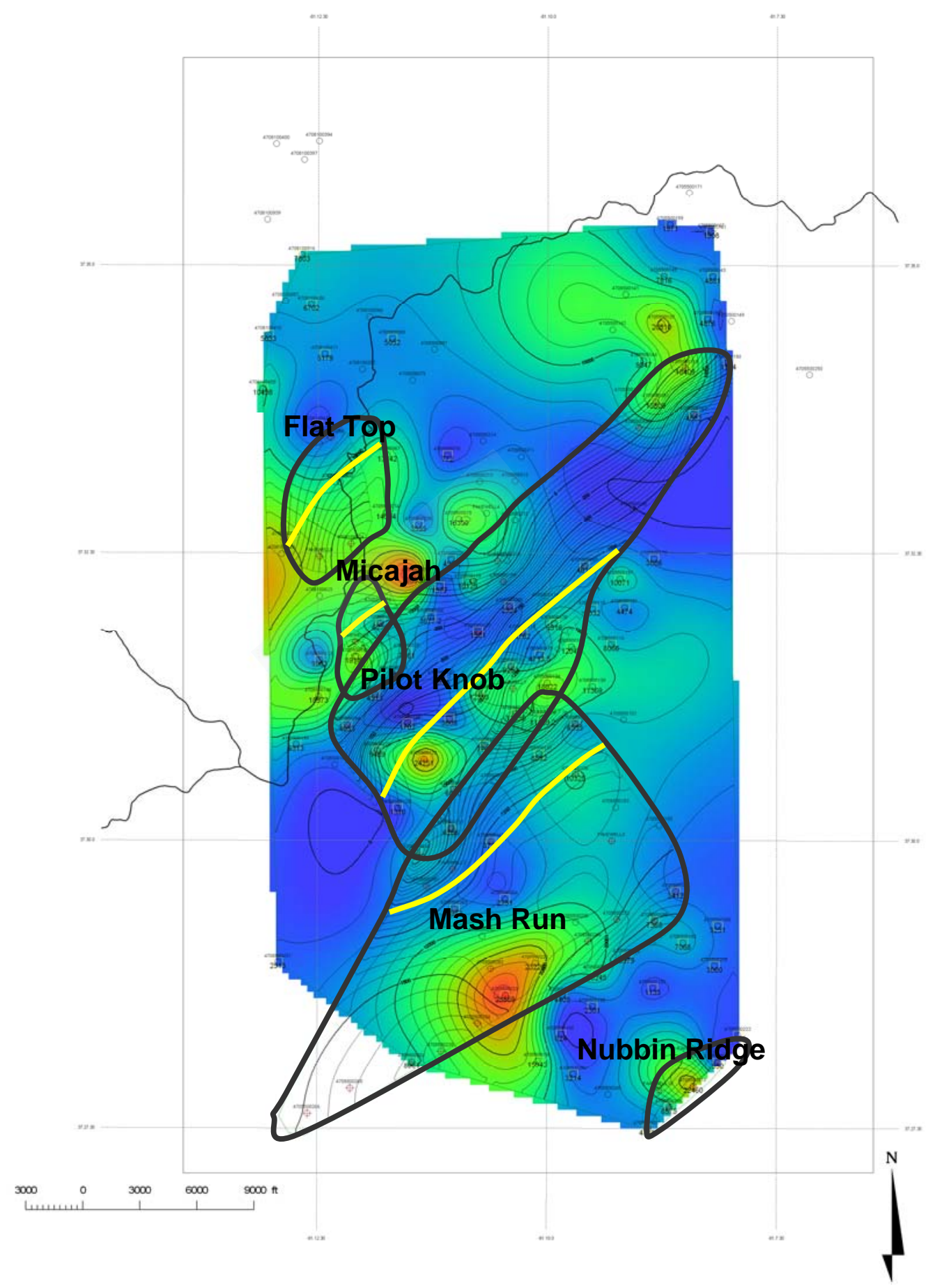

Figure 37: Natural gas production (3 month) compared with the fault model. Dark gray lines indicate mapped fault boundaries. Yellow lines indicate approximate Upper Price Top-fault intersection. Therefore, everything down dip of the yellow lines is within the Price Formation along the fault planes. 


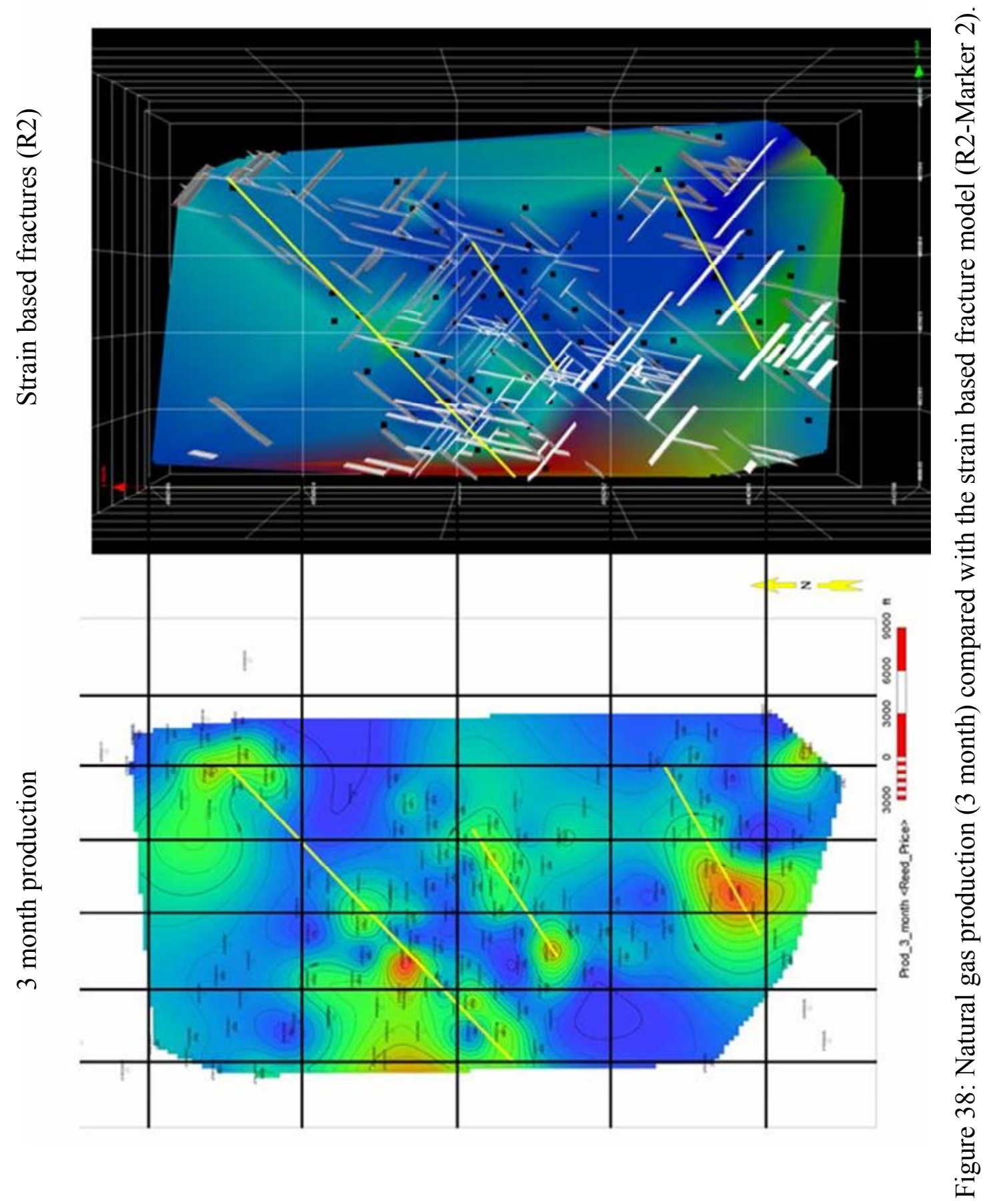




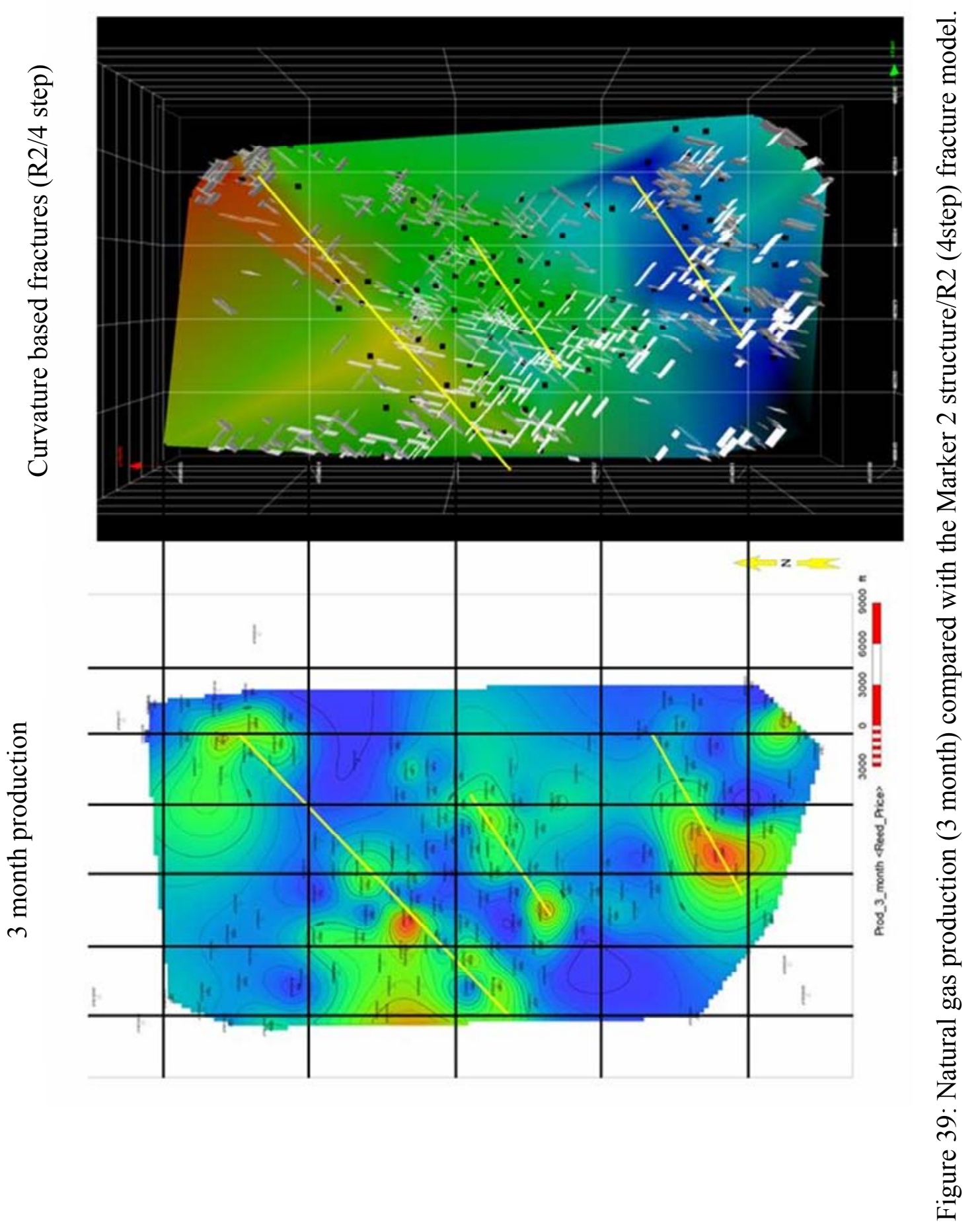




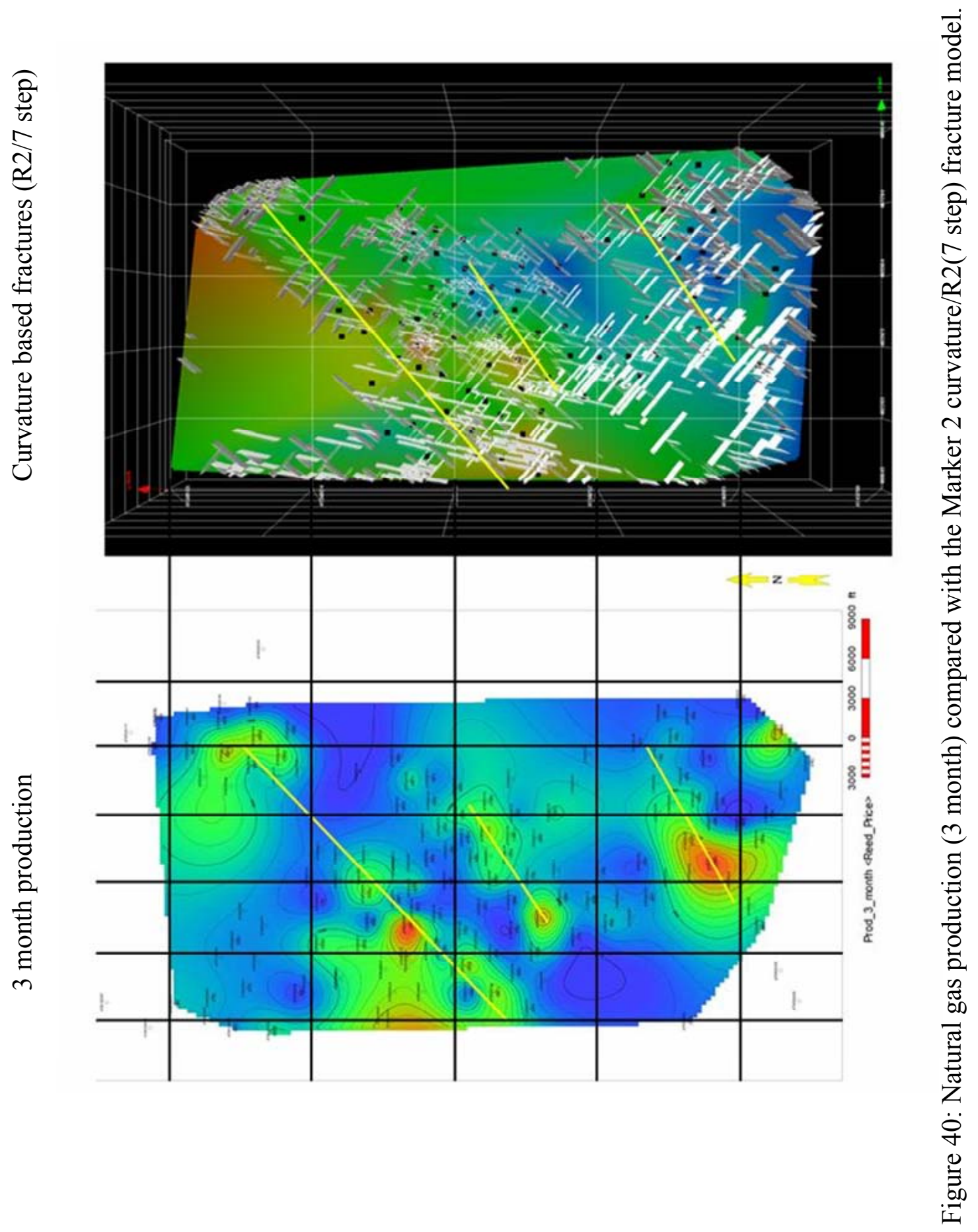


porosity gas effect and temperature deflections in faulted zones on geophysical logs. The lack of correlation between curvature and production suggests that the curvature-based joint systems modeled in this thesis may not significantly impact natural gas production in this area (Figure 33).

There are two explanations for this: 1) either jointing does exist in a similar fashion to the models produced but does not enhance production significantly with traditional vertical wells, or 2) jointing does not exist in a similar fashion to the models produced. The first explanation could be accounted for by a lack of connectivity in the joint sets presented or with one or more joint sets being absent, limited spatially, or having significantly higher fracture spacing, thus limiting connectivity and hydrocarbon flow. The second explanation suggests that the models are invalid which I feel is improbable for the following reasons: 1) Jointing in outcrop suggests a high degree of connectivity of joints within the Price Formation, and 2) productive wells exist within the subsurface study areas that do not encounter faults observed in this study. However, the highest values of gas production were noted at wells intersecting the lower portion of the Mash Run fault and NW portion of the Pilot Knob fault (Table 4). Therefore, in terms of impact on production, the curvature based jointing that exists in the subsurface is secondary to the faults and likely enhances production little. This could possibly be because modern day stress conditions ( $\sigma_{1}$ is approximately $50^{\circ}$ according to drilling induced fractures observed in Edmonds, 2004) are holding the joint sets closed or the joints at depth have been healed by cements. The drilling of a horizontal well to intersect the modeled subsurface analogue to the primary joint set observed at the Alta outcrop 
could be a potential way to further test the feasibility of natural gas production from joints within the subsurface study area.

No subsurface fracture model can reproduce all of the fracture patterns in reservoirs with complete accuracy. The multiple models created here represent a subsurface scenario thought to be geologically feasible. Jointing in the subsurface is probably highest in the areas of high curvature and strain. However, the curvature data correlates poorly with production data and thus curvature based joints most likely have little to no effect on production. The data collected in outcrop suggests that joint networks should exist in the subsurface in a similar fashion to the networks produced in these models. However, even with significant joining in the subsurface, undetermined subsurface characteristics are hindering production from jointed areas. In the future, technological advances may make completion of jointed intervals within the Price producible. However, current data strongly suggests that the thrust faults and the shear fracture networks they produce are the key to this gas play. 


\section{Chapter 6: Conclusions and Further Studies}

A variety of conclusions can be gathered from this thesis. They are as follows:

1. This thesis has proven that the normalization of joints in outcrop to a subsurface structure can produce a viable subsurface fracture model. This fracture model used both strain and curvature to create vertical joints in a series of runs where variables were altered. Areas of fracture high density in all runs were concentrated around areas of high curvature or strain, suggesting joint formation in folded areas. Non folded areas illustrated significantly less joint density than folded areas overall.

2. Structural modeling suggests that the folding and thrust faulting in the subsurface study area are related and that the thrust faults have very low displacements (150$400 \mathrm{ft}$ ). The folds are most likely fault propagation or fault bend folds. There is a possibility that a detachment fold also exists in the subsurface study area. A total of five thrust faults, two anticlines, and two synclines were observed in the area. The fault geometries are flat-ramp which is typical of thrust faults.

3. Sinuosity along the faults was observed and could be explained by differential stresses across the fault, multiple parallel faults in very close proximity to one another, or transform faults linking thrust fault sections. 
4. At least two of the faults (and possibly three) within the subsurface study area for this thesis correlate with the faults found by Edmonds (2004). They are the Micajah and Pilot Knob faults.

5. Jointing of the Price Formation in outcrop is most strongly tied to mechanical unit thickness. This is in turn strongly correlated with lithology and degree of deformation. Analyses show that as mechanical unit thickness decreases, joint density increases. Shear fractures in outcrop do not constitute a major portion of the connected fractures.

6. Outcrop analyses illustrated that as strain increases, mechanical unit thickness changes from non-stratabound to stratabound.

7. Gas production for the study area is strongly tied to structures such as those observed. The faults/shear fractures act as hydrocarbon conduits, significantly enhancing production. These trends can be easily seen in maps that illustrate gas production and fault locations. The thrust faults have large gas catchment area and shatter zones which capture gas from matrix porosity. It is unlikely that the joints have enough surface area and connectivity to capture and serve as gas conduits. If the joints do enhance production it is likely minimal.

Several follow up studies could be done to add to this research. Lidar based fracture measurements at outcrops could acquire excellent fracture data that could then be applied 
to an outcrop based study or subsurface study such as this one. A study concentrating on answering the question of joint timing at the Alta outcrop would also be beneficial. If significant amounts of FMI data were to become available for the subsurface study area then that could also be very useful for a follow up study. 


\section{References}

Allmendinger, R.W., 1998, Inverse and forward numerical modeling of trishear faultpropagation folds: Tectonics, v. 17, p. 640-656.

Bjerstedt T.W., 1986, Stratigraphy and deltaic depositional systems of the Price Formation (Upper Devonian-Lower Mississippian) in West Virginia, Unpublished Dissertation, West Virginia University, 730 p.

Bjerstedt, T.W. and Kammer, T.W., 1988, Genetic stratigraphy and depositional systems of the Upper Devonian-Lower Mississippian Price-Rockwell deltaic complex in the central Appalachians, U.S.A.: Sedimentary Geology, v. 54, p.265-301.

Bonnett, E., Bour, O., Odling, O., Davy, P., Main, I., Cowie, P., and Berkowitz, B, 2001, Scaling of fractures in geological media, Reviews of Geophysics, v. 39, no.3, p. 347-383.

Cardwell, D.H., Erwin, R.B., Woodward, H.P., Lotz, C.W., 1986, Geologic Map of West Virginia, Williams \& Heintz Map Corporation, Capitol Heights, 2 maps.

Cardwell, D.H., 1976, Oil and Gas Fields of West Virginia - South Half, Williams \& Heintz Map Corporation, Capitol Heights

Dean, S.L., Kulander, B.R., and Skinner, J.M., 1988, Structural chronology of the Alleghenian Orogeny in southeastern West Virginia: Geological Society of America Bulletin, v. 100, p. 299-310.

Davis, G.H., and Reynolds, S.J., 1996, Structural geology of rocks and regions, Second edition, John Wiley and Sons, Inc., New York, 776 p.

Edmonds, C.A., 2004, Natural gas exploration associated with fracture systems in Alleghenian thrust faults in the Greenbrier Formation, southern West Virginia, Unpublished Thesis, West Virginia University, Morgantown, W.V., 94 p.

Engelder, T., 1984, Loading paths to joint propagation during a tectonic cycle: an example from the Appalachian Plateau, USA: Journal of Structural Geology, v.7, p. 459-476.

Ettensohn, F.R., 1985, The Catskill Delta Complex and the Acadian Orogeny: a model. In: R.L., Woodrow and W.D. Sevon eds., The Catskill Delta. The Geological Society of America Special Paper 201, p. 39-49.

Ettensohn F.R., 2005, The sedimentary record of foreland basin, tectophase cycles: Examples from the Appalachian Basin, USA: Developments in Sedimentology 57, Elsevier B.V., $39 \mathrm{p}$. 
Florez-Nino, J., Aydin, A., Mavko, G., Antonellini, M., and Asterio, A., 2005, Fault and fracture systems in a fold and thrust belt: An example from Bolivia: American Association of Petroleum Geologists Bulletin, v. 89, p. 471-493.

Fisher, M.P., and Wilkerson, M.S., 2000, Predicting the orientation of joints from fold shape: Results of pseudo-three-dimensional modeling and curvature analysis: Geology, v. 28, p.15-18.

Hubbert, M.K., and Rubey, W.W., 1959, Role of fluid pressure in mechanics of overthrust faulting. Part 1:Geological Society of America Bulletin, v. 70, p.115-166.

Knipe R.J., 1993, The Influence of fault zone processes and diagenesis on fluid flow. In Horbury, A.D., and Robinson A., eds: Diagenesis and basin development,. American Association of Petroleum Geologists Studies in Geology, v. 36, p.135-151.

Kulander, B.R., and Dean, S.L., 1986, Structure and tectonics of central and southern Appalachian Valley and Ridge and Plateau provinces, West Virginia and Virginia: American Association of Petroleum Geologists Bulletin, v. 70, p. 1674-1684.

Kulander, B.R., 1987, Structural style and tectonics of the central and southern Appalachians: West Virginia Geologic and Economic Survey Circular, v. 40, p. 55.

Ladiera, F.L., and Price, N.J., 1981, Relationship between fracture spacing and bed thickness: Journal of Structural Geology, v.3, p.179-183.

Lisle, R.J., 1994, Detection of zones of abnormal strains in structures using Gaussian Curvature Analysis: American Association of Geologists Bulletin, v.78, p.1811-1819.

Matchen, D.L., 1992, Sequence stratigraphy of the lower Mississippian clastic wedge in West Virginia and Kentucky, Unpublished Thesis, West Virginia University, Morgantown, 177 p.

Matchen, D.L., and Kammer, T.W., 1994, Sequence stratigraphy of the lower Mississippian Price and Borden Formations in southern West Virginia and eastern Kentucky: Southeastern Geology, v. 34, p. 25-41.

Matchen, D.L., and Kammer, T.W., 2006, Incised valley fill interpretation for Mississippian Black Hand Sandstone, Appalachian Basin, USA: Implications for glacial eustacy at Kinderhookian-Osagean (Tn2-Tn3) boundary: Sedimentary Geology, v. 191, p. 89-113.

Matchen, D.L., and Vargo, A.G., 1996, Play Mws: Lower Mississippian Weir Sandstones: The Atlas of Major Appalachian Gas Plays, West Virginia Geological and Economic Survey Publication, 201 p.

McKeown, C., 2001, The use of structural modeling in the simulation of naturally fractured 
reservoirs: Search and Discovery Article 40026, online, http://www.searchanddiscovery.net/documents/mckeown/index.htm

McDowell, R.C., 1982, The Hurricane Ridge, Glen Lyn, and Caldwell synclines of southeastern West Virginia and southwestern Virginia; a reinterpretation: Southeastern Geology, v. 23, p.83-88.

Midland Valley, 2000, 2DMove Manual, Complementary document for software, 217 p.

Midland Valley, 2004-A, 3DMoveV4.1 Tutorial, Complementary document for software, $91 \mathrm{p}$.

Midland Valley, 2004-B, 3DMove Installation Guide, Complementary document for software. $21 \mathrm{p}$.

Milici, R.C., 1996, Sratigraphic history of the Appalachian Basin, in Roan, J.B., and Walker, B.J., eds., The Atlas of Major Appalachian Gas Plays, West Virginia Geological and Economic Survey Publication V-25, 201 p.

Narr, 1991, Fracture density in the deep subsurface: Techniques with spplication to Point Arguello Oil Field: American Association of Petroleum Geologists Bulletin, v. 75, p. 1300-1323.

Nelson, R.A., 2001, Geologic analysis of naturally fractured reservoirs: 2nd Edition, Gulf Professional Publishing, Boston, 332 p.

Nelson R.A., 2004, Exploration \& evaluation of fractured reservoirs, AAPG Eastern Section Notes, Petroleum Technology Transfer, Council, 77 p.

Nur, A., 1982, The origin of tensile fracture lineaments: Journal of Structural Geology,v. 4, p. 31-40.

Odling, N.E., Gillespie, P., Bourgine, B., Castaing, C., Chiles, J-P., Christensen, N.P., Fillion, E., Genter, A., Olsen, C., Thrane, L., Trice, R., Aarseth, E., Walsh, J.J., and Waterson, J., 1999, Variations in fracture system geometry and their implications for fluid flow in fractured hydrocarbon reservoirs: Petroleum Geoscience, v. 5, p. 373-354.

Pollard, D.D., and Aydin, A., 1988, Progress in understanding jointing over the past century: GSA Bulletin, v. 100, p. 1181-1204.

Pollard, D.D., and Fletcher, R.C., 2005, Fundamentals of structural geology, Cambridge University Press, Cambridge, 500 p.

Price, N.J., 1966, Fault and joint development in brittle and semi-brittle rock. Permagon Press, Oxford. 
Reger, D.B., and Price, P.H.,1926, Mercer, Monroe, and Summers Counties: West Virginia Geological Survey County Report, Wheeling News Lithograph Company, Wheeling, 963 p.

Schwartz, B.C., 2006, Fracture pattern characterization of the Tensleep Formation, Teapot Dome, Wyoming, Unpublished Thesis, West Virginia University, Morgantown, 148 p.

Shackleton, J.R., Cooke, M.L., Sussman, A.J., 2005, Evidence for temporally changing mechanical stratigraphy and effects on joint network architecture: Geology, v. 33, no. 2, p. 101-104.

Shumaker, R.C., 1987, Regional setting of the Appalachian Basin: West Virginia Geologic and Economic Survey Circular, v.38, p.56-60.

Shumaker, R., 1996, Structural history of the Appalachian Basin, in Roan, J.B., and Walker, B.J., eds., The Atlas of Major Appalachian Gas Plays, West Virginia Geological and Economic Survey Publication V-25, 201 p.

Smosna, R., and Bruner, K.R., 1997, Braid-delta facies interpreted from cores, Granny Creek Oil Field of West Virginia: Southeastern Geology, v. 37, p. 37-54.

Stearns, D.W., and Friedman M., 1972, Reservoirs in fractured rock: Stratigraphic oil and gas fields classification, Exploration methods and case histories, AAPG Memoir 16, Issue 10. $23 \mathrm{p}$.

Thomas, W.A., 1977, Evolution of the Appalachian Ouachita salients and recesses from reentrants and promontories in the continental margin: American Journal of Science, v. 2, p. 1233-1278.

Titley, S.R., 1976, Evidence for a Mesozoic linear tectonic pattern in southeastern Arizona: Arizona Geol. Soc. Digest, v.10, p. 71-101.

Virginia Division of Mineral Resources, 1993, Geologic Map of Virginia: Virginia Division of Mineral Resources, scale 1:500,000

Williams, K. W., 2001, Surface vs. subsurface fracture characteristics along cross strike transect in eastern Massachusetts, Abstract Only, GSA annual meeting: Dec 2001, Online, http://gsa.confex.com/gsa/2001AM/finalprogram/abstract_23905.htm

Zou, X., 1993, Sequence stratigraphy of the lower Mississippian in western West Virginia: Correlation, depositional environments, controls on sedimentation and related reservoir heterogeneities, Unpublished Dissertation, West Virginia University, 414 p. 


\section{Appendix I: Outcrop Data Tables}

\begin{tabular}{|c|c|c|c|c|c|c|c|c|c|c|}
\hline \multicolumn{11}{|l|}{ ALTA } \\
\hline Lithology & linear density (joints $/ \mathrm{m}$ ) & UTM zone & UTM northing & UTM easting & JO:strike & JO:dip & JO:dir & BO:strike & BO:dip & BO:dir \\
\hline FGSS & 2.34 & $17 \mathrm{~s}$ & 539813 & 4190666 & 82 & 89 & $\mathrm{~s}$ & 100 & 1 & $\mathrm{~s}$ \\
\hline SH, SS ITBDS & 1.82 & $17 \mathrm{~s}$ & 539813 & 4190666 & 79 & 89 & se & 105 & 4 & $\mathrm{~s}$ \\
\hline ss & 1.41 & $17 \mathrm{~s}$ & 539686 & 4190789 & 174 & 86 & $\mathrm{e}$ & 130 & 10 & nw \\
\hline SS & 0.15 & $17 \mathrm{~s}$ & 539414 & 4190888 & 87 & 82 & $\mathrm{~s}$ & 118 & 9 & nw \\
\hline SS & 0.82 & $17 \mathrm{~s}$ & 539387 & 4190900 & 166 & 84 & $\mathrm{e}$ & 104 & 8 & $w$ \\
\hline SS & 1.97 & $17 \mathrm{~s}$ & 540071 & 4190711 & 84 & 87 & $\mathrm{nw}$ & 88 & 4 & $\mathrm{~s}$ \\
\hline ss & 5.49 & $17 \mathrm{~s}$ & 540146 & 4190695 & 88 & 89 & $\mathrm{~s}$ & 110 & 6 & $\mathrm{~s}$ \\
\hline SS, SLTSTN, SH & 0.51 & $17 \mathrm{~s}$ & 540146 & 4190695 & 81 & 87 & $\mathrm{~s}$ & 84 & 10 & $\mathrm{~s}$ \\
\hline SS & 1.97 & $17 \mathrm{~s}$ & 539875 & 4190774 & 15 & 88 & $\mathrm{e}$ & 44 & 10 & $\mathrm{nw}$ \\
\hline SS, SH ITBDS & 1.77 & $17 \mathrm{~s}$ & 539783 & 4190799 & 87 & 89 & se & 30 & 10 & nw \\
\hline
\end{tabular}

\begin{tabular}{|c|c|c|c|c|c|c|c|c|c|c|}
\hline \multicolumn{11}{|l|}{ CALDWELL } \\
\hline Lithology & linear density (joints/m) & UTM zone & UTM northing & UTM easting & JO:strike & JO:dip & JO:dir & BO:strike & BO:dip & BO:dir \\
\hline FGSS & 0.47 & $17 \mathrm{~s}$ & 554681 & 4180750 & 47 & 55 & se & 58 & 32 & $n w$ \\
\hline FGSS & 4.37 & $17 \mathrm{~s}$ & 554681 & 4180750 & 42 & 42 & se & 24 & 40 & $w$ \\
\hline FGSS & 4.92 & $17 \mathrm{~s}$ & 554648 & 4180772 & 0 & 27 & $w$ & 34 & 70 & se \\
\hline FGSS & 13.13 & $17 \mathrm{~s}$ & 554648 & 4180772 & 47 & 10 & se & 37 & 81 & $w$ \\
\hline FGSS & 17.23 & $17 \mathrm{~s}$ & 554603 & 4180810 & 90 & 32 & se & 26 & 68 & nw \\
\hline MGSS & 3.75 & $17 \mathrm{~s}$ & 554575 & 4180837 & 63 & 63 & se & 64 & 47 & nw \\
\hline FGSS & 1.31 & $17 \mathrm{~s}$ & 554511 & 4180906 & 101 & 89 & se & 45 & 31 & $n w$ \\
\hline MGSS & 2.34 & $17 \mathrm{~s}$ & 554495 & 4180937 & 28 & 80 & $\mathrm{n}$ & 45 & 36 & $w$ \\
\hline MGSS & 1.09 & $17 \mathrm{~s}$ & 554503 & 4180812 & 38 & 57 & se & 57 & 30 & $\mathrm{nw}$ \\
\hline SLTSTN,SH ITBDS & 0.94 & $17 \mathrm{~s}$ & 554454 & 4180878 & 114 & 89 & se & 46 & 20 & $n$ \\
\hline SLTSTN & 45.90 & $17 \mathrm{~s}$ & 554651 & 4180777 & 119 & 87 & $\mathrm{~s}$ & 36 & 86 & e \\
\hline $\mathrm{SH}$ & 171.05 & $17 \mathrm{~s}$ & 554689 & 4180757 & CBM & CBM & CBM & 32 & 31 & $w$ \\
\hline $\mathrm{SH}$ & 92.11 & $17 \mathrm{~s}$ & 554689 & 4180757 & 110 & 86 & $\mathrm{~s}$ & 31 & 34 & $w$ \\
\hline SLTSTN & 9.84 & $17 \mathrm{~s}$ & 554706 & 4180747 & 2 & 59 & $\mathrm{e}$ & 63 & 31 & $w$ \\
\hline $\mathrm{SH}$ & 52.63 & $17 \mathrm{~s}$ & 554713 & 4180747 & 2 & 79 & $w$ & 57 & 50 & $w$ \\
\hline
\end{tabular}

\begin{tabular}{|l|c|}
\hline \multicolumn{1}{|c|}{ CALDWELL } & \\
\hline FGSS & linear density (joints/m) \\
\hline FGSS & 0.00 \\
\hline FGSS & 0.00 \\
\hline FGSS-CG & 1.09 \\
\hline SLTY SH & 1.17 \\
\hline FGSS & 3.94 \\
\hline FGSS & 0.00 \\
\hline FGSS & 2.62 \\
\hline SS-CG & 2.62 \\
\hline FGSS & 2.81 \\
\hline FGSS & 0.66 \\
\hline FGSS & 3.83 \\
\hline FGSS-CG & 1.79 \\
\hline FGSS & 4.10 \\
\hline FGSS, SH ITBDS & 6.56 \\
\hline FGSS & 1.64 \\
\hline FGSS, SLTSTN & 2.81 \\
\hline SLTSTN-FGSS & 3.94 \\
\hline FGSS & 5.47 \\
\hline FGSS & 7.22 \\
\hline FGSS & 0.82 \\
\hline SH & 1.64 \\
\hline
\end{tabular}

\begin{tabular}{|c|c|}
\hline \multicolumn{2}{|c|}{ Abbreviation Legend } \\
\hline jo & Joint Orientation \\
\hline $\mathrm{BO}$ & Bedding Orientation \\
\hline CBM & Could Not Be Measured \\
\hline SH & Shale \\
\hline SLTSTN & Siltstone \\
\hline ss & Sandstone \\
\hline FGSS & Fine Grained Sandstone \\
\hline MGSS & Medium Grained Sandstone \\
\hline CG & Conglomerate \\
\hline
\end{tabular}

\begin{tabular}{|l|c|}
\cline { 2 - 2 } SLTY & Silty \\
\hline ITBDS & Interbeds \\
\hline
\end{tabular}




\section{Appendix II: Production Data Per Well}

$\begin{array}{llll}\text { Well API \# } & \text { First month (mcf) } & \text { First Three Months (mcf) } & \text { First Twelve Months (mcf) }\end{array}$

\begin{tabular}{|c|c|c|c|}
\hline 4705500021 & 2024 & 2513 & 6415 \\
\hline 4705500067 & 5137 & 13142 & 54855 \\
\hline 4705500069 & 2184 & 5052 & 18424 \\
\hline 4705500074 & 1781 & 14054 & 48856 \\
\hline 4705500075 & 1969 & 16350 & 64098 \\
\hline 4705500076 & 113 & 772 & 4731 \\
\hline 4705500078 & 18101 & 28530 & 45926 \\
\hline 4705500084 & 5959 & 8271 & 21708 \\
\hline 4705500085 & 1015 & 2924 & 6653 \\
\hline 4705500087 & 1881 & 2518 & 5448 \\
\hline 4705500104 & 820 & 3977 & 29242 \\
\hline 4705500105 & 1468 & 7361 & 19621 \\
\hline 4705500106 & 1069 & 12353 & 39396 \\
\hline 4705500107 & 691 & 2638 & 6082 \\
\hline 4705500109 & 2206 & 11259 & 45346 \\
\hline 4705500110 & 825 & 9252 & 41592 \\
\hline 4705500112 & 481 & 3008 & 7942 \\
\hline 4705500113 & 1112 & 4762 & 14550 \\
\hline 4705500115 & 2049 & 6532 & 32583 \\
\hline 4705500116 & 1684 & 8066 & 28193 \\
\hline 4705500118 & 1606 & 18409 & 62224 \\
\hline 4705500119 & 340 & 10129 & 34418 \\
\hline 4705500120 & 538 & 1981 & 6207 \\
\hline 4705500121 & 644 & 7709 & 18870 \\
\hline 4705500122 & 10168 & 24251 & 79748 \\
\hline 4705500123 & 1564 & 6650 & 20282 \\
\hline 4705500127 & 2784 & 6266 & 16232 \\
\hline 4705500128 & 686 & 1310 & 7811 \\
\hline 4705500129 & 2073 & 9489 & 21947 \\
\hline 4705500130 & 560 & 1702 & 4150 \\
\hline 4705500131 & 923 & 4913 & 11825 \\
\hline 4705500132 & 342 & 19180 & 60189 \\
\hline 4705500133 & 1013 & 20810 & 83521 \\
\hline 4705500134 & 3879 & 18022 & 54816 \\
\hline 4705500135 & 402 & 6535 & 40280 \\
\hline 4705500136 & 1018 & 10325 & 31452 \\
\hline 4705500137 & 755 & 8892 & 23593 \\
\hline 4705500139 & 1806 & 11369 & 36142 \\
\hline 4705500140 & 1035 & 12049 & 31450 \\
\hline 4705500143 & 2099 & 4881 & 14143 \\
\hline 4705500144 & 1867 & 9847 & 48874 \\
\hline 4705500145 & 887 & 7816 & 38731 \\
\hline 4705500146 & 5792 & 18573 & 66277 \\
\hline 4705500147 & 1068 & 3728 & 9812 \\
\hline 4705500148 & 3455 & 7660 & 19804 \\
\hline 4705500150 & 397 & 1104 & 4362 \\
\hline 4705500151 & 3744 & 15800 & 52052 \\
\hline 4705500154 & 1522 & 4653 & 11253 \\
\hline 4705500155 & 649 & 6313 & 26424 \\
\hline 4705500156 & 1458 & 4876 & 12512 \\
\hline 4705500157 & 3357 & 10071 & 22490 \\
\hline 4705500159 & 840 & 1971 & 5662 \\
\hline 4705500162 & 1139 & 4582 & 12369 \\
\hline 4705500163 & 2358 & 6256 & 18670 \\
\hline 4705500165 & 596 & 4619 & 17204 \\
\hline
\end{tabular}




\section{Production data per well continued.}

Well API \# $\quad$ First month (mcf) $\quad$ First Three Months (mcf) $\quad$ First Twelve Months (mcf)

\begin{tabular}{|c|c|c|c|}
\hline 4705500167 & 889 & 1908 & 5871 \\
\hline 4705500168 & 1251 & 2619 & 6259 \\
\hline 4705500172 & 162 & 3963 & 13222 \\
\hline 4705500173 & 1099 & 3086 & 11014 \\
\hline 4705500174 & 565 & 1577 & 5107 \\
\hline 4705500175 & 1855 & 4714 & 7567 \\
\hline 4705500176 & 1819 & 11489 & 37036 \\
\hline 4705500177 & 3546 & 14613 & 60252 \\
\hline 4705500178 & 2320 & 9516 & 19778 \\
\hline 4705500181 & 1343 & 4474 & 12446 \\
\hline 4705500184 & 3845 & 15942 & 67798 \\
\hline 4705500185 & 1693 & 5979 & 31244 \\
\hline 4705500188 & 2094 & 7368 & 30786 \\
\hline 4705500189 & 725 & 3412 & 16678 \\
\hline 4705500190 & 300 & 624 & 1072 \\
\hline 4705500192 & 442 & 7068 & 39759 \\
\hline 4705500193 & 46 & 1135 & 6488 \\
\hline 4705500198 & 1068 & 2301 & 4865 \\
\hline 4705500200 & 344 & 3214 & 15111 \\
\hline 4705500206 & 491 & 8575 & 39018 \\
\hline 4705500207 & 1210 & 4763 & 6523 \\
\hline 4705500208 & 817 & 3251 & 14340 \\
\hline 4705500209 & 662 & 3060 & 16167 \\
\hline 4705500210 & 2180 & 22460 & 100177 \\
\hline 4705500217 & 639 & 950 & 981 \\
\hline 4705500221 & 2088 & 10245 & 37810 \\
\hline 4705500222 & 83 & 1455 & 4909 \\
\hline 4705500223 & 2020 & 28869 & 198824 \\
\hline 4705500225 & 2020 & 23226 & 152626 \\
\hline 4705500228 & 882 & 3555 & 11520 \\
\hline 4705500229 & 1324 & 4997 & 20969 \\
\hline 4705500250 & 11166 & 34667 & 68563 \\
\hline 4705500252 & 3032 & 9391 & 29863 \\
\hline 4705500253 & 2518 & 8964 & 34257 \\
\hline 4705500263 & 75 & 4973 & 33154 \\
\hline 4705500264 & 316 & 2751 & 7179 \\
\hline 4705500267 & 1728 & 4409 & 9916 \\
\hline 4708100266 & 6031 & 17468 & 47376 \\
\hline 4708100406 & 3576 & 6702 & 35742 \\
\hline 4708100409 & 4893 & 10498 & 33748 \\
\hline 4708100410 & 1402 & 5633 & 31719 \\
\hline 4708100411 & 1625 & 5179 & 21982 \\
\hline 4708100434 & 674 & 984 & 5905 \\
\hline 4708100916 & 3308 & 7803 & 18741 \\
\hline 4708100939 & 447 & 4160 & 23923 \\
\hline 4708100987 & 1579 & 2775 & 5768 \\
\hline
\end{tabular}




\section{Appendix III: Guide to using 3DMove to create models similar to those in this thesis.}

Midland Valley's 3D Move version 4.1 is a complex program that is highly effective at modeling structure and fracture networks in three dimensions. It also has the capability to perform various types of restorations and analyses. Other features available include hydrocarbon system modeling, which includes migration pathways and analyses of catchment areas, decompaction analyses, slicing and volume tracking. This thesis primarily focused on the strain and curvature analyses, fracture modeling and, to a lesser extent, the restoration capability of 3D Move.

\section{Getting Started}

3DMove is currently only available in Unix and Linux environments. This requires some basic skills in these operating systems as they are quite different than Microsoft Windows. The version used in this thesis was Linux-based. The path used to start 3DMove within the Linux terminal is as follows:

[prompt]\# cd /opt/3DMove4.1/bin

[prompt]\# ./3dmove

Note: If the license manager is not running then it must be started before program initialization (Midland Valley, 2004-B). Use the following prompts to start the LMGRD license manager and re-read to license file:

To start the license manager:

[prompt]\# ./etc/init.d/mve_flex_license start

To reread the license file:

[prompt]\# ./opt/MVEflexlm8.4a/bin/lmutil lmreread -c /usr/lib/mve_flex_license/ license.lic

(Midland Valley, 2004-B)

\section{Importing Data}

3D Move will accept a number of different data formats for import. All files imported into 3D Move during this thesis were of the ".xyz" format which 3DMove reads as an ASCII. To import data in this manner go to "File" and "Import." Chose ASCII and be sure the "insert" button is depressed if you are adding data to a preexisting model. Otherwise, the "load" button should be depressed. You have the option of creating a variety of objects from this data including surfaces, data clouds, lines, and wells. This project used surfaces and data clouds only.

Note: if importing xyz data from Landmark GeoGraphix or other software, then some editing of the column specifications may be required. GeoGraphix typically exports xyz data in the " $000000.000000,0000000.000000, \pm 0000.000000$ ” format. 3DMove must be told which space holds the beginning and ending digits for each coordinate. 


\section{Mouse Configuration and Parameter Entry}

Only textboxes that are pink can be edited in 3DMove. To type data into these boxes the mouse cursor MUST be also be within the box area. Often times one must also press the enter key after entering numerical parameters for 3DMove to recognize them.

Mouse Configuration: Left button $=$ grab, center $/$ scroll button depress $=$ zoom, right button $=$ zoom .

\section{Important Tools for all Models}

It is a good idea to keep several toolboxes open for simple model manipulation and viewing. These toolboxes can all be easily accessed though the drop down menus at the top of the 3DMove screen. They are as follows:

Picking Toolbox: This toolbox illustrates which layers or datasets that you currently have active and allows you to select items that may be invisible. It is also handy for displaying all of the available units within a model. Use this toolbox when “collecting” data for other processes, as it is easier than picking directly from the model itself.

Display Toolbox: This toolbox allows you to change viewing angles, access to lighting toolbox, and manipulate the visibility of units within your model. Visibility can be changed for individual units (by clicking the "apply to picked only" tab) or all of the available units within the model.

Lighting Toolbox: The lighting toolbox allows you to change lighting settings for the model and can be very useful for visualizing structural features.

Attribute Browser: This dialogue is accessible by double clicking and unit and clicking "edit" in the data dialogue. It shows all imported data for a specific horizon or data cloud and any other analysis based attribute data in a spreadsheet format.

Colour Mapper: The colour mapper can create maps for several values including depth, curvature, dip, or other selected attributes. The color scale created by the colour mapper is often not adjusted to the data being mapped and thus must be calibrated. To do this you must click "edit" in the colour mapper dialogue and then click "New colour map." Here the maximum and minimum values being mapped along with the interval can be edited.

Note: To map curvature or strain with the colour mapper the attribute data must already exist. This data is created in the curvature and strain analysis dialogues. 


\section{Curvature and Strain Analyses}

3DMove will create curvature values for each data point that currently exists. The curvature analysis must be performed prior to any curvature based fracture generation. Both Gaussian and simple curvature methods can be used. Be sure to save your generated data to the attribute "curvature." Color maps can also be created here. Curvature analysis data can be seen in the Attribute Browser. To locate the curvature analysis tool click the "analysis" drop down menu and click "curvature."

Strain analyses require deformation from the original state to produce strain values. This can be done by copying a current surface, flattening the copy to an elevation target, and then refolding it to the current structure using the original surface as a target. This can all be done in the "Flexural Slip Unfolding" dialogue. The "Flexural Slip Unfolding" dialogue is located under the Restoration menu and "Unfold to Target" submenu. The direction for unfolding can also be specified here.

To measure the strain values the strain analysis dialogue must be open during deformation with the correct horizon collected in the strain analysis object box. Be sure to save your data to the attribute "strain" and chose your preferred dilatation options. RMS dilatation was used in this thesis. Color maps can also be created in this dialogue. The strain analysis must be applied before deformation and the "continuous update" option seems to work well. After the model has been run, strain data should be available for viewing in the Attribute Browser for the selected horizon.

\section{Fracture Generation}

Once the strain or curvature analyses have been completed for the surface(s) of study then attribute fracture modeling based on these parameters can begin. The fracture modeling module is located under the "modules" pull down. In this dialogue, bounding beds for the fractures must be picked and surfaces can be specified to control the seeding, orientation, and impedance for the fracture generation. For example,to use strain as a parameter for fracture generation the "seed probability" must be set to "map" with the attribute of "strain." Fractures will propagate in steps, the number of which is also controllable.

Note: Constants or other attributes can also be used to model fractures in 3DMove.

\section{Advanced Fracture Generation}

Fractures can be also created in the "Advanced Fracture Modeling” module. In this module statistical distribution can be used as a parameter for modeling. This module

also allows for dip azimuth and angle to be entered as a parameter. Once again, bounding beds must be specified and the propagation proceeds in steps.

\section{Troubleshooting}

Problem: Imported data should appear as surfaces but instead appears as lines or as incorrect shapes.

Check to make sure the coordinates are correct and that the column specifications in 3DMove's import dialogue are set to fit the format of the data in the file being imported. Also be sure that the "create surfaces" button is depressed in the import dialogue. 
Problem: 3DMove clears or deletes my current model when I import new data.

Be sure to use the "insert" button when importing new data. Using the "load" button will open a new model.

Problem: I am trying to model fractures or run a restoration and nothing happens after I apply or run the process.

3DMove may not be accepting the numerical parameters you have entered. Be sure to hit enter after each numerical parameter entry into the pink textboxes. If 3DMove accepts the entry then two zeros should appear after the number entered (i.e. 2763 changes to 2763.00).

Problem: I can see my surfaces or my data as a cloud but can't visualize them both at the same time.

Re-import the data for the given horizon under a separate name so that you can use one set as a surface and the other set as a data cloud.

Final Note: Many of the analyses and operations available in 3DMove are also available in 2DMove which has a similar interface. 2DMove is slightly more intuitive so a usage guide for it was not included in this thesis. 


\section{Appendix IV: Previous Work on the Price Formation}

The Price formation has been extensively studied for stratigraphy and depositional systems but its structure has received less attention. The Price was originally examined in 1894 at an exposure near Price Mountain in Montgomery County, Virginia (Bjerstedt and Kammer, 1988). It has been steadily researched partly due to its qualities as an oil and gas reservoir. The Mercer County Geologic Report (Reger and Price, 1926) states that the formation was named the "Pocono" as early as 1877 . This nomenclature was ultimately found to be incorrect because of erroneous correlations with the "Pocono" in Pennsylvania (Bjerstedt and Kammer, 1988). The Big Injun sandstone, a highly productive reservoir in the Upper Price Formation, was the primary target for the Granny Creek Oil Field along with other productive fields in West Virginia (Smosna and Bruner, 1997). Important recent work includes: Matchen (1992), a stratigraphic study of the lower Mississippian interval in West Virginia and Kentucky, Bjerstedt and Kammer (1988), a study outlining the stratigraphy and depositional systems related to the Price Formation in the central Appalachians, Smosna and Bruner (1997), a facies study dealing with the Price Formation and the Granny Creek Oil field, Zou (1993), a study dealing with the stratigraphy of the Lower Mississippian and its properties as a reservoir unit. 